Portland State University

PDXScholar

Winter 3-20-2017

\title{
Contextualization: an Experimental Model for EFL Writing Instruction in China
}

Guimin Tang

Portland State University

Follow this and additional works at: https://pdxscholar.library.pdx.edu/open_access_etds

Part of the Education Commons, and the First and Second Language Acquisition Commons Let us know how access to this document benefits you.

\section{Recommended Citation}

Tang, Guimin, "Contextualization: an Experimental Model for EFL Writing Instruction in China" (2017). Dissertations and Theses. Paper 3487.

https://doi.org/10.15760/etd.5371

This Dissertation is brought to you for free and open access. It has been accepted for inclusion in Dissertations and Theses by an authorized administrator of PDXScholar. Please contact us if we can make this document more accessible: pdxscholar@pdx.edu. 
Contextualization: An Experimental Model for EFL Writing Instruction in China

by

Guimin Tang

A dissertation submitted in partial fulfillment of the requirements for the degree of

Doctor of Education

in

Educational Leadership: Curriculum and Instruction

\author{
Dissertation Committee: \\ Yer J. Thao, Chair \\ Dannelle D. Stevens \\ Samuel D. Henry \\ Sharon Carstens
}

Portland State University

2017 
(C) 2017 Guimin Tang 


\begin{abstract}
Chinese students learning English as a foreign language seem to get good marks in tests, but are poor or limited in their ability to write in English. This dilemma of China's EFL writing instruction seems to be related to the decontextualized EFL writing practices. This study aims to examine how Chinese EFL college students respond to changes in their writing instruction that pays attention to the context of EFL teaching and learning. In this study, context refers to three levels: linguistic context, situational context and cultural context.

Using the mixed methods approach, I conducted the study by engaging 60 secondyear undergraduate students from a university in China and five Chinese students studying in a joint program in a university in the United States. The Write-to-learn Model based on my context-oriented framework was used in the study.

The findings of the study show that following a 5-month training with the Write-tolearn Model, the experimental group improved significantly more than the control group with respect to English writing, indicating that adding context to EFL teaching and learning created positive writing outcomes for EFL students. In addition, the results of this study also demonstrate that the Chinglish phenomenon was related to decontextualized EFL writing practices and thought patterns resulting from culture. Adequate comprehensible input of authentic materials was found to be a good remedy to minimize EFL students' Chinglish expressions. This study found that the Write-to-learn Model was an effective approach in China's EFL writing classes.
\end{abstract}




\section{Acknowledgements}

Along the journey of my EdD studies at the Graduate School of Education, Portland State University, I have been supported, encouraged, and inspired by many people. Without your help, it would have been impossible for me to complete the program. My first acknowledgements go to four prestigious professors from the Portland State University. I am very much indebted to my advisor, Dr. Yer Thao, who has generously offered your expertise, wisdom, and continuous encouragement in guiding me and mentoring me step by step through the whole research process. I am eternally grateful to Dr. Stevens, whose profound knowledge, intelligent questions on every committee meeting, and passionate love for academic work has always been an inspiration for me. I would also like to give my sincere and deep gratitude to Dr. Henry, for your careful reading of every version of my thesis and for your wonderful lectures, which broadened my horizons in terms of politics and education policy. I am also thankful to Dr. Carstens for your constructive remarks in leading me to take a critical perspective on the literature reviewed, the research methodology and data analysis.

I wish to thank Prof. Lu Shen for the great help and support you gave to Sub-study 1 conducted in a university in China. Your insightful comments and suggestions are greatly appreciated. I'm also appreciative of Dr. Chuming Wang for your everlasting encouragement and strong faith in my becoming a scholar. I have benefited greatly from you in the areas of second language acquisition, cultural studies and quantitative research methods. Special thanks also go to all the participants in experiments, surveys and interviews for your energetic enthusiasm and active involvement in my research. 
I owe special thanks to my sister, brother and relatives who have given me unconditional love and strong support in every way that you can from so far away. I also would like to thank my colleagues and friends for your emotional support: Vicki Roscoe, Luxia Qi, Yongbing He, Junyu Zhang, Jason Xu, Kathie Xu and many others.

Finally, my greatest debt of thanks is to my family. I am eternally indebted to my wife, Hongying, for your continued and unfailing love, support, encouragement and faith in me during my five years of being a graduate student. As my first reader of my dissertation drafts, your comments are also valuable to the final completion of my dissertation. 


\section{Table of Contents}

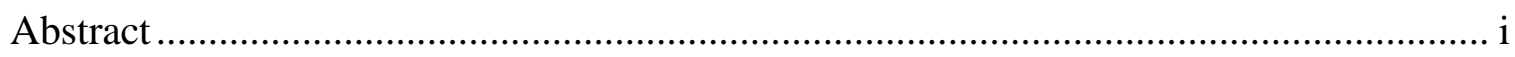

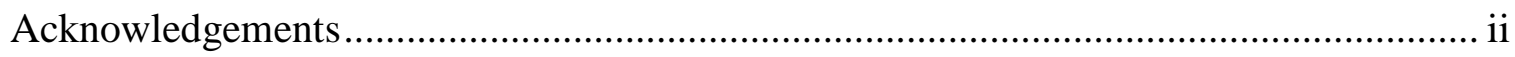

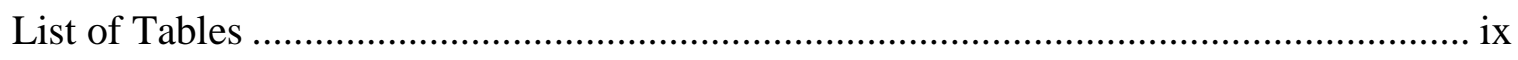

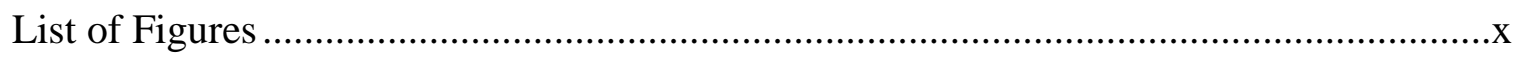

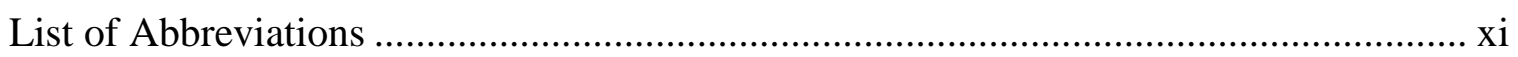

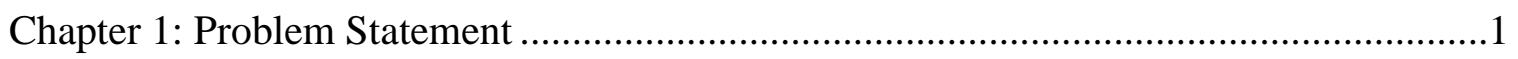

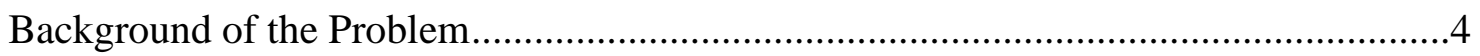

A Brief Overview of China's EFL History .............................................................

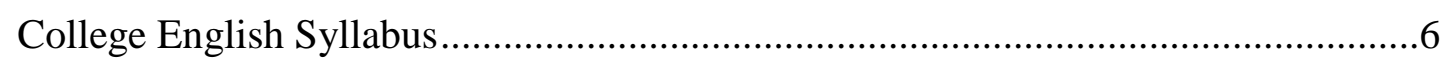

College English Test............................................................................................6

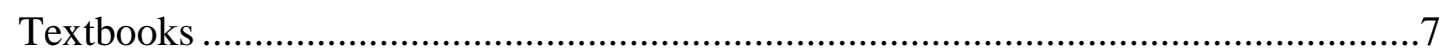

Status Quo of China's EFL Writing Instruction ...................................................

Statement of the Research Problem ........................................................................10

Significance of the Research Problem ................................................................11

Presentation of the Methods and Research Questions .................................................12

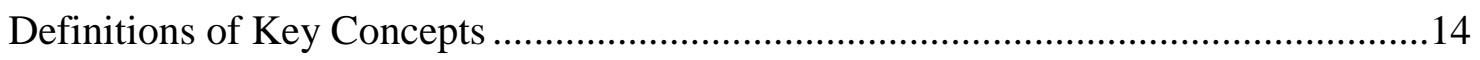

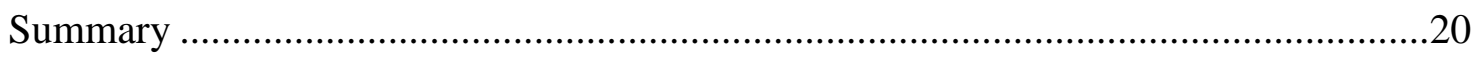

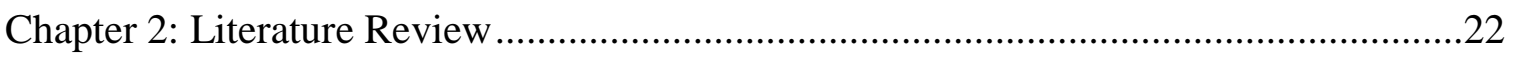

Review of the Research Literature .......................................................................22

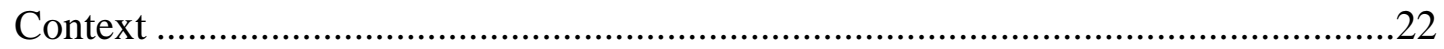

Vocabulary: Learning in Context or Learning Out of Context ...............................22

Grammar: Explicit Instruction or Implicit Instruction ...........................................26

Relationships between Reading and Writing ..................................................28

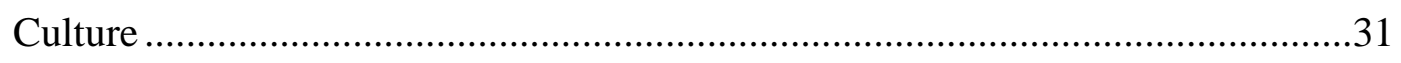

Written Corrective Feedback.........................................................................40

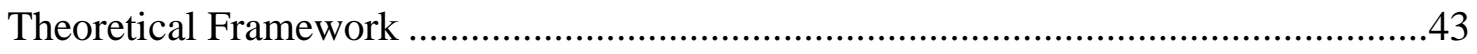




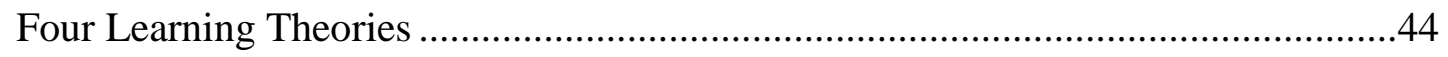

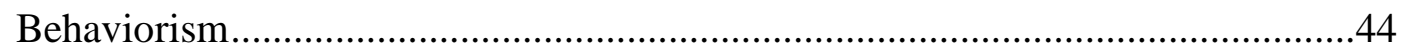

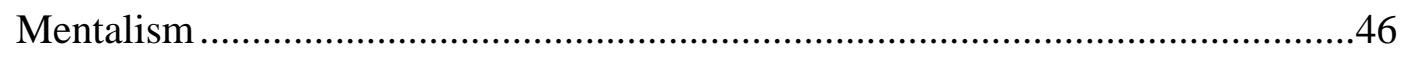

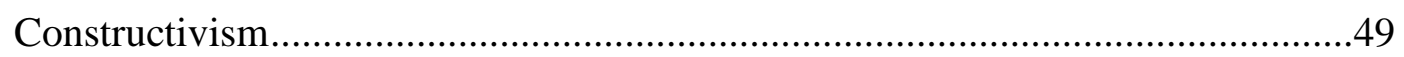

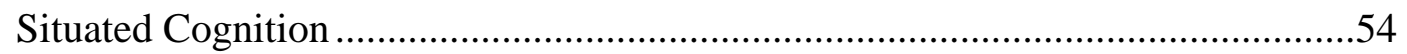

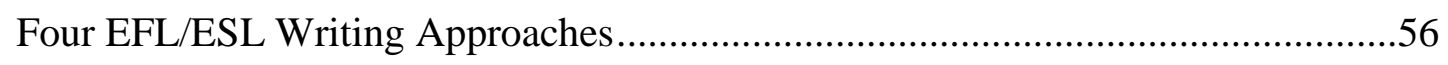

Controlled/Guided Approach.........................................................................56

Functional Approach ....................................................................................57

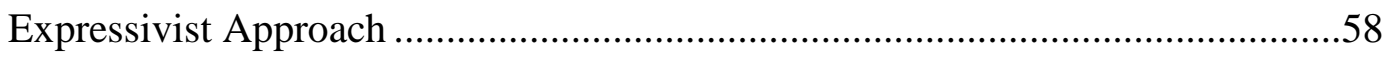

Process Approach.......................................................................................59

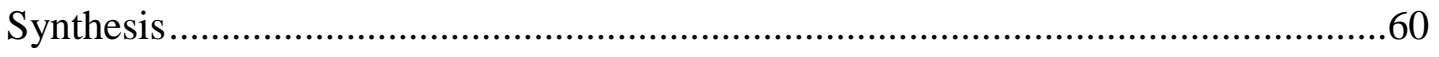

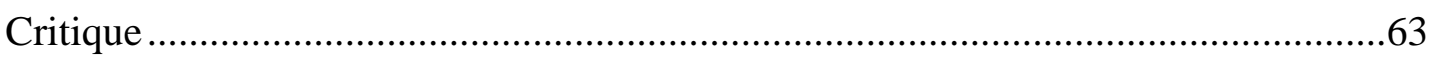

My Conceptual Framework ..................................................................................67

Review of the Methodological Literature ………....................................................

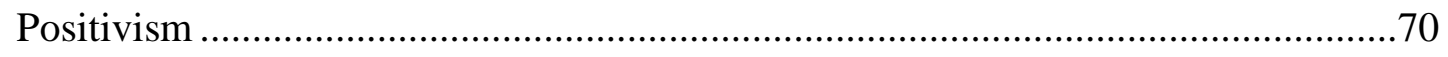

Constructivism..............................................................................................

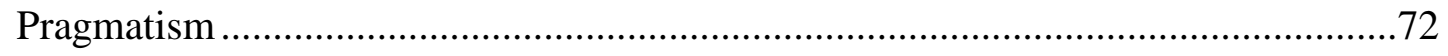

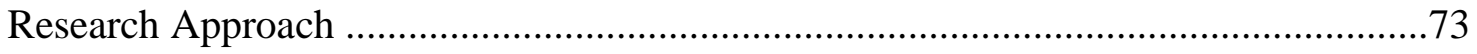

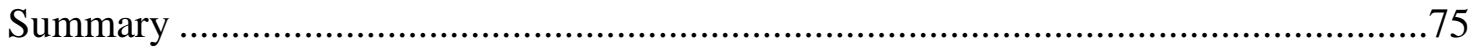

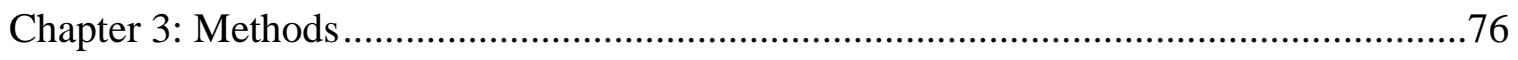

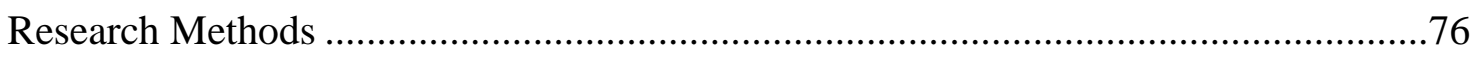

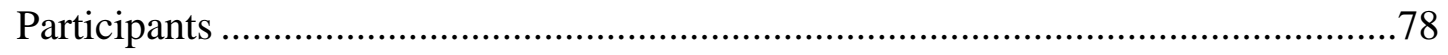

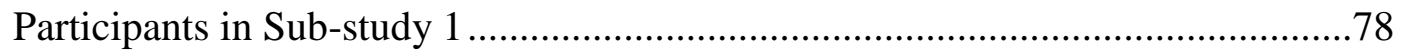

Participants in Sub-study 2 2...........................................................................79

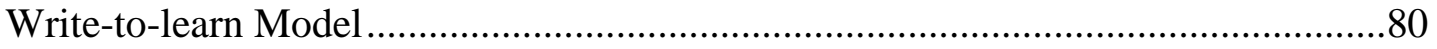

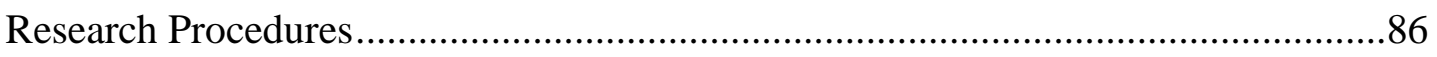

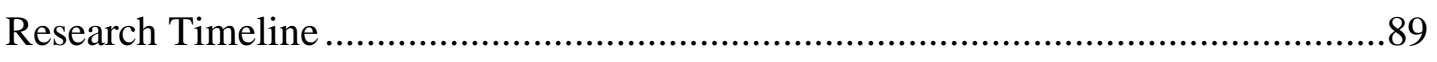

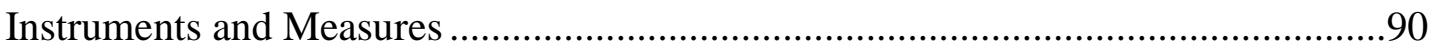

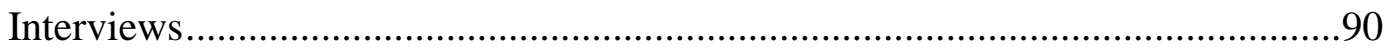




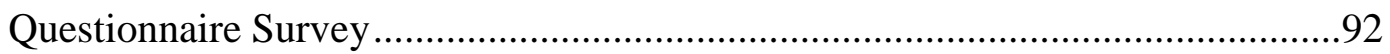

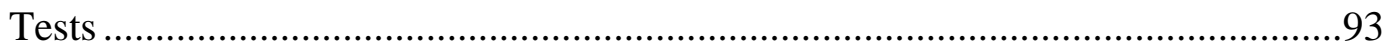

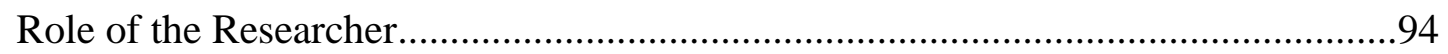

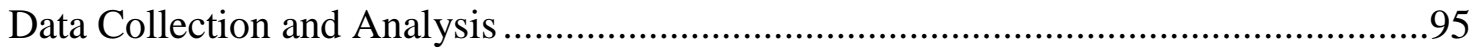

Quantitative Data Collection and Analysis ...........................................................96

Qualitative Data Collection and Analysis ..............................................................97

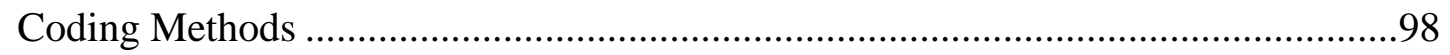

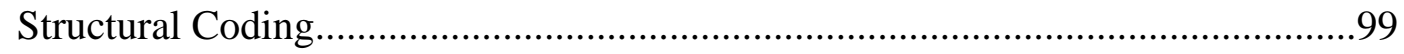

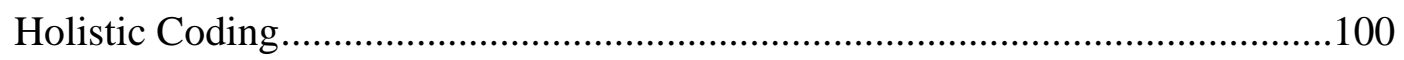

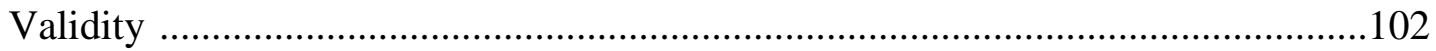

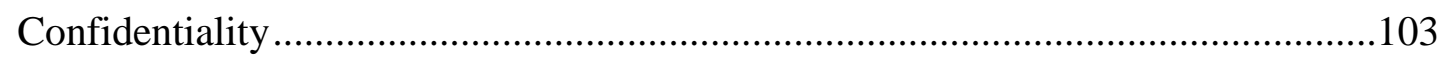

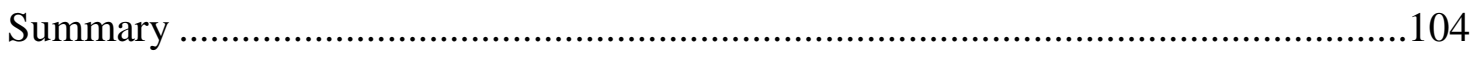

Chapter 4: Results and Analysis ...............................................................................105

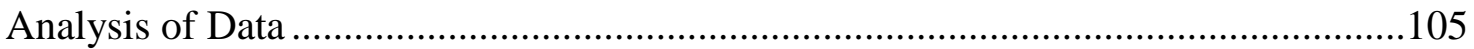

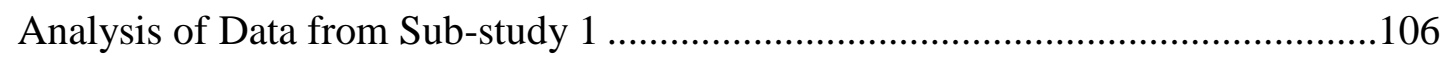

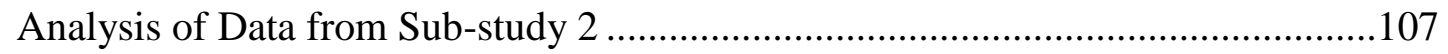

Analysis of Data from Sub-study 1 and Sub-study 2 ...........................................108

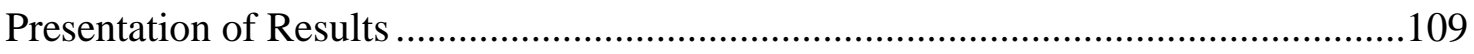

Results of Sub-study 1 ........................................................................................109

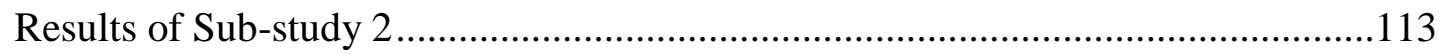

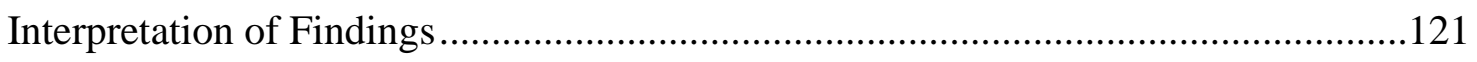

Outcome of Adding Context to Teaching and Learning of Writing ........................121

Ways of Developing Ways of Writing Skills and Use of Writing Skills .................123

Students' Comparison of Writing in Chinese and Writing in English .....................129

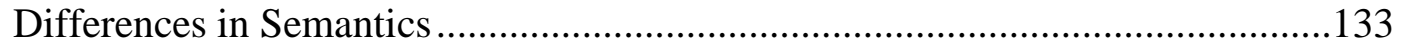

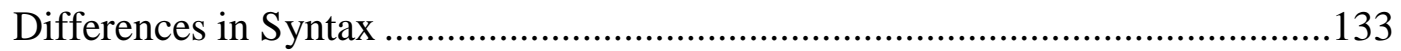

Differences in Culture ……………………………..................................135

Limitations of the Study .......................................................................................137

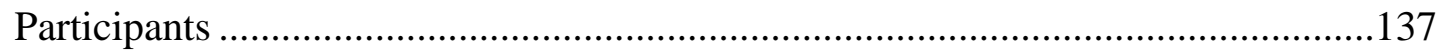




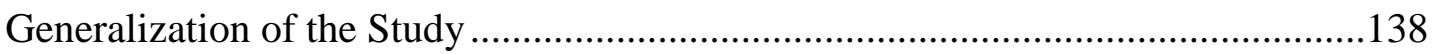

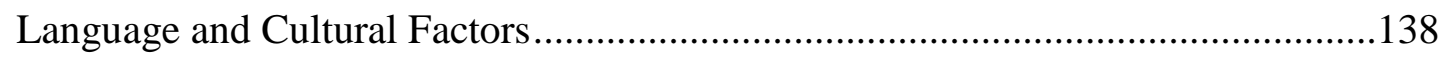

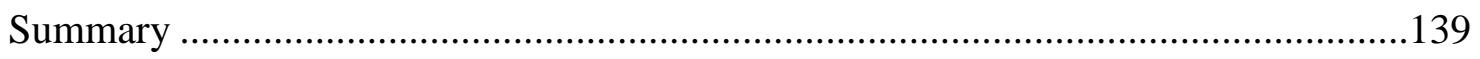

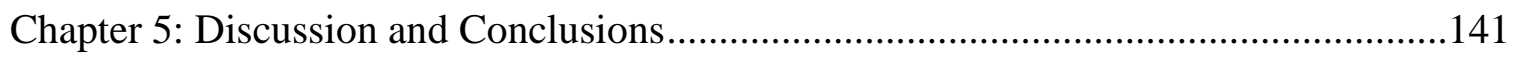

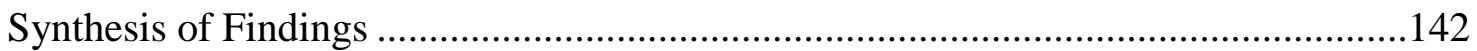

Write-to-learn Model: a Well-received and Effective Teaching Model ..................142

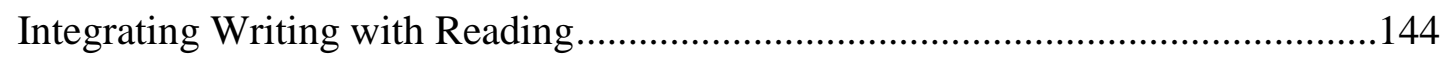

Combining Vocabulary and Grammar with Reading and Writing ..........................146

Effectiveness of Positive Corrective Feedback .......................................................149

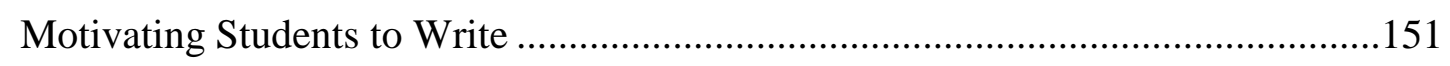

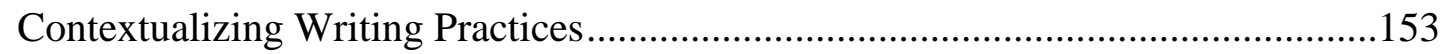

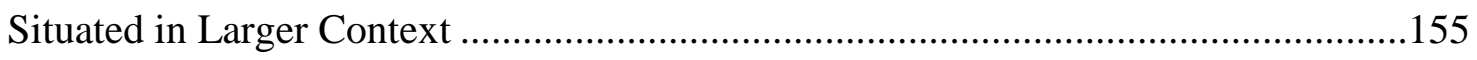

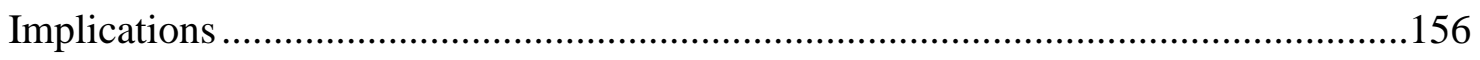

Recommendations for EFL Policymakers ......................................................157

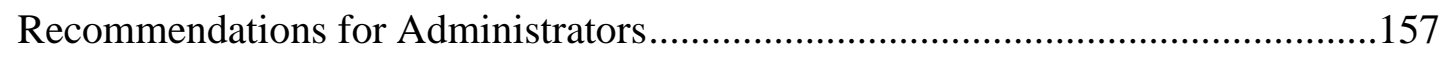

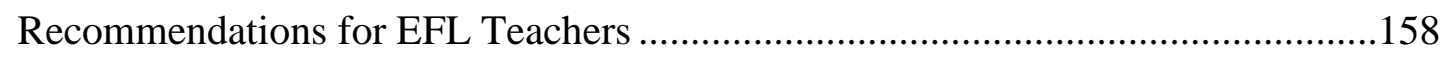

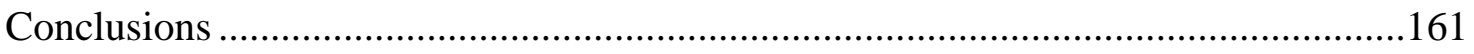

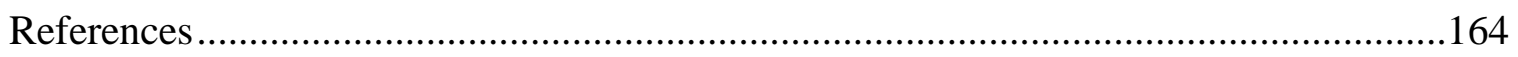

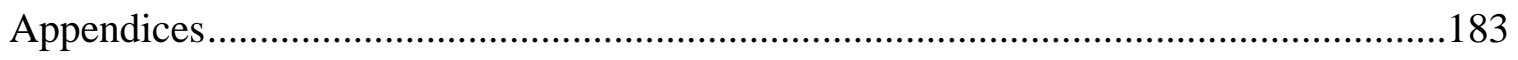

Appendix A: A sample text of Reading and Writing in College English Course ........183

Appendix B: A sample text of writing in English Writing Course ............................186

Appendix C: Letter of information and consent form..........................................189

Appendix D: Questionnaire for the experimental group .......................................192

Appendix E: Cloze test for the two groups of 2nd year undergraduate students .........197

Appendix F: Interview questions for the experimental group.................................198

Appendix G: Interview questions for the five students in the joint program ..............199

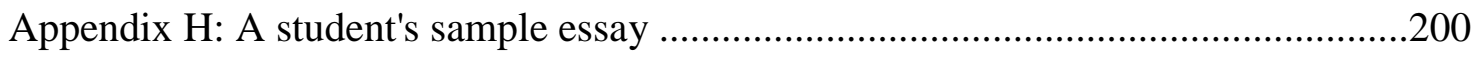

Appendix I: Data of the questionnaire survey in Sub-study 1 ................................204

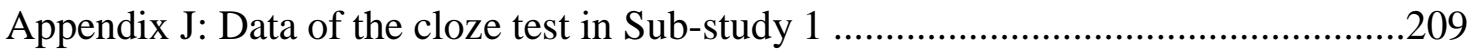


Appendix K: Data of the writing tests in Sub-study 1 ...........................................211

Appendix L: Key data from the interviews of the 30 students in Sub-study 1 ...........214

Appendix M: Key data from the interviews of the five students in Sub-study 2 ........215

Appendix N: Key data from the interviews of Sub-study $1 \&$ Sub-study 2................220 


\section{List of Tables}

Number Page

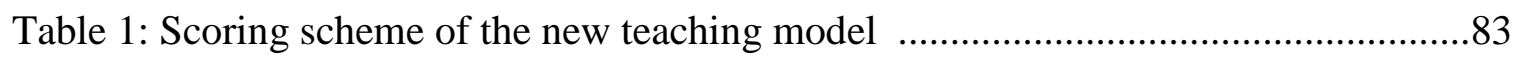

Table 2: Summary of the research procedures in Sub-study 1 ....................................8

Table 3: Schedule for the interview with the five students in the joint program..............89

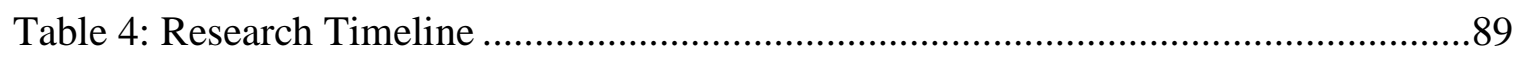

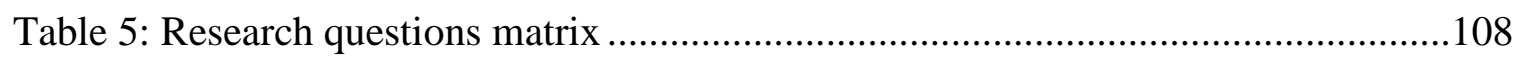

Table 6: Differences in questionnaire responses .................................................. 110

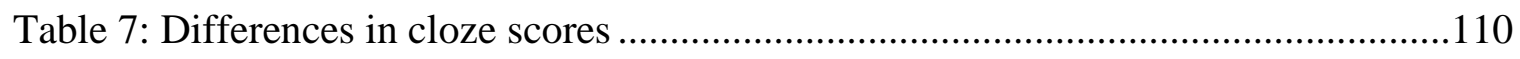

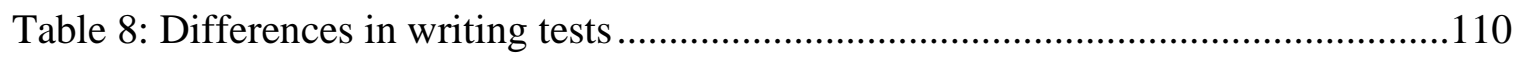

Table 9: Summary of the key data about the five themes of the 30 students in

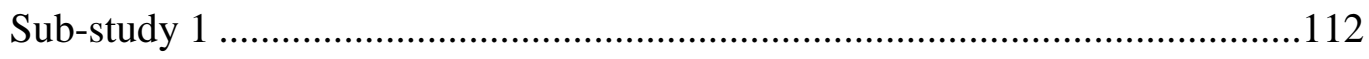

Table 10: Summary of the key data from the interviews of the 5 students in the joint

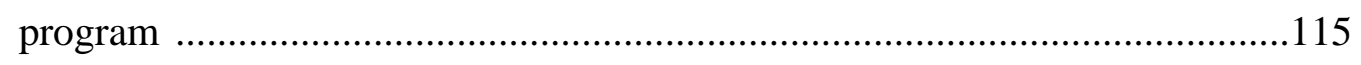

Table 11: Summary of the key data from the interviews of Sub-study $1 \&$ Sub-study 2 regarding ways of developing writing skills \& use of English writing

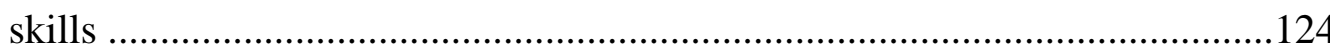

Table 12: Summary of the key data from the interviews of the 5 students in the joint program regarding the differences between writing in Chinese and writing in English 


\section{List of Figures}

Number

Page

Figure 1: Three levels of context in this study........................................................18

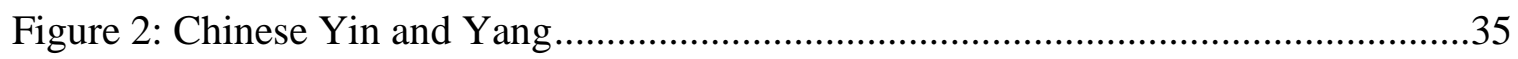

Figure 3: Equal-status concurrent triangulation design .......................................... 74

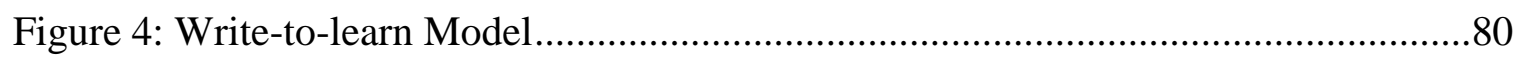

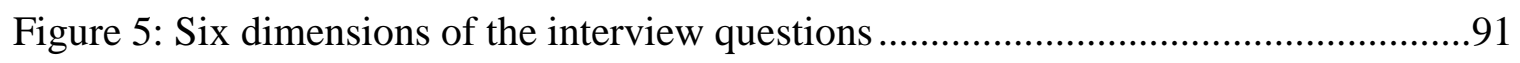

Figure 6: Steps in analysis employing thematic networks .......................................98

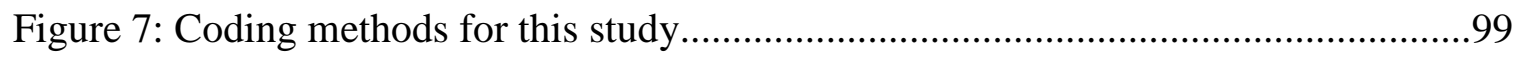




\section{List of Abbreviations}

$\begin{array}{ll}\text { CET } & \text { College English Test } \\ \text { EFL } & \text { English as a Foreign Language } \\ \text { ELT } & \text { English Language Teaching } \\ \text { ESL } & \text { English as a Second Language } \\ \text { IELTS } & \text { International English Language Test System } \\ \text { LAD } & \text { Language Acquisition Device } \\ \text { L1 } & \text { First Language } \\ \text { L2 } & \text { Second Language } \\ \text { SLA } & \text { Second Language Acquisition } \\ \text { TOEFL } & \text { Test of English as a Foreign Language } \\ \text { ZPD } & \text { Zone of Proximal Development }\end{array}$




\section{Chapter 1: Problem Statement}

A significant educational issue that arouses my interest is EFL (English as a foreign language) writing in China. Since China's reform and opening up in the early 1980s, English teaching and learning has been occupying an important position in China's education. From elementary school to high school, school curriculums have included English as one of the three important subjects, with the other two being Chinese and math. English is also offered as a two- or three-year compulsory course in colleges and universities (College English Curriculum Requirements, 2004). Now that schools and colleges attach importance to English teaching and learning, and students spend over ten years learning English, Chinese students should have a good English proficiency when they graduate from high school or college. However, quite a number of Chinese EFL students, who seem to get good marks in English exams or tests, are poor or limited in their ability to use the language. This is especially true to English writing (Wang et al. 2000). It is important for Chinese students to have the skill to write well in English so that they can continue to be good English writers for their future academic pursuit and achievement.

As a former EFL teacher at a middle school, high school and a university in China respectively, I observed this phenomenon in my EFL teaching experience and it has also been reported in relevant scholarly literature (e.g. Yan, 2010; Zhang \& Mi, 2010; Wang et al., 2000). My observation and the relevant literature identify five problems with China's EFL writing instruction at the tertiary level. First and foremost, teaching practices for writing tend to be decontextualized and teaching focuses on accuracy of 
form rather than thought and meaning-making. In-class writing practices lack meaningful contexts (Yan, 2010; Wang, 1999). Second, there is an over-emphasis on writing as a product. The writing process is neglected or simplified and students do not receive sufficient and effective teacher scaffolding during the process of construction of a piece of writing (Yan, 2010). This may be partially due to China's long-standing exam-oriented education system (Han, 2005). For many students, the purpose of learning English is to score high on tests. Third, teacher feedback is predominantly concerned with lexicogrammatical errors (Yan, 2010; Wang et al., 2000), which is related to College English Test (CET) requirements for writing and the writing approaches adopted by EFL teachers. Fourth, inadequate input prevents students from writing more effectively and naturally (Zhang \& Mi, 2010; Wang et al. 2000;). As both teachers and students rely heavily on the designated set of textbooks, and the College English Test is also based on the textbooks, students are not encouraged or motivated to read other books in the original, resulting in their scant exposure to authentic materials and the emergence of the Chinglish phenomenon. Finally, learners' needs are ignored, resulting in a lack of selfmotivation to write more for some learners (Yan, 2010; Zhang \& Mi, 2010). The absence of communicative purposes in the design and the requirements of the curriculum may lead to learners' frustration and antipathy, as learners' individual needs for English are hardly acknowledged.

Chinese students' limited ability to write in English is reflected in such tests as SAT (Scholastic Aptitude Test), TOEFL (Test of English as a Foreign Language) and IELTS (International English Language Testing System). According to Yang (2011), a report on 
the 2010 SAT performance of Chinese students conducted by DK Education, an overseas study agency based in Beijing, found that the average score was 1,213 points out of the total of 2,400, some 296 points lower than US students and 337 points lower than the benchmark set by College Board, the organizer of the test. The gap is mainly derived from the reading and writing parts of the test. Chinese students scored 170 points less than US students in these two parts. In addition, based on the test data (Li \& Curtis, 2010), IELTS test-takers from mainland China received somewhat lower scores compared with test-takers worldwide. They were strongest in academic reading, with an average reported band score of 5.76 (the average for test-takers worldwide was 5.88) but weakest in writing with an average band score of 5.12 (the average for test-takers worldwide was 5.47). Chinese students' relative poor English writing ability is also reflected in their overseas academic pursuit and actual application. For instance, Zhang and Mi (2010) found that Chinese students encounter language-related problems in their academic studies in Australian universities. The biggest problem is their writing across academic disciplines. In their academic writing, one common problem is the Chinglish phenomenon. Chinglish refers to a variety of English used by speakers of Chinese or in a bilingual Chinese and English context, typically incorporating some Chinese vocabulary or constructions, or English terms specific to a Chinese context. According to Li (1993), Chinglish is the misshapen English produced by Chinese learners who draw upon Chinese rules and structures mechanically as the result of mother tongue interference in their use of English. Pinkham (2000) also put it, "Chinglish is a misshapen, hybrid language that is neither English nor Chinese but that might be described as 'English with 
Chinese characteristics'" (p.1). In most cases, Chinglish is characterized by word-to-word translation of Chinese expressions and is considered to be a deformed language phenomenon. As its composition and scope of use are both unstable and limited, it tends to "cause barriers in international communication and cultural exchanges" (Li, 1993, p. 18).

\section{Background of the Problem}

\section{A Brief Overview of China's EFL History}

It was in 1978 that China initiated the reform and opening-up policy. Since then, China's economy has been developing at a fast pace. To respond to the needs of its rapid economic development, and to further enhance international cooperation and strengthen economic competitiveness in the world, English assumed an increasingly important position in China's education. Thus, the reform and opening-up policy brought about fundamental changes in China's EFL policies. In 1982, the Ministry of Education promulgated the Secondary English Syllabus. It was the first time in the history of China's education that foreign languages were considered "an important tool for the study of cultural and scientific knowledge and the promotion of international relations" (Secondary English Syllabus, 1982, p.1). According to the Syllabus, the purpose of teaching English was to "provide students with basic training in listening, speaking, reading and writing, with particular emphasis on listening and speaking stage, and reading and writing at a later stage, after the basic grammatical structures were mastered" (Secondary English Syllabus, 1982). In the meanwhile, the Ministry of Education included English as one of the three core elements in China's college entrance 
examinations (the other two being Chinese and math). As English has become a major part of matriculation exams and counts heavily in entrance exams for college and university students, English has never been so important as it is today in terms of China's EFL history.

To align with the Secondary School Syllabus, the College English Syllabus was officially published in 1986 by the Higher Institution Foreign Languages Teaching and Learning Committee, authorized by the Ministry of Education. This policy led to the popularity and importance of China's EFL at the tertiary level. This policy has then been used to guide and standardize China's EFL education.

As the 1986 syllabus for college English education was fundamentally test-oriented, it failed to improve students' comprehension competence, especially in speaking and writing abilities (Hu, 2005). To address this problem, the Ministry of Education issued a third revised syllabus in 1999. Although the new syllabus raised some significant issues about the reform of teaching models and curriculum, it was still test-focused in nature because the College English Testing System greatly limited the scope and effect of its practical implementation $(\mathrm{Hu}, 2005)$. When the demerits of the 1999 syllabus were gradually brought to light after over five years' practice, the fourth version, also the current version, of the syllabus was released in 2004, and its title was changed to College English Curriculum Requirements. Rather than merely test-based, this new policy conceptualizes EFL teaching and learning at both the knowledge and application level, and encourages an integrated teaching model for cultivating both students' language skills and cross-cultural communication ability. 


\section{College English Syllabus}

As China's EFL policy at the tertiary level, the College English Syllabus has exerted a tremendous influence on English teaching and learning (Wang, 2010). Since it was officially released in 1986, all Chinese universities and colleges have virtually adopted the College English Syllabus (Wang, 2010). In other words, English is taught under the guidance of the nationally standardized syllabus in Chinese colleges and universities. The requirements in the Syllabus are used as benchmarks for curriculum development, material development, and teaching evaluation.

The Syllabus prescribes descriptors for the requirements in seven different areas: vocabulary, grammar, reading, listening comprehension, speaking, writing, and translation. In light of the College English Teaching Requirements (2004), in the area of writing, the requirements are:

Students should be able to complete writing tasks for general purposes, e.g., describing personal experiences, impressions, feelings, or some events, and to undertake practical writing. They should be able to write within 30 minutes a short composition of no less than 120 words on a general topic, or an outline. The composition should be basically complete in content, clear in main idea, appropriate diction and coherent in discourse. Students are expected to be able to have a command of basic writing strategies (p. 24).

\section{College English Test}

When the College English Syllabus was first published in 1985, the Ministry of Education postulated that the goals and requirements prescribed in the syllabus were used as criteria for the ministry to evaluate college English teaching and learning, and that for the colleges and universities that followed the syllabus, students who completed their 
Band 4 and 6 studies would need to take a standardized test (CET Committee, 1999). Thus, the CET Committee was established and such standardized tests were officially launched in 1987. The test designed for Band 4 (CETB-4) is composed of five sections: listening comprehension, vocabulary, structure, reading comprehension, and writing. The test syllabus for Band 4 stated the requirements for each section of the test. For the writing section, students are required to write a short composition of 100 to 120 words within 30 minutes. The writing needs to be correct in expression, coherent, and without significant grammatical mistakes. Expressions such as correct in expression, coherent, and without significant grammatical mistakes in both the College English Syllabus and the CET syllabus all suggest that correct form rather than well-developed thought is most valued in the CET writing section.

\section{Textbooks}

Textbooks play an important role in China's college English education. As far as teachers are concerned, the benefits of using textbooks include time advantage, access to more choices of professionally produced resources, relieving teachers from the pressure of searching for original materials and providing a guide to teach more effectively (Hutchinson \& Torres, 1994; Richards, 1998; Harmer, 1991). In light of Hutchinson and Torres (1994), textbooks save time, give direction to lessons, guide discussion, facilitate giving of homework, making teaching easier, better organized, more convenient, and learning easier, faster and better. Therefore, textbooks provide confidence and security, especially for inexperienced teachers. In terms of students, textbooks provide an orientation to their learning program, helping them understand what they will be studying, 
in what sequence, and how much material needs to be covered in the course of their learning.

As every coin has two sides, textbooks are also viewed as an impediment to EFL teaching and learning, and teacher development. According to Richard (1998), textbooks can lead to the unjustifiable attribution of qualities of excellence, authority, and validity to published textbooks. With this belief, teachers fail to look at textbooks critically and creatively. In the scenario of China's EFL education, textbooks are "compiled by a government-appointed panel of experts according to the curriculum set by the government and are universally used by universities and colleges throughout the country" (Wang, 1999). The two designated sets of textbooks that were developed under the guidelines of the College English Syllabus are College English, for students of arts and sciences and College Core English: Reading and Writing, for students of science and engineering. Textbooks represent the syllabus and dictate what should be taught in the classrooms. Teachers teach according to textbooks, students acquire language input mainly from textbooks, and achievement tests are designed based on the content of textbooks. As both teachers and students rely heavily on textbooks, students cannot be sufficiently exposed to English authentic materials. Inadequate exposure to English authentic materials may result in students' limited ability to use the English language.

\section{Status Quo of China's EFL Writing Instruction}

In my perspective, such a policy worked well in the initial stage primarily because China's EFL education has a comparatively short history (about one hundred years) and its EFL educational foundation was rather weak. Furthermore, China is a huge country 
with 56 ethnic groups, and the level of EFL education varied from one province to another and one area to another. Officially released in 1986, the College English Syllabus has seen more than 20 years of reforms and revisions. As the benchmarks for college English teaching and learning, the Syllabus has gained wide recognition and made contributions to the quality and efficiency of College English teaching and learning in China (Wu, 2005). Although the College English Syllabus has been playing an important role in improving college students' English level, some problems have also arisen in this policy implementation process. Virtually, educators and researchers have recognized the problematic nature of implementing an educational policy such as curriculum (Snyder, Bolin \& Zumwalt, 1992). The process of curriculum is often described as a "black box" (O'Sullivan, 2002), in which challenges to implementation can arise. According to Bekalo and Welford (2000), a discrepancy often exists between what was intended and what is enacted. The view that these two objectives should match pose challenges for policymakers, administrators, and teachers in particular (Connelly \& Lantz, 1991).

Based on my observation and experience, a discrepancy tends to exist between theory and practice. This mismatch emerges when curriculum policy is implemented in practice. In her research on the implementation of College English Syllabus in China, Wang (2004) also found that there is a discrepancy between policymakers and administrators and between policymakers' intentions and teachers' implementation. In terms of China's EFL curricular policy, policymakers regulate a general, open-ended, and abstract policy to offer local colleges and universities and teachers some flexibility and autonomy when they put it into practice. However, administrators interpret the open- 
endedness of the curricular policy differently from the policymakers intended. Instead of using the flexibility to help students gain proficiency, they seem to place emphasis on only one outcome: students' good score on the national English test (Wang, 2004).

As the CET is used as the exclusive assessment of college English education and a criterion to evaluate and rank higher education institutions. In turn, these institutions award teachers' merit rewards and promotion based on the pass rate of the CETB-4 and CETB-6 and peg the CET score to the students' academic degree and gradation (Gu, 2005). What's more, the CETB-4 and CETB-6 certificates are increasingly used as a gatekeeping device for access to higher degree education, employment, and even residential certification in big cities (Wang, 2007; Gu, 2005). Under such circumstances, the College English curriculum is narrowed to give way to coaching materials; students spend most of their time memorizing vocabulary and doing simulation tests rather than developing communicative competence; developing test-wise skills are common practices $(\mathrm{Gu}, 2005$; Yang, 2005). As a result, teachers teach to the test and students learn for the test. Eventually, EFL teachers may lack autonomy, flexibility and creativity, resulting in the current dilemma of China's EFL instruction. This dilemma begins to backwash negatively on College English teaching and learning practices. To change this dilemma, some colleges and universities are beginning to face the problems by changing local policies and encouraging innovative teaching methodology (Tang, 2005; Gu, 2005).

\section{Statement of the Research Problem}

The purpose of this study is to examine how Chinese college EFL students respond to changes in their writing instruction that pays attention to the context of EFL teaching 
and learning. I argue that this dilemma of China's EFL writing instruction at the tertiary level is mainly due to the decontextualization of writing practices in EFL classes, impacted by the College English Syllabus, a curricular policy that sets standards for college English teaching and learning in China. In this study, I contend that in EFL writing instruction, what teachers teach or what students learn should be contextualized, and contextualization is a key factor contributing to EFL learners' writing skill development, and students' adequate comprehensible input of authentic materials will be a breakthrough in the issue of contextualization.

\section{Significance of the Research Problem}

This study is one of the few empirical studies using both quantitative and qualitative methods to explore the contextualization of EFL writing in China. Evidence shows that Chinese students' limited ability to write in English has affected their further academic pursuit and achievement (e.g. Zhang \& Mi, 2010; Wang et al. 2000). By exploring the issue of context in EFL writing, using the mixed methods approach, I will develop an understanding of the EFL writing dilemma in China's tertiary education. It is hoped that the research findings will help administrators, curriculum specialists, EFL teachers and material developers gain a better understanding of the status quo and the challenges of China's EFL writing education at the tertiary level. It is also hoped that this study will provide information and implications to Chinese EFL teachers for future planning and innovation with regard to EFL writing instruction. 


\section{Presentation of the Methods and Research Questions}

This study employed the mixed methods approach design to examine how Chinese EFL college students respond to changes in their writing instruction that pays attention to the context of EFL teaching and learning. According to Creswell (2009), the mixed methods is "an approach to inquiry involving collecting both quantitative and qualitative data, integrating the two forms of data, and using distinct designs that may involve philosophical assumptions and theoretical frameworks" (p. 32).

In the case of my study, the dilemma of China's writing instruction was assumed to be related to the decontextualization of writing practices in EFL classes. A new model that placed a focus on the contextualization of writing practices was used to explore the outcome of adding context to EFL teaching and learning. Using the mixed methods approach to evaluate the effectiveness of the new teaching model and elicit the perceptions and attitudes of the students about contextualized writing practices in EFL classes provides a means of data triangulation. This triangulation of data through the use of multiple methods to study a single problem is considered essential to verify and cross-check the research findings in a study (Creswell, 2003; Morgan, 2013). Therefore, the mixed methods approach was considered to be a useful approach for such a study.

According to Creswell (2009), Maxwell (2005) and Merriam (2009), quantitative

methods are ideal for measuring pervasiveness of known phenomena and central patterns of association, including inferences of causality while qualitative methods allow for identification of previously unknown processes, explanations of why and how phenomena occur, and the range of their effects. Mixed methods research, then, is more than simply 
collecting qualitative data from interviews, or collecting multiple forms of qualitative evidence or multiple types of quantitative evidence. It involves the intentional collection of both quantitative and qualitative data and the combination of the strengths of each to answer research questions. Based on Creswell (2009), the mixed methods approach has three advantages: 1) variation in data collection leads to greater validity; 2) triangulation of data can help answer the research questions from a number of perspectives; 3) one method does not provide all the information required.

The mixed methods approach was considered well suited to this study because the use of either quantitative or qualitative approaches did not completely address the research problem, whereas a combination of approaches did. To have a better understanding of the role of context in China's EFL writing instruction, I designed two sub-studies in this study: Sub-study 1 and Sub-study 2. In Sub-study 1, an experiment was conducted to test the effectiveness of the new writing model - the Write-to-learn Model. In the experiment, I used such research instruments as survey and test. Such a design was useful for obtaining data that allow quantitative predictions to be made and can generalize research findings when the data are based on random samples of sufficient size. The research results are relatively independent of the researcher and may have higher credibility (Creswell, 2009; Morgan, 2013). In addition, at the end of the experiment, the students were interviewed about their perceptions and attitudes concerning the Write-to-learn Model I developed that focused on the contextualization of writing practices. In Sub-study 2, five students in the joint program were interviewed about their respective learning experiences in a university in China and in a university in 
the United States in an attempt to elicit their perceptions regarding writing instruction in China and in the United States. Therefore, the combination of quantitative and qualitative approaches "provides a more complete understanding of a research problem than either appropriate alone" (Creswell, 2009, p. 32).

With the goal of examining how Chinese EFL students respond to changes in their writing instruction that pays attention to the context of EFL teaching and learning, three research questions were designed to explore the impact of context on EFL students' writing achievement. The three research questions were as follows:

1. How does adding context create different writing outcomes for Chinese EFL students?

2. How do Chinese students imagine/reflect the ways of developing writing skills and the use of English writing skills?

3. How do Chinese EFL students compare/contrast writing in Chinese and in English?

\section{Definitions of Key Concepts}

The following are the definitions of concepts and terms that are highly relevant to this study.

\section{Affective factors}

The learner's attitude towards the learning process has been identified as being critically important to second language acquisition. Research has shown that learning a language involves the emotions and the identity in a way other subjects do not (Guiora, et al., 1972; Horwitz, et al., 1986; Lybeck, 2002). Schumann (1998) states, "I believe that 
emotion underlies most, if not all cognition and I will argue that variable success in second language acquisition is emotionally driven" (p. xv). He also argued that emotion filters all learning and cognition. If this is true, then a study of the affective factors in second language learning would be especially important. Krashen (1985) proposed the Affective Filter Hypothesis as an explanation for the lack of success of some learners. According to Krashen (1985), the learner's subconsciousness screens second language (L2) language input based on affective factors such as individual needs, motives, attitude and emotional state. Depending on how strong or weak the filter, the learner will either convert input into knowledge or screen it out. This would account for the different outcomes in learners of the same age and in the same situation. Lower achievers would be said to have a higher filter than those who acquire a higher level of competency. In this sense, it is of great important for EFL teachers to meet students' affective needs in the process of second language acquisition. In this study, affective factors in second language acquisition are summarized as acculturation, ego, personality, emotion, beliefs about learning, attitudes, and motivation.

\section{Authentic materials}

There are many references to authentic materials in the English language teaching (ELT) literature. According to Peacock (1997), authentic materials refer to the materials that have been produced to fulfill some social purpose in the language community. Widdowson (1990) differentiates the term as material designed for native speakers of English used in the classroom in a way similar to the one it was designed for. Hamer (1991) defines authentic texts (either written or spoken) as those that are designed for native 
speakers; they are real texts designed not for language students but for the speakers of the language in question. Nunan (1989) defines authentic materials as material which has not been specifically produced for the purposes of language teaching. In this study, authentic materials are defined as real in the sense that they are not created for students as the target audience but for native speakers, including newspapers, TV programs, magazines, the Internet, movies, songs, brochures, comics, literature (novels, poems, and short stories), and so forth.

\section{Comprehensible input}

Comprehensible input is language input that can be understood by learners despite their not understanding all the words and structures in it. It is described as one level above that of the learners if it can only just be understood. According to Krashen's (1985) theory of language acquisition, giving learners this kind of input helps them acquire language naturally rather than learn it consciously.

\section{Context}

Context has been a perennial topic in linguistics and has been a key concept both in the field of pragmatics and in ethnographically oriented studies of language use as well as quantitative ones (Goodwin \& Duranti, 1992). For example, Ochs (1988) argued that the process through which a child learns to speak cannot be analyzed simply as language acquisition, but instead constitutes a profound process of language socialization through which the child by learning how to speak in a community becomes a competent socialized member of his or her society. Such research indicates that it is important to pay 
attention to the details of how human beings employ language to build the social and cultural worlds that they inhabit.

When the issue of context is raised, it is argued that the focal event cannot be properly understood, interpreted appropriately, or described in a relevant fashion unless one looks beyond the event itself to other phenomena within which the event is embedded. Focal event here is a term used to identify the phenomenon being contextualized. Thus, context is a frame that surrounds the event being examined and provides resources for its appropriate interpretation (Goodwin \& Duranti, 1992). For example, from a perspective of ethnography, context is viewed as a process of inference, the study of the contextualization cues through which context is invoked, and how the cultural loading of such cues can lead to miscommunication in cross-cultural settings (Gumperz, 1982).

In the study of context, some researchers attempted to specify some of the basic parameters of context. For example, Ochs (1979) noted the range of phenomena that the notion of context must include: 1) setting, i.e. the social and spatial framework within which encounters are situated; 2) behavioral environment, i.e. the way that participants use their bodies and behavior as a resource for framing and organizing their talk; 3) language as context, i.e. the way in which talk itself both invokes context and provides context for other talk; 4) extrasituational context, i.e. background knowledge that extends far beyond the local talk and its immediate setting. Based on this, Hymes (1974) proposed SPEAKING model, in which, context is considered to contain eight components: setting and scene, participants, ends, act sequence, key, instrumentalities, norms and gene. As 
Hymes is a sociolinguist, his SPEAKING model mainly looks at context from a socialcultural perspective.

In this study, my understanding of context includes three levels: linguistic context, situational context and cultural context, as Figure 1 shows. Linguistic context refers to the discourse that surrounds a language unit and helps to determine its interpretation according to the internal settings of discourse, i.e. the relationships between words, phrases, sentences and discourse. Therefore, linguistic context can also be subdivided into sentential context and discourse context. Situational context deals with the surroundings of the discourse, including time, place, manner, nature of an event and the relationships between the participants. Cultural context refers to the history, culture and customs of a society. In general, context has two functions: restriction and interpretation. The restriction function means that language context eliminates the ambiguity and vagueness of discourse through the restriction of linguistic units while the interpretation function means that language context can help people interpret all kinds of complex linguistic phenomena.

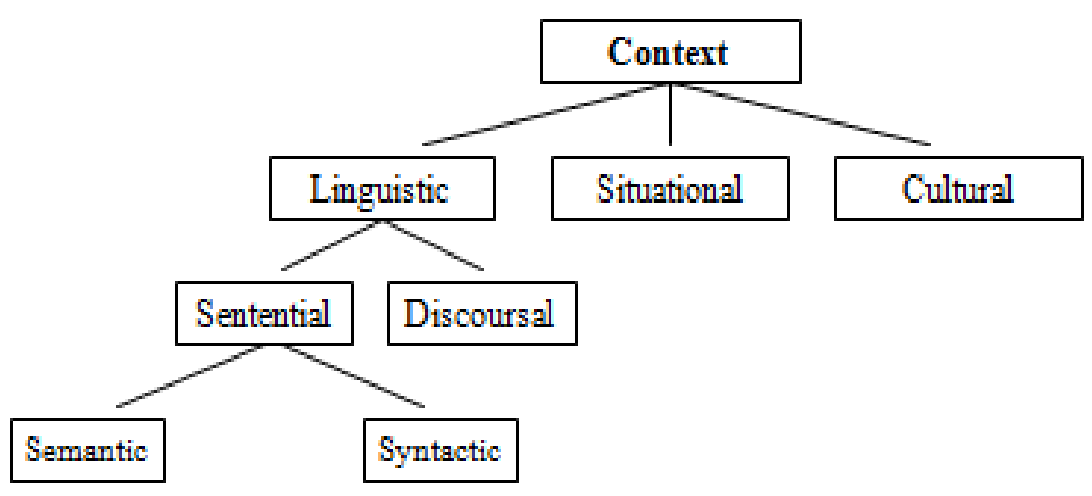

Figure 1. Three levels of context in this study 


\section{Contextualization}

Contextualization in this study means placing the target language in a realistic setting to make the learning process meaningful to students.

\section{Input}

Input that learners receive in the learning process plays a very important role in second language acquisition (SLA). As Gass (1997) pointed out, second language learning simply cannot take place without input of some sort. Learners need to be provided with the opportunities to make sense of what they hear or see, to notice the contexts in which the samples of the target language are used, to interact with them as well as to compensate for the insufficiency. The importance of input has been recognized and advocated by researchers. Krashen (1982) assumed that the success in the second language acquisition requires a comprehensible input, i.e. the input slightly beyond the level of the learner's comprehensibility. This input should be meaningful and interesting to the learners although it does not necessarily have to be grammatically sequenced. Long (1983) also supported the meaningfulness of the interaction between the learner and the message, and underlines the importance of preparing learners from the early stages to express non-comprehension through the simplest possible ways. However, ESL/ELF teachers seem to opt for the finely-tuned input, which is exactly at the learner's current level. All that goes beyond tends to be translated into the mother tongue.

In the meanwhile, not all the available data in the learner's environment can be absorbed and used in building the learner's interlanguage system. According to Krashen (1982), even if input is understood, it may not be processed by the learner's internal 
mechanisms because comprehensible input is not a sufficient condition for second language acquisition. It is only when input becomes intake that second language acquisition takes place. Corder (1967) discussed the difference between input and intake as follows:

The simple fact of presenting a certain linguistic form to a learner in the classroom does not necessarily qualify it for the status of input, for the reason that input is "what goes in" not what is available for going in, and we may reasonably suppose that it is the learner who controls this input, or more properly his intake (p.165).

As input is converted into intake, learners make use of this material for dual purposes, i.e. comprehension and acquisition. Chaudron (1985) proposed an intake model that consists of three intake stages: 1) the preliminary intake (i.e., the perception of input); 2) the subsequent stage of recoding and encoding semantic information into long-term memory, and 3) final intake (i.e., where learners fully integrate and incorporate the linguistic information in the input into their developing grammars).

\section{Interculturality}

Interculturality is the interaction of people from different cultural backgrounds using authentic language appropriately in a way that demonstrates knowledge and understanding of the cultures.

\section{Summary}

Chapter 1 was an introduction of the study. In this chapter, I first presented the research problem. I then provided the background of the research problem. I next talked about the significance of the research problem. Finally, I discussed the purpose of the 
study, the research methods and research questions and furnished the definitions of the key concepts. In the next chapter, Chapter 2, I will review the literature related to the study. 


\section{Chapter 2: Literature Review}

The purpose of this study was to examine how Chinese EFL college students respond to changes in their writing instruction that pays attention to the context of EFL teaching and learning. In this chapter, I first provide a review of the literature relevant to context and EFL/ESL writing instruction. Then I review the literature on four learning theories relevant to EFL writing instruction and four major writing approaches used in EFL/ESL classrooms as the theoretical framework of this study. After that, I synthesize the literature and critique the relevant studies in relation to China's EFL writing instruction at the tertiary level and come up with my hypothesized conceptual framework used to guide this study. Finally, I review the methodological literature that informs and guides the study that aims at helping improve China's EFL writing instruction at the tertiary level.

\section{Review of the Research Literature}

\section{Context}

Based on Lave (1988), most learning occurs naturally through activities, contexts, and cultures, and schools too often abstract learning, unsituate it, teach concepts removed from natural contexts and applications. I assume that if students learn a foreign language out of context, it is likely that the phenomenon like Chinglish will occur. In the next section, I will focus on reviewing the literature concerning lexical context, syntactic context and cultural context.

Vocabulary: Learning in Context or Learning out of Context. The importance of vocabulary is well-recognized as a prerequisite for writing. Laufer and Nation (1995) found that a learner's vocabulary size can be reflected in that person's productive use of 
the language such as writing. Nation (2001) suggested that an increase in L2 learners' academic vocabulary can contribute to higher ratings of their academic written texts.

How is vocabulary learned in EFL/ESL classes? It seems that there are conflicting views on learning words in context and learning words out of context. Some researchers believe that the former approach results in better vocabulary acquisition than the latter (Judd, 1978; Krashen, 1989; Oxford \& Scarcella, 1994). Judd (1978), for example, noted, "Most people agree that vocabulary should be taught in context. ... Words taught in isolation are generally not retained. In addition, in order to grasp the full meaning of a word or phrase, students must be aware of the linguistic environment in which the word or phrase appears" (p. 73). Oxford and Scarcella (1994) assumed that while decontextualized learning word lists may help students memorize vocabulary for tests, students "rapidly forget words memorized from lists in most cases" (p.237). McCarthy (1990) also observed that a word learned in a meaningful context is best remembered and assimilated. Krashen's (1989) osmosis hypothesis holds that acquiring vocabulary through massive reading for pleasure is more effective than learning words through purposeful vocabulary exercises. Schouten-van Parreren (1989) contended that teaching words in context is preferable because words presented in this manner have "many points of support" (p. 77), while words presented in isolation lack points of support and cognitive footholds in learners' memory, and will, therefore, be easily forgotten. From these studies, it is not difficult to conclude that learning vocabulary in context is superior to learning vocabulary without a context. 
From the perspective of L2 writing instruction, Hyland (2007) proposed a genre approach to help L2 learners understand the vital roles of vocabulary choices and cohesion patterns in achieving literacy in a second language. More and more research is showing that vocabulary is often made up of formulaic multi-word sequences (Cortes, 2004; Wray, 2002). According to Cortes (2004), formulaic sequences are of great importance for L2 writers for at least three reasons: (1) the formulaic sequences are often repeated and become a part of the structural material used by advanced writers, making the students' task easier because they work with ready-made sets of words rather than having to create each sentence word by word; (2) as a result of their frequent use, such sequences become defining markers of fluent writing and are important for the development of writing that fits the expectations of readers in academia; (3) these sequences often lie at the boundary between grammar and vocabulary; they are the lexico-grammatical underpinnings of a language so often revealed in corpus studies but much harder to see through analysis of individual texts or from a linguistic point of view that does not study language-in-use (Coxhead \& Byrd, 2007, p. 134). Ermma and Warren (2000) claimed that various types of formulaic sequences are found to make up $52.3 \%$ of the writing discourse investigated. One reason for this widespread use is that formulaic sequences are pragmatically efficient. Therefore, appropriate use of formulaic sequences is considered of great importance to L2 writing.

The importance of formulaic sequences in L2 learning and writing is also supported by my observation and experience. A good example is to sleep like a log. Many Chinese students will use to sleep like a pig instead of to sleep like a log because they are 
influenced by the similar Chinese expression of 睡得像猪一样死 (shuì de xiàng zhū yí yàng š̌). Another good illustration is what happened to me in 2005. In 2005, my family and I came to the United States. Once, I took my son to the MacDonald's near where we lived. When we were ordering the food, I did not even understand the expression "For here or to go" although I had learned English for many years before I came to the United States. In 2012, I met with several professors of English from the university where I used to work. I asked them if they knew how to express this phrase. To my great surprise, none of them knew for sure how to say it. Without exception, it occurred to them that the expression should be "Would you like to eat here or take it away?" instead of "For here or to go?".

In the case of China's EFL instruction at the tertiary level, teaching and learning are guided by the College English Syllabus and College English Test; teachers and students have to rely heavily on textbooks. Students generally learn vocabulary from the word list of each unit in the textbooks (see Appendix A). The limited context where the words are used tends to be the text itself. In such a case, words are mainly learned out of context. As students are not encouraged or motivated to be exposed to the authentic materials, they tend to resort to the negative transfer of the Chinese language, resulting in the Chinglish phenomenon. This implies that it is far from enough to learn vocabulary merely for tests or from the textbooks. Vocabulary acquisition should be incorporated into grammar in the extensive reading of authentic materials. Next, I will have a review of literature concerning grammar instruction. 
Grammar: Explicit Instruction or Implicit Instruction. As grammar is defined as a set of rules used to describe an infinite number of sentence structures, and these rules can explain all the grammatically and ungrammatically acceptable sentences (Chomsky, 1965), there is no controversy that grammar plays an important role in L2 writing instruction. There has been considerable focus of attention on the relationship between explicit (analyzed) grammatical knowledge and implicit (unanalyzed) grammatical knowledge and how this might relate to language development. It is generally accepted that explicit knowledge is acquired through controlled processes in declarative memory, while implicit knowledge is acquired through much less conscious or even subconscious processes (Macaro \& Masterman, 2006).

According to Krashen (1985), grammar instruction does not improve learners' use of the language, only their declarative knowledge of it. Knowing explicit grammar rules may not turn into accurate, fluent language production in oral or written communications. He therefore concluded that grammar instruction is unnecessary for L2 acquisition. Frantzen (1995) investigated whether explicit grammar teaching and corrective feedback improved grammatical knowledge and accuracy and fluency of writing, as measured by a discrete-point grammar test and an essay before and after the intervention. Both treatment and comparison groups made significant progress in both areas. However, the experimental group outperformed the comparison group on the grammar test only. Macaro and Masterman (2006) investigated the effect of explicit grammar instruction on grammatical knowledge and writing proficiency in first-year students of French at a UK university, and found that explicit instruction leads to gains in some aspects of grammar 
tests but not gains in accuracy in either translation or free composition. Frodesen and Holten (2003) pointed out that "grammar in ESL writing is not just about error, and this aspect should not be the sole focus of grammar instruction in second language writing pedagogy" (p. 157). They suggested considering several factors, such as learners, texts and writing processes, when planning grammar instruction. Similarly, Byrd and Reid (1998) recommended that grammar instruction should be built upon an understanding of students, culture, language learning, and English grammar as it is used in various contexts for various communicative purposes. Martinsen (2000) also pointed out that grammar must be taught in the context of students' writing. For instruction to be effective, grammar teaching in writing classrooms must link rules with usage or difficulties students encounter in authentic writing tasks.

Evidence from intervention studies (e.g. Martinsen, 2000; Frodesen \& Holten, 2003) suggests that if learners are taught rules explicitly, they will perform better in grammar tests, but there is little evidence so far that they will perform better in less structured production tasks. Therefore, teachers should take into consideration the needs of students in terms of grammar acquisition. If teachers prepare students for exams or test, they can teach rules explicitly, otherwise, it would be better to associate students' grammar acquisition with their reading materials.

When it comes to the EFL instruction in China, according to my experience and observation, all grammar rules are often explicitly taught and learned in the Intensive English Course. In some colleges and universities, grammar is even offered as a course. Students are required to understand the grammar terminology and do plentiful grammar 
exercises. This kind of grammar exercises tends to lack a discourse context. With such grammar instruction, students may perform well in tests, but their ability to use the grammar in English writing is still poor or limited (Wang et al., 2000). The above discussion shows that implicit instruction of grammar seems to be more effective than explicit instruction of grammar in terms of writing. It is therefore advocated that grammar teaching in China's EFL writing classrooms link rules with usage or difficulties students encounter in authentic writing tasks. To this end, writing should not be separated from reading. In the next section, I will review the relationships between reading and writing.

Relationships between Reading and Writing. There are some studies concerning the relationships between second language reading and writing (e.g. Reid, 1993; Nystrand, 1986; Esmaeili, 2002). These studies indicate that reading and writing skills are interconnected. Writers read and reread their drafts in order to improve them. Readers, on the other hand, paraphrase and summarize in writing what they have read. Thus, reading and writing are "integrally connected" (Reid, 1993, p. 64). Nystrand (1986) expounded the connectedness between reading and writing by explicating the roles the readers and writers as interdependent of each other. Writers write on the premises of the readers, gearing their texts towards readers' expectations. Readers, on the other hand, read on the premises of the writer, since their goals and expectations are directly influenced by those of the writers. Thus, Ferris and Hedgecock (1988) suggested that ESL instruction should include reading and writing tasks that will prepare learners for the demands of their academic disciplines. 
Lee (2000) investigated reading-writing connections through a pedagogical focus on coherence. She concluded from her findings that reading and writing can be and should be taught as integrated skills. Through a pedagogical focus on coherence, she demonstrated the connections between reading and writing, with reading being seen as an essential and positive contributor to ESL students' emerging composing skills, and writing being used to help students prepare for, respond to, and comprehend reading selections more effectively.

Esmaeili (2002) explored the role of reading in a reading-to-write task by focusing on the test-takers' process when completing the task. By analyzing writing strategies through a post-task questionnaire and interview, he found that reading plays a critical role and concluded that for integrated tasks, "[e]xamining participants' writing strategies, overall, reveal how writing involves reading. In fact, one can hardly view reading and writing as stand-alone skills" (p. 615). Plakans (2009) studied the discourse synthesis process in reading-writing tasks and found that reading ability facilitates writing by providing content.

From the studies discussed above, it seems that there is no controversy over the close relationship between reading and writing. It occurs to me that the relationship between reading and writing is somewhat like that of the chicken and egg. Which came first is not as important as the fact that without one the other cannot exist. If reading is viewed as input, then writing should be regarded as output. Reading is a prerequisite for writing while writing is a stimulus for reading. The development and improvement of good writing call for a virtuous input-intake-output cycle. 
In the scenario of China's EFL curriculums at the tertiary level, based on my 20-odd experience and observation, reading and writing are often treated as two independent courses and separated from the other. The writing course focuses on teaching students how to write correct sentences, organize paragraphs and prepare for the College English Test (see Appendix C). Therefore, teaching practices for writing tend to be decontextualized, and teaching focuses on accuracy of form rather than meaning-making and thought. In-class writing practices tend to lack meaningful contexts.

The analysis of the above studies seems to indicate that reading instruction is more effective when intertwined with writing instruction and vice versa. When learners read extensively, they can become better writers. Reading a variety of genres helps learners learn text structures and language that they can then transfer to their own writing. In addition, reading provides learners with prior knowledge that they can use in their writing. Therefore, it is important that reading and writing be interconnected in China's EFL curriculums.

In the above sections, I have reviewed the literature regarding vocabulary, grammar and the relationships between reading and writing. The literature review shows that vocabulary and grammar are two essential components of a language that play an important part in determining and interpreting sentential meanings. However, only vocabulary and grammar are not enough to understand and interpret the meanings of all sentences of a language. Culture is another component that facilitates our appropriate understanding and interpretation of sentential meanings. It is generally agreed that language and culture are closely related. Language can be viewed as a verbal expression 
of culture. It is used to maintain and convey culture and cultural ties. The values and customs in the country where we grow up shape the way in which we think. In the next section, I will review culture in relation to second language teaching and learning.

Culture. Language is considered to be closely connected to culture. According to UNESCO (2007), language is one of the most universal and diverse forms of expression of human culture. It is at the heart of identity, memory and transmission of knowledge. Linguistic diversity is likewise a reflection of cultural diversity and cannot be precisely quantified or categorized. Therefore, language issues are central to culture. Languages result from a historical and collective experience and express cultural specific world views and value systems.

Chlopek (2008) stated that culture is a multidimensional concept, so to get to know a certain culture means to gain extensive knowledge. It appears useful to make a distinction between the so-called big-C culture and small-c culture. The big-C part of a given culture constitutes factual knowledge about the fine arts such as literature, music, dance, painting, sculpture, theater, and film. The small-c culture, on the other hand, comprises a wide variety of aspects, many of which are interconnected, including attitudes, assumptions, beliefs, perceptions, norms and values, social relationships, customs, celebrations, rituals, politeness conventions, patterns of interaction and discourse organization, the use of time in communication, and the use of physical space and body language. In this sense, language is also part of what we call culture, and it also reflects and interprets culture.

Some of the small-c cultural aspects are directly observable, and relatively easy to grasp and learn, such as celebrations and rituals. However, some other dimensions of a given culture 
are imparted to us from birth. Chlopeck (2008) argued that these small-c cultural aspects are deeply internalized and subconscious and are often noticed only in contrast with another culture. It is these intangible cultural aspects that have an enormous influence on peoples' way of thinking and their linguistic/non-linguistic behavior and that, importantly, determine the expectations and interpretations of other people's linguistic/non-linguistic behavior. A person who encounters an unfamiliar culture will lack knowledge of such behaviors, which may lead to amusing situations, and even conflict, caused by miscommunication. This happens because these aspects of culture are unspoken rules created by a community.

In the past decades, culture has been considered to be closely related to communication (Kaplan, 1996; Wang, 2003; Chen, 2005; Chen, 2009). Morillas (2001) stated,

Humans communicate linguistically in a cultural environment that constrains the form and nature of communication. Culture constrains both what is acquired and how it is acquired. In turn, communicative processes shape the culture that is transmitted from generation to generation (p. 295).

According to Saez (2002), culture plays three roles in the communicative process. First, it is from and through the communicators' cultural schemata that the communicative situation is perceived and understood and the communicative act created; second, it is also from and through the communicators' cultural schemata that the meaning of the addresser's communicative act may be inferred; third, the result of the communicative act is a modification of the communicators' cognitive schemata. Thus, culture and communication are two intimately related elements of the process of meaning construction. From the perspective of the relationship between culture and 
communication, interculturality needs to be understood and defined. Interculturality is often defined as the interaction of people from different cultural backgrounds using authentic language appropriately in a way that demonstrates knowledge and understanding of the cultures.

Based on American Council on the Teaching of Foreign Languages (2009), demonstrating intercultuality requires both the ability to use the language and to interact appropriately in cultural contexts. In order to communicate successfully, language learners must be able to relate appropriately to their audience. They should be able to react and respond appropriately to their own personal feelings, attitudes, and perceptions as well as those of people of other cultures. By having ample opportunities for authentic interaction, not only will learners progress through the levels of the language scale and increase their knowledge of culture, but they will also develop commensurate levels of interculturality.

To develop high levels of intercultural competence, language learners have to understand different cultural thought patterns. Thought patterns or ways of thinking are viewed as an important cue in culture. Thought patterns vary from culture to culture. Deng (1997) stated that different cultures result in different ways of thinking. People living in certain areas have their ways of thinking. Ways of thinking are related to many factors, such as geography, history, nation and world view. Therefore, different ways of thinking are one of the major causes of cultural differences. These differences lie in knowledge, perceptions, customs, methods and languages. In the past decades, a few studies have been conducted to explore the relationships between language and thought 
patterns. The most influential theory is the Sapir-Whorf Hypothesis or Whorfian Hypothesis (Perlovsky, 2009). This theory holds two claims: (1) people using different languages have different ways to thinking, which is called Linguistic Relativity; (2) language determines the way of thinking, i.e. thinking cannot exist in the world without language, which is termed as Linguistic Determination. However, some scholars (e.g. Lennberg, 1953; Pinker, 1994) came to different conclusions in their studies. They argued that thought patterns determine the use of language and the language is restricted by the cognition of human beings.

Some studies (e.g. Kaplan, 1996; Wang, 2003; Chen, 2009; Huang \& Wang, 2011) have been conducted to explore the impact of the different thought patterns between Chinese and English on writing. Kaplan (1996) thought that the English language and its related thought patterns evolved out of the Anglo-European cultural pattern. The expected sequence of thought in English is essentially a Platonic-Artistotelian sequence, descended from the philosophers of ancient Greece and shaped subsequently by Roman, Medieval European, and later Western thinkers. By contrast, Chinese culture was greatly influenced by the principle of yin and yang (see Figure 2) in Chinese philosophy. This principle means that all things exist as inseparable and contradictory opposites, for example female-male, dark-light and old-young. The two opposites attract and complement each other and, as their symbol illustrates, each side has at its core an element of the other (represented by the small dots). Neither pole is superior to the other and, as an increase in one brings a corresponding decrease in the other, a correct balance 
between the two poles must be reached in order to achieve harmony. Chinese yin-yang philosophy lays great stress on unity and harmony.

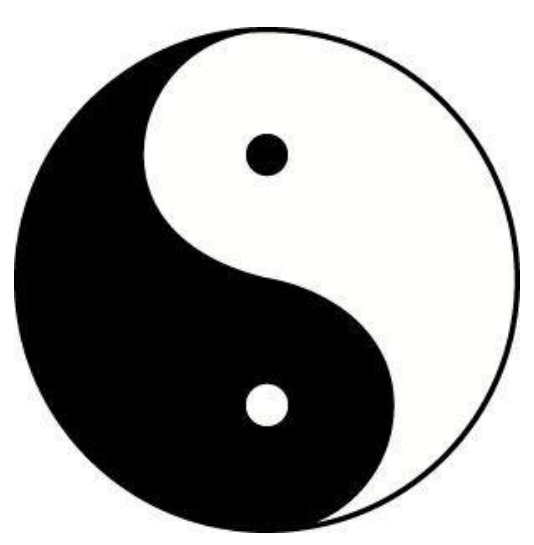

Figure 2. Chinese Yin and Yang

Chinese culture and western culture are based on different philosophies. They are two typical cultures in the world. The differences between these two cultures are reflected through different thought patterns. Dodd (1997) characterized American culture as having a linear thought pattern. As members of linear culture, Americans tend to stress beginnings and ends of events, to prefer unitary themes and to rely heavily on empirical evidence. They tend to present points sequentially and to follow an underlying organizational structure. By contrast, Chinese culture was characterized as having a cyclical thought pattern. With a cyclical culture, Chinese people tend to emphasize unity and synthesis of events and to express their views indirectly by means of idioms, proverbs and quotes. Huang and Wang (2011) summarized three major differences between Chinese and Western thought patterns as follows:

1. Entirety and synthesis thought pattern vs. analysis and logic thought pattern 
The Chinese have the thinking habit from whole to part, from big to small, and then reach a balance while Westerners consider things from part to whole, from small to big, and then draw a conclusion.

2. Specific thought pattern vs. abstract thought pattern

The Chinese use the form of metaphor, symbol and analogy to express something abstract while Westerners use logic, analysis and inference to express abstract ideas.

3. Tortuous thought pattern vs. straightforward thought pattern

The Chinese tend to present relevant information in great detail before hitting upon the main idea or theme while Westerners prefer to stick to the main idea or theme and then proceed to details.

Different cultural thought patterns are often reflected through different discourse patterns in writing. Kaplan (1996) stated,

The thought patterns which speakers and readers of English appear to expect as an integral part of their communication is a sequence that is dominantly linear in its development. An English expository paragraph usually begins with a topic statement, and then, by a series of subdivisions of that topic statement, each supported by example and illustrations, proceeds to develop that central idea and relate that idea to all the other ideas in the whole essay, and to employ that idea in its proper relationship with the other ideas, to prove something, or perhaps to argue something (p. 14).

Based on Huang and Wang (2011), there exist some distinctions between Chinese discourse pattern and English discourse pattern. The construction of English discourse pays attention to the integration. There is usually a topic sentence in each paragraph and one main idea. The content must be straightly relevant to the topic. Vocabulary, sentences 
and paragraphs must be logically connected with each other. Thus, cohesions are of great importance in English writing. In addition, clauses are often used in English writing so as to make meanings within a sentence clearer and more logical. This is called hypotaxis, a term used to refer to the subordination of one clause to another, or when the clauses are coordinated or subordinated to one another within sentences. By contrast, the construction of Chinese discourse stresses the entirety and takes vocabulary as its core. Generally, as long as sentences are semantically connected, the discourse can be smoothly developed. Because of this, cohesions are not so important as in English writing. In this sense, Chinese is of parataxis. This may account for the reason why Chinese students often write some sentences considered not so relevant to the topic.

In the past decades, the connection between language and culture has always been a concern of L2 teachers and educators. Recent studies (e.g. Byram, 1997; Kramsch, 2001) focus on the seamless relationship between L2 teaching and target culture teaching. These researchers claim that without the study of culture, teaching L2 is inaccurate and incomplete. For L2 students, language study seems senseless if they know nothing about the people who speak the target language or the country in which the target language is spoken. Therefore, acquiring a new language means a lot more than the manipulation of syntax and lexicon. Bada (2000) emphasized the role of culture in L2 by saying, "The need for cultural literacy in ELT (English language teaching) arises mainly from the fact that most language learners, not exposed to cultural elements of the society in question, seem to encounter significant hardship in communicating meaning to native speakers." (p. 101) 
McDevitt (2004) argued that there is no such thing as human nature independent of culture; studying an L2, in a sense, is trying to figure out the nature of another people. McKay (2003) contended that culture influences language teaching in two ways: linguistic and pedagogical. Linguistically, it affects the semantic, pragmatic, and discourse levels of the language. Pedagogically, it influences the choice of the language materials because cultural content of the language materials and the cultural basis of the teaching methodology are to be taken into consideration while deciding upon the language materials. For example, while some textbooks provide examples from the target culture, some others use source culture materials.

In discussing why culture should be involved in L2 teaching and learning, Kitao (2000) summarized some of the benefits of teaching culture as follows:

1. Studying culture gives students a reason to study the target language as well as rendering the study of L2 meaningful.

2. From the perspective of learners, one of the major problems in language teaching is to conceive of the native speakers of target language as real person. Although grammar books give so called genuine examples from real life, without background knowledge those real situations may be considered fictive by the learners. In addition, providing access into cultural aspect of language, learning culture would help learners relate the abstract sounds and forms of a language to real people and places.

3. In achieving high motivation, culture does have a great role because learners like culturally based activities such as singing, dancing, role playing, doing research 
on countries and peoples, etc. The study of culture increases learners' not only curiosity about and interest in target countries but also their motivation.

4. Studying culture gives learners a liking for the native speakers of the target language. Studying culture also plays a useful role in general education; studying culture, learners could also learn about the geography, history, etc. of the target culture.

The above studies show that language and culture are closely related. Culture has a humanizing and motivating effect on the language learner and the learning process. They help learners observe similarities and differences among cultural groups. Brown (1980) proposed that SLA is related to stages of acculturation, i.e. the ability of the learner to relate and respond easily to the foreign language culture. For a learner, the assimilation or adaption to the new culture is of crucial importance in SLA. Therefore, it is important that culture be incorporated into L2 teaching. In China's EFL instruction at the tertiary level, based on my experience and observation, culture is, to a great extent, ignored. The major reason is that EFL teachers are required to use the designated set of textbooks in EFL classrooms. The content of the materials for the textbooks is carefully selected and screened. Students do not have enough opportunities to be exposed to the culturally authentic materials. Consequently, learning without cultural context affects students' ability to use the target language properly. A case in point is that Chinese learners of English tend to greet foreigners with two expressions "Where are you going?" and "Have you eaten yet?". It is polite and appropriate to greet people this way in Chinese culture, but inappropriate in Western culture because these two expressions are considered to be 
personal questions. Therefore, it is of great importance that foreign/second language learners be exposed to culturally authentic materials. I assume that a good solution to this problem is to offer a culture-integrated course and provide students with adequate opportunities to be immersed in culturally authentic materials.

Written Corrective Feedback. Responding to student writing has been a perennial topic for research on L1/L2 writing (e.g. Leki, 1990; Silva and Brice, 2004) and a central concern in writing instruction (Campbell, 1998; Harmer, 2004; Reid, 1994). Thus far, a lot of studies (e.g. Ferris, 2003; Silva \& Brice, 2004; Harmer, 2004) have been conducted to investigate the effectiveness of teacher-written corrective feedback, most of which have reported the effectiveness of corrective feedback in second language writing. In spite of this, these studies have led to a debate over the advantages for direct (explicit) over indirect (implicit) corrective feedback, or vice versa. According to Ferris (2003), direct corrective feedback refers to the provision of the correct linguistic form or structure by the teacher to the student above the linguistic error while indirect corrective feedback is that which indicates that in some way an error has been made without explicit attention drawn, which may be provided in one of four ways: underlining or circling the error, recording in the margin the number of errors in a given line; or using a code to show where the error has occurred and what type of error it is. In this scenario, rather than the teacher providing an explicit correction, students are left to resolve and correct the problem that has been drawn to their attention.

Some studies show that direct corrective feedback is more effective than indirect corrective feedback. For example, Chandler (2003) found that direct feedback is more 
helpful to students because 1) it reduces the type of confusion that can occur if learners fail to understand or remember what the feedback is saying; 2) it provides learners with sufficient information to resolve more complex errors, such as errors in syntactic structure and idiomatic usage; 3 ) it provides learners with more immediate feedback on hypotheses that they may have made. However, some other studies (e.g. Ferris and Roberts, 2001) indicate that indirect feedback is more effective than direct feedback because it requires students to engage in guided learning and problem solving and, as a result, promotes the type of reflection, noticing and attention that is more likely to foster long-term acquisition.

As for positive feedback and negative feedback, a few other studies have also found that students appreciate feedback that includes praise (e.g. Reed \& Burton, 1985; Daiker, 1989). However, the same feedback to different students can elicit different reactions: some students prefer constructive criticism that indicates where there are problems in the writing whereas others prefer positive feedback (Enginarlar, 1993; Radecki \& Swales, 1988). Burkland and Grimm (1984) found that in general, students dislike feedback that dwells only on the negative aspects of their writing, and suggested that a mixture of both praise and criticism may be most beneficial. Hitz and Driscoll (1989) also pointed out in their study that praise needs to be credible and informative to be effective and that insincere praise is unlikely to encourage successful revisions. Cleary (1990) found that the key to positive feedback is clear communication in which the teacher genuinely communicates his/her feedback in students' ability to do good work. Prolonged negative feedback, however, has a detrimental effect on writers' confidence and motivation. 
There is a need to recognize that not all studies point to the helpfulness of teacherwritten feedback. For example, Ziv (1984) found that some students may disregard feedback given to their written efforts, as they view the teacher as an evaluator rather than a genuinely interested reader. Dohrer (1991) also found that some students may feel hostility towards their teachers as they want to maintain authority over their own texts. Ferris (1997) argued that students who do not revise based on teacher feedback might not be lazy but, instead, might be thinking independently and creatively. This may be related to their proficiency in writing.

Due to the increasing popularity of the process approach, some researchers (e.g. Paulus, 1999; Zhu, 2001) argued that peer review should be an important feature of process-oriented writing instruction as peer review is a collaborative activity involving students reading, critiquing and providing feedback on each other's writing, both to secure immediate textual improvement and to develop, over time, stronger writing competence via mutual scaffolding. So far, there is some literature that claims positive effects for peer feedback. Mittan (1989) considered that peer feedback can be more authentic and honest than teacher response. Chaudron (1984) claimed that since students' reviewers will soon perceive that other students experience the same difficulties in writing that they do, peer feedback may also lead to a reduction in writer apprehension and an increase in writer confidence. It may benefit the revision processes of reviewers as well as writers, making them less reliant on teacher feedback by helping them to internalize an audience and a checklist of evaluative questions to apply to their writing. 
It is hard to conclude that one type of corrective feedback is superior to the other. In the scenario of China's EFL writing at the tertiary level, teacher feedback is predominantly concerned with lexico-grammatical errors (Yan, 2010), which seems to be related to the College English CET. The CET requirements for writing stress language accuracy, so do the controlled/guided approach and the current-traditional approach. Based on my own teaching experience in a university in China, writing teachers point out and correct each and every error that the students commit in their compositions. This is a time-consuming and painstaking task for writing teachers and is sometimes hard for students to understand. On one hand, teachers spend a lot of time correcting each and every lexico-grammatical error; on the other hand, students are afraid of reading teachers' feedback because of the pages filled with corrected errors in red. Moreover, teachers' corrections may go beyond the students' ability to understand, and students commit similar errors in their future writing tasks. It seems to me that negative feedback like this does have detrimental effect on students' confidence and motivation. Therefore, I consider it helpful that positive feedback and peer feedback are to be used in China's EFL writing instruction to help build up students' confidence and satisfy their affective needs.

\section{Theoretical Framework}

Given the purpose of this study, a new teaching model called the Write-to-learn Model was used in the experiment of this study to examine the outcome of contextualizing writing practices in Chinese EFL classes. In this section, I review the literature on four learning theories and four writing approaches used in the EFL/ESL classrooms respectively as the theoretical framework of this study. On this basis, I 
synthesize and critique the literature reviewed as the theoretical framework of this study, and come up with my hypothesized conceptual framework.

\section{Four Learning Theories}

Learning theories are conceptual frameworks that describe how information is absorbed, processed and retained during learning. Each theory defines learning differently, and views the role of teacher, student and learning with differing perspectives. Therefore, learning theories can help us understand students' learning process and account for the theoretical foundation of teachers' methodology. In this section, I will review four learning theories: behaviorism, mentalism, constructivism and situated cognition. I view these four learning theories as relevant in the discussion of China's EFL writing instruction at the tertiary level.

Behaviorism. Behaviorism, also known as behavioral psychology, is a theory of learning based upon the idea that all behaviors are acquired through conditioning. Conditioning occurs through interaction with the environment (Skinner, 1957). Behaviorists believe that our responses to environmental stimuli shape our behaviors. Educationally, behaviorism thinks that a learner is essentially passive, responding to environmental stimuli. The learner starts off as a clean slate and behavior is shaped through positive reinforcement or negative reinforcement. Both positive reinforcement and negative reinforcement increase the probability that the antecedent behavior will happen again. In contrast, punishment decreases the likelihood that the antecedent behavior will happen again. Positive reinforcement indicates the application of a stimulus 
while negative reinforcement indicates the withholding of a stimulus. Learning is therefore defined as a change in behavior in the learner.

Behaviorists (e.g. Watson, 1924; Skinner, 1969) believe that a habit is formed when a particular stimulus becomes regularly linked with a particular response. If the stimulus occurs sufficiently frequently, the response becomes practiced and automatic. The learning of a habit, then, could occur through imitation, i.e. the learner copies the stimulus behavior sufficiently often for it to become automatic or through reinforcement, i.e. the response of the learner is rewarded or punished depending on whether it is appropriate until only appropriate responses are given.

In first language (L1) acquisition, children are said to master their native language by imitating utterances produced by adults and having their efforts at using language either rewarded or corrected. In this way, children are supposed to build up knowledge of the patterns or habits that constitute the language they are trying to learn. It is also believed that second language acquisition can proceed in a similar way. Imitation and reinforcement are the means by which the learner identifies the stimulus-response associations that constitute the habits of the second language.

According to the behaviorist learning theory, old habits get in the way of learning new habits. In terms of second language acquisition, "the grammatical apparatus programmed into the mind as the first language interferes the smooth acquisition of the second" (Bright \& McGregor, 1970, p. 236). Inference is the result of proactive inhibition, which is concerned with the way in which previous learning prevents or inhibits the learning of the new habits (Ellis, 1985). In second language acquisition, where the first 
and second languages share a meaning but express it in different ways, an error is likely to arise in the L2 because the learner will transfer the realization device from his/her first language into the second. Behaviorist learning theory predicts that transfer will take place from the first to the second language. Transfer will be negative when there is proactive inhibition. In this case, errors will arise. Transfer will be positive when the first and second language habits are similar or the same. In this case, no errors will occur. Thus, differences between the first and second language create learning difficulty which results in errors, while the similarities between the first and second language facilitate rapid and easy learning (Ellis, 1985). Based on the behaviorist learning theory, errors were considered undesirable, and were the results of non-learning, rather than wrong learning. Therefore, errors should be avoided in second language acquisition. To this end, attempts have been made to predict when they will occur. By comparing the learner's mother tongue with the target language, differences can be identified and used to predict areas of potential error. Thus, Contrastive Analysis Hypothesis was proposed and used in second/foreign language learning and teaching to predict potential errors.

Mentalism. Chomsky’s (1959) attack on Skinner's behaviorist learning theory led to the emergence of mentalist learning theory, which stresses the active contribution of the learner and minimizes the importance of imitation and reinforcement. This learning theory contradicted the behaviorist learning theory at almost every point of basic structure. The major principle of mentalist learning theory is that "everybody learns a language, not because they are subjected to a similar conditioning process, but because they possess an inborn capacity which permits them to acquire a language as a normal 
Maturational Process" (Wilkins, 1972, p. 168). Chomsky (1965) claimed that there are innate properties of language because a child masters his/her native language in a very short time despite the highly abstract nature of rules. Chomsky termed this innate knowledge as Language Acquisition Device (LAD). He argued that every normal human being is born into a society with an LAD, which represents the nature and the structure of human language. He also claimed that the learning capacity of human being by definition is not only universal but also innate, and this innate capacity is not something to be obtained socially. In this sense, language learning is not socially oriented. Language learning and its environment should be regarded as biologically acquired process rather than a result of social learning.

Chomsky (1959) claimed that the learner's knowledge of his/her native language is derived from a Universal Grammar, which specifies the essential form that any natural language can take. Based on Chomsky, the Universal Grammar exists as a set of innate linguistic principles which constitutes the initial state and which controls the form which the sentences of any given language can take. Also part of the Universal Grammar is a set of discovery procedures for relating the universal principles to the data provided by exposure to a natural language. In other words, a child is exposed to language utterances, which start to manipulate the learning levels as the child grows up in his/her native language environment. At each learning level, the child subconsciously develops hypotheses, and tests them in his linguistic formations and thus induces rules from his/her data. As he/she discovers that his/her hypotheses fall short for his/her utterances, he/she rechecks them and makes necessary modifications to come up with new rules. In this way, 
the child builds up an internal adult grammar of his/her native language through these hypotheses.

Mentalists, represented by Chomksy, believe that the behaviorist learning theory cannot account for the development of language and its learning in the following aspects:

1. Language learning is mostly of inborn nature, and thus, "language is not a habit structure" (Chomsky, 1966, p. 412). In addition, language learning and language development are a biological process rather than the result of social learning. For this reason, language acquisition is innately determined and embodied as LAD.

2. Human linguistic behavior is not composed of responses to stimuli and not a matter of habit - formation and generalization. The behaviorist learning theory mostly analyzed animal behavior in labs, but human behavior is so unique to humans that it cannot be explained by means of animal behavior (Demirezen, 1989).

3. LAD, according to Chomsky, is peculiar to human beings who use language. Since all human beings learn their languages successfully, they ought to possess some internal capacity for language learning that other animals do not own. Therefore, it is the inborn capacity which is responsible for the language acquisition process.

4. Analogizing and generalizations made by children are production and application of rules, because "ordinary linguistic behavior characteristically involves innovation, formation of new sentences and new patterns in accordance with rules of great abstractness and intricacy. Therefore, there are "no known 
principles of association or reinforcement, and no known sense of generalization that can begin to account for this characteristic 'creative' aspect of normal behavior" (Chomsky, 1966, p.48).

Constructivism. Constructivism has emerged from the work of psychologists and educators such as Jerome Bruner, Jean Piaget and Lev Vygotsky. There are, however, two major strands of the constructivist perspective: cognitive constructivism and social constructivism. These two strands share many common perspectives about teaching and learning, but are different in emphasis.

Cognitive constructivism is based on the work of Swiss developmental psychologist Jean Piaget. Cognitive constructivists propose that humans cannot be "given" information which they immediately understand and use. Instead, humans must "construct" their own knowledge. They build their knowledge through experience. Experiences enable them to create schemas - mental models in their heads. These schemas are changed, enlarged, and made more sophisticated through two complimentary processes - assimilation and accommodation. Cognitive constructivism emphasizes two principles for teaching and learning: 1) Leaning is an active process; 2) Learning should be whole, authentic and real. Based on these two principles, students must be given opportunities to construct knowledge through their own experiences. They cannot be "told" by the teacher. There is less emphasis on directly teaching specific skills and more emphasis on learning in a meaningful context. In the cognitive constructivist perspective, the role is to provide a rich environment for the spontaneous exploration of the child. A classroom filled with interesting things to explore encourages students to become active constructors of their 
own knowledge (their own schemas) through experiences that encourage assimilation and accommodation.

Another cognitive psychologist, Lev Vygotsky, shared many of Piaget's assumptions about how students learn, but placed more emphasis on the social context of learning. Therefore, Vygotsky's constructivist theory is often called social constructivism. In spite of the fact that there is a great deal of overlap between cognitive constructivism and social constructivist theory, social constructivism has more room for an active, involved teacher. For Vygotksy, culture gives the child the cognitive tools needed for development. The type and quality of those tools determines, to a greater extent than they do in Piaget's theory, the pattern and rate of development. Adults such as parents and teachers are conduits for the tools of the culture, including language. The tools the culture provides a child include cultural history, social context, and language. Accordingly, what makes social constructivism different from cognitive constructivism is that the former emphasizes the critical importance of cultural and the importance of the social context for cognitive development. Vygotsky (1978) proposed the zone of proximal development (ZPD), which argues that students can, with help from adults or children who are more advanced, master concepts and ideas that they cannot understand on their own. Social constructivism stresses the four principles for teaching and learning: 1) Learning and development is a social, collaborative activity; 2) The zone of proximal development can serve as a guide for curricular and lesson planning; 3) School learning should occur in a meaning context and not be separated from learning and knowledge children develop in 
the real world; 4) Out-of-school experiences should be related to the child's school experience.

The social constructivist theory describes knowledge as "temporary, developmental, nonobjective, internally constructed, and socially and culturally mediated" (Fosnot, 1996, p.9). In the social constructivist perspective, learning is an active, contextualized process of constructing knowledge rather than acquiring it. Knowledge is constructed based on personal experiences and hypotheses of the environment. Learners continuously test these hypotheses through social negotiation. Each person has a different interpretation and construction of knowledge process. The learner is not a blank slate but brings past experiences and cultural factors to a situation (Vygotsky, 1978; Von Glasersfeld, 1995; Fosnot, 1996). Social constructivism views each learner as a unique individual with unique needs and backgrounds. It stresses the importance of the nature of the learner's social interaction with knowledgeable members of the society, and takes into account the background and culture of the learner throughout the learning process, as this background also helps to shape the knowledge and truth that the learner creates, discovers and attains in the learning process (Wertsch, 1997). Furthermore, it also emphasizes learners' level and source of motivation for learning (Von Glasersfeld, 1989).

In the social constructivist perspective, a teacher creates a context for learning in which students can become more engaged in interesting activities that encourages and facilitates learning. The teacher does not simply stand by, however, and watch children explore and discover. Instead, the teacher may often guide students as they approach problems, may encourage them to work in groups to think about issues and questions, and 
support them with encouragement and advice as they tackle problems, adventures, and challenges that are rooted in real life situations that are both interesting to the students and satisfying in terms of the result of their work. The teacher thus facilitates cognitive growth and learning as do peers and other members of the child's community. In short, the teacher becomes a guide for the learner, providing bridging or scaffolding, helping to extend the learner's zone of proximal development, and the learner is encouraged to develop metacognitive skills such as reflective thinking and problem-solving techniques. Thus, the independent learner is intrinsically motivated to discover and construct his or her own framework of knowledge (Bauersfeld, 1995).

Social constructivism involves three important components: Zone of Proximal Development (Vygotsky, 1978), Scaffolding (Bruner, 1978), and Approximation (Holdaway, 1979). Zone of Proximal Development (ZPD) proposed by Vygotsky (1978), is defined as "the distance between the actual developmental level as determined by independent problem-solving under adult guidance in collaboration with more capable peers" (p. 86). Teachers find a child's ZPD through various methods of systematic observations. The analysis of drawings, writing, reading, speaking and spelling provides evidence of a child's understandings and help teachers decide a next step for instruction. Vygotsky's hypothesis leans heavily on the social construction of knowledge which grows from the support of more capable others, such as parents, teachers and older siblings.

Scaffolding involves a teacher finding a child's ZPD and engaging with a child or group of children in a learning task while providing temporary supports that are removed 
as students show evidence of independence. As student show progress in language development, scaffolds are gradually removed to release responsibility to the child. Teachers engage in scaffolding student learning by designing lessons and using intentional language the move from teaching to prompting to reinforcing particular concepts.

Approximation is a process in which English language learners imitate the language behaviors of their models. As they test hypothesis about their new language acquisition, they grow more proficient. Approximation is dependent on oral and written opportunities within the context of authentic wholes. In other words, language learners address listening, speaking, reading, and writing as a totality or whole, not separate entities. Skillful teachers engage students in integrated language and literacy tasks in which they listen, talk, read, and write in a safe community of problem-solvers.

In order for the theory to be transferred into the second language classroom in a productive and meaningful way, two elements need to be addressed. The first is a student-centered environment. In other words, students need to discover and construct knowledge on their own. Jonassen (2010) argued that a teacher must focus on three particular areas when implementing student-centered learning environment: problem context (the social framework in which the problem interacts), problem presentation or simulation (the problem must engage the learner) and problem manipulation space (the learner must be able to critically interact with and influence the problem). The second is authentic learning, which means the problem and the situation should not be decontextualized since context provides necessary and relevant information for the 
learner to understand and construct his/her knowledge. Based on Newman and Wehlage (1993), authentic instruction contains four elements essential to the effective implementation of student-centered instruction: conversation, higher-order thinking, connections to real problems and real world contexts, and in-depth understanding.

Situated Cognition. Emerging from anthropology, sociology, and cognitive science, situated cognition theory represents a major shift in learning theory from traditional psychological views of learning as mechanistic and individualistic, and moves toward perspectives of learning as emergent and social. Situated cognition posits that knowing is inseparable from doing, and all knowledge is situated in activity bound to social, cultural and physical contexts (Brown, Collins \& Duguid, 1989). Wilson and Meyers (2000) also argued that thinking and learning making sense only within particular situations. All thinking, learning and cognition are situated within particular context. In the perspective of situated cognition, people need to learn in context because knowledge and physical actions to reinforce that knowledge cannot occur separately, which is a radical shift from many traditional approaches to pedagogy, where educators provide instruction in a classroom environment and expect students to acquire knowledge and skills in the classroom that they can apply elsewhere.

According to Di Vesta (1987), there is no one set of generalized learning laws with each law applying to all domains. Decontextualized knowledge does not give us the skills to apply our understandings to authentic tasks because, as Duffy and Jonassen (1992) indicated, we are not working with the concept in the complex environment and experiencing the complex interrelationships in that environment that determine how and 
when the concept is used. The contrary case is that of authentic or situated learning, where the student takes part in activities directly relevant to the application of learning and that takes place within a culture similar to the applied setting (Brown et al., 1989). Therefore, an effective model of learning should attempt to "enculturate students into authentic practices through activity and social interaction in a way similar to that evident, and evidently successful, in craft apprenticeship" (Ackerman, 1996).

Proponents of situated cognition argue that real life is complex and often presents people with tasks that are poorly defined, complicated, and unique. If people only learn in a classroom environment, it can be difficult to apply their understanding of concepts, including complex ones, to experiences in the real world. Life can also require higher order thinking, sometimes on multiple levels, and this is very different from the classroom, where things are usually logical, orderly, and presented one at a time. Thus, situated cognition theory encourages educators to immerse learners in an environment that approximates as closely as possible context in which their new ideas and behaviors will be applied (Schell \& Black, 1997).

In this section, I have reviewed and discussed four learning theories in relation to China's EFL writing instruction. Behaviorism emphasizes the learning of habit through imitation. Mentalism stresses the importance of learner's innate mechanisms and exposure to authentic materials. Constructivism and situated cognition see language development as active, contextualized process of constructing knowledge.

The discussion of the last three learning theories leads to our understanding that learning should be situated in context, which serves as an important part of the theoretical 
framework to support my assumption that EFL teaching and learning are to be contextualized, and sufficient exposure to authentic materials will be a breakthrough in China's EFL writing instruction. As each learning theory is translated into appropriate methodologies, I will next examine the dominant teaching methods used in EFL classrooms in relation to these four learning theories.

\section{Four EFL/ESL Writing Approaches}

Since EFL/ESL writing emerged as a distinctive area of scholarship in the 1980s (Hyland, 2003), a number of theories supporting teachers and educators' efforts to understand L2 writing has developed. In most cases, each theory has been translated into appropriate methodologies and put to work in classrooms. In most cases, everything teachers do in the classroom, the methods and materials they adopt, the teaching style they assume, the tasks they assign represent their theories and beliefs about what writing is and how people learn to write (Hyland, 2003). In this section, I will review how different perceptions of writing and learning influence teaching practices in L2 classrooms. I will focus on four major EFL/ESL writing methods. For clarity, I present them under subtitles.

Guided/controlled Approach. This approach originates from the marriage of structural linguistics and the behaviorist learning theories of second language teaching (Silva \& Matsuda, 2001). Writing is seen as a product of constructing the writer's command of grammatical and lexical knowledge, and writing development is considered to be the result of imitating and manipulating models provided by the teacher. According to the theory of this approach, writing is rigidly controlled through guided compositions 
where learners are given short texts and asked to fill in gaps, complete sentences, transform tenses or personal pronouns, and complete other sentences that focus on learners' accuracy and avoiding errors (Hyland, 2003). This orientation emphasizes writing as combinations of lexical and syntactic forms and good writing as the demonstrations of the knowledge of these forms, and of the rules used to create texts. Thus, accuracy and clear exposition are viewed as the main criteria of good writing, while the communicative content, the meaning, is left to be dealt with later. This writing approach, with an emphasis on language structures, is a process of four steps:

1. Familiarization: Learners are taught certain grammar and vocabulary usually through a text;

2. Controlled writing: Learners manipulate the fixed patterns, often from substitution tables;

3. Guiding writing: Learners imitate model texts;

4. Free writing: Learners use the patterns they have learned and developed to write an essay, a letter, and so on.

This approach is still quite widely used today in ESL writing classes in lower levels of language proficiency, for it plays a role in helping learners build vocabulary, scaffold writing development and enhance writing confidence (Hyland, 2003).

Functional Approach. The limitations of the guided/controlled approach gave rise to the functional approach, also called current-traditional approach. This approach focuses on helping students develop effective paragraphs through the creation of topic sentences, supporting sentences and transitions. Students are guided to produce connected 
sentences according to different types of texts such as descriptions, narratives, definitions, exemplification, classification, comparison and contrast, cause and effect, and generalizations (Hyland, 2003).

What makes this approach distinct from the above approach is that it takes textual manipulation beyond the sentence level to the discourse level, but it also originates from structural linguistics, as paragraphs are seen almost as syntactic units like sentences, in which learners can fit particular functional units into given slots. Texts can then be seen as composed of structural entities such as Introduction-Body-Conclusion. This approach is influential where L2 students are being prepared for academic writing at college or university, and is a step forward in comparison with the guided/controlled approach.

Expressivist Approach. This approach focuses on writers as the point of departure rather than form. Some researchers (e.g. Elbow, 1993; Murray, 1985) view writing as a means to discover and explore ideas. They see teaching goals as fostering students' expressive abilities, encouraging classroom activities, such as free writing that promote writing fluency and allow students to "think without the constraints of audience, register or convention" (Blau, 1991, p. 290). These writing classes are organized around students' personal experiences and opinions, and writing is considered to be a creative act of selfrecovery. From this perspective, writing is learned rather than taught, so writing is personal and nondirective. Teachers see their roles as merely to provide students with the space to make their own meaning within a positive and cooperative environment. They avoid imposing their views, offering models or suggesting responses to writing topics beforehand. This approach also urges teachers to respond to the ideas that students 
produce instead of dwelling on formal errors (Murray, 1985). In contrast to the practice of a rigid form-oriented approach, students are encouraged to be creative and take chances through free writing.

Although many students have learned successfully through this approach, others may experience difficulties, as it tends to neglect cultural backgrounds of students, the social consequences of writing, and the purposes of communication in the real world where writing matters (Hyland, 2003). In addition, it is difficult to extract clear principles from which to teach and evaluate "good writing".

Process Approach. The process approach is similar to the expressivist approach in that it also emphasizes students as an independent producer of texts. However, it goes further to address the issue of what teachers should do to help a student perform a writing task. This orientation considers basic cognitive processes as essential to writing activity and stresses the necessity of "developing students' ability to plan, define a rhetorical problem, and propose and evaluate a problem" (Hyland, 2003, p.15). The widely accepted model of this approach is the planning-writing-reviewing framework established by Flower and Hayes (1981). This views writing as a "non-linear, exploratory, and generative process whereby writers discover and reformulate their ideas as they attempt to approximate meaning" (Zamel, 1983, p. 165). In this approach to teaching writing, the teacher's role is to guide students through the writing process, avoiding an emphasis on form to help them develop strategies for generating, drafting and refining ideas. 


\section{Synthesis}

Different theoretical orientations tend to focus on different aspects of L2 writing competencies and to emphasize the importance of learning and teaching them in different ways (Cumming, 2001; Hyland, 2003). In the behaviorist perspective, language is a set of habits that can be acquired by means of conditioning, and through conditioning, a person learns to make an association between a particular behavior and the resultant consequence (Skinner, 1957). In addition, Bandura (1986) argued that most human behavior is learned by observation through modeling. By observing others, one forms rules of behavior, and on future occasions, this coded information serves as a guide for action. In terms of the guided/controlled approach and the current traditional approach, these two approaches take root in behaviorism (Hyland, 2003). According to these two orientations, grammar study, handbook rules and exercises lead to good writing and good writing is based on models and formal guidelines. Thus, writing is language-based, structuring and combining sentences to produce a short piece of discourse (Reid, 2001). Prototypical activities of these two approaches are copying, reordering, expansion, contraction, and modeling. Both approaches emphasize language accuracy, and are therefore considered monotonous, form-based and reader-oriented.

In the scenario of China's EFL education at the tertiary level, recall that writing is taught under the guidance of the nationally unified College English Syllabus. The College English Test (CET) is used to evaluate English learning in colleges and serve as a guarantor for implementing the College English Syllabus (Wang, 2007). For many EFL teachers, the CET is the benchmark for the English teaching and learning, and all the 
teaching and learning practices are centered on this benchmark. As writing is also included as a section in the CET, accounting for $15 \%$ out of a total of $100 \%$, writing is receiving more attention from both teachers and students. As the College English Syllabus is "evaluated almost exclusively by the results of students' scores on the CET" (You, 2004, p. 108), teachers have to teach to the test. Due to the test format and the requirements for the college English writing, teachers often "make the choice from no choice" (You, 2004, p.1). Recall that correct form and language accuracy rather than well-developed thought are emphasized in the writing session in the CET. To prepare their students for the CET, teachers tend to adopt the guided approach and the currenttraditional approach in their EFL writing classes. So far, these two approaches are the dominant writing approaches used in China's EFL classes.

In contrast to behaviorism, constructivism posits that learning is an active, contextualized process of constructing knowledge rather than acquiring it. Knowledge is constructed based on personal experiences and hypotheses of the environment. Learners continuously test these hypotheses through social negotiation. Each person has a different interpretation and construction of knowledge process. The learner is not a blank slate but brings past experiences and cultural factors to a situation.

In terms of the expressivist approach and the process approach, these two approaches align with the constructivist learning theory situated cognition. They focus on personal writing, student creativity and fluency (1983). Accuracy of spelling and punctuation is no longer a central concern, and writing is writer-oriented self-discovery. Meaning precedes and determines questions of form. As writing is believed to be learned rather than taught, 
writing is personal and nondirective, and teachers' role is to provide students with the space to make their own meaning within a positive and cooperative environment. Learning L2 writing is seen as the acquisition of such macro strategies as planning, drafting and revising.

The two process-oriented approaches see writing as cyclical, recursive or even disorderly rather than simple and linear. The focus shifts from the text to the writer. It places particular emphasis on "a cycle of writing activities which move learners from the generation of ideas and the collection of data through to the publication of a finished text" (Tribble, 1996, p. 37). Consequently, the teacher's role as model provider and examiner also shifts to that of a facilitator who helps in a typical four-stage process: prewriting, drafting, revising and editing (Tribble, 1996). The provision of input or stimulus is considered to be less important. And it is linguistic skills, not knowledge that are primarily valued.

Although these two orientations are quite popular in EFL/ESL writing classes (Hyland, 2003), few EFL teachers in China seem to use them in their EFL writing classes for two reasons: 1) they are not well suited for EFL teachers preparing students for tests in China's EFL tertiary education setting; 2) EFL teachers find it hard to use them with students with intermediate English levels (Yan, 2010; You, 2004).

As for the mentalist learning theory, it is a challenge to many claims of the behaviorist learning theory. Though this learning theory seems too much theoretical, it suggests that in mentalist type of learning, all that is needed is the adequate exposure to the target language, which will give ideas to the learner to form hypothesis on linguistic 
utterances. In addition, external factors will not influence the learning process, and learning will take place without repetitions and reinforcements. In view of the problems faced with China's EFL writing instruction, I assume that adequate exposure to authentic materials will be a breakthrough in the issue of contextualization. This learning theory can, to some extent, lend support to my assumption.

Situated cognition posits that knowing is inseparable from doing and all knowledge is situated in activity bound to social, cultural and physical contexts. Situated cognition emphasizes students' learning in context. Arguably, it may be unrealistic to situate everything that students learn in real contexts when it comes to China's EFL teaching and learning. With this being said, the notion of situated cognition gives EFL teachers a message that EFL teaching and learning should take place in context.

\section{Critique}

Behaviorism is the theoretical foundation of the guided/controlled approach and the current traditional approach. A few criticisms have emerged since behaviorism was proposed. In a review of Skinner's book on verbal behavior, Chomsky (1959) charged that behaviorist models of language learning cannot explain various facts about language acquisition, such as the rapid acquisition of language by young children, which is sometimes referred to as the phenomenon of "lexical explosion." A child's linguistic abilities appear to be radically underdetermined by the evidence of verbal behavior offered to the child in the short period in which he or she expresses those abilities. Chomsky also argued that it seems just not to be true that language learning depends on the application of reinforcement. A child does not, as an English speaker in the presence 
of a house, utter "house" repeatedly in the presence of reinforcing elders. Language as such seems to be learned without, in a sense, being explicitly taught or taught in detail, and behaviorism doesn't offer an account of how this could be so. In this sense, behaviorism does not account for other types of learning, especially learning that occurs without the use of reinforcement and punishment. Vygotsky (1962) also criticized the behaviorist approach as being too narrow, specialized, isolated and intrapersonal in standpoint.

I would also like to contend that behaviorism seems to be a one-dimensional approach to understanding human behavior and that does not account for free will and internal influences such as moods, thoughts and feelings. In addition, behaviorism does not account for other types of learning, especially learning that occurs without the use of reinforcement and punishment. Moreover, people and animals are able to adapt their behavior when new information is introduced, even if a previous behavior pattern has been established through reinforcement.

In the scenario of China's writing instruction at the tertiary level, the guided/controlled approach and the current traditional approach are two dominant writing approaches used in China's EFL writing classrooms. Two drawbacks concerning these two writing approaches are pointed out. First, formal patterns are presented as short fragments that are based on the intuitions of materials writers rather than analyses of real texts (Hyland, 2003). This not only hinders students from developing their writing beyond a few sentences, but also likely mislead or confuse them when they have to write in real situations. Second, syntactic complexity and grammatical accuracy are not 
necessarily the features of good writing. While ESL students need to have an understanding of appropriate grammar and vocabulary when they learn to write, writing is not only these two things. In addition to the two drawbacks, with these two approaches, learning is teacher-centered, and students' affective needs tend to be ignored, resulting in a lack of self-motivation to read more and write more. Subsequently, inadequate comprehensible input prevents students from writing more effectively and fluently. In addition, teacher feedback is predominantly concerned with lexico-grammatical errors (Yan, 2010), which also dampens students' enthusiasm.

As the theoretical foundation of the process-oriented approaches, constructivism has also received some critiques. According to Liu and Matthews (2005), social constructivism overemphasizes social community construction of learning and claimed that cross-community transfer of learning cannot and should not be counted on. This claim leads to epistemological relativism, where there exists no absolute truth and any truth is as good as other. Terhart (2003) contended that constructivism does not present a new didactic paradigm different from traditional educational theories. Although successful in practical teaching recommendations in some educational areas, constructivism does not introduce a shift from the traditional dualist framework of thinking. A paradigm shift requires a deeper level of correction. Fox (2001) also argued that in its emphasis on learners' active participation, it is often seen that constructivism too easily dismisses the roles of passive perception, memorization, and all the mechanical learning methods in traditional didactic lecturing. Other researchers (Biggs, 1998; Jin \& Cortazzi, 1998) have noted that while constructivist teaching approaches, 
including one-to-one or small group classroom interaction, do not always guarantee teaching effectiveness, traditional didactic lecturing in large classes of 50 to 70 students in China has not always meant the doom of teaching efforts.

In my perspective, one issue with social constructivism is the issue of students being responsible for their own learning process. As students construct their own meaning from the information provided for them, they could lead each other to learning something incorrectly. Learning process might also become slow without adequate support or guidance from teachers. Furthermore, there may be an issue with those students who have learning difficulties, or struggle in a social context.

A significant number of writing teachers adopt the two process-oriented approaches as the focus of their courses, and the approaches have had a major impact on writing research and teaching, but some teachers, such as Reid (1994) who argued that it does not address issues such as the requirements of particular writing tasks, the development of schemata for producing written discourse, and variation in individual writing situations. Others, such as Horowitz (1986), also questioned whether the process approach realistically prepares students for the demands of writing in particular settings. Due to the above two issues and besides others, these two orientations are not popular in the case of China's EFL writing instruction at the tertiary level.

As far as mentalism is concerned, there are also criticisms on this learning theory. One counterargument is that language is not totally of inborn nature, nor is it merely a matter of biological make-up. There is an undeniable effect in language learning resulting from the social environment since children grow up biologically in a social environment 
from which they cannot be divorced (Demirezen, 1988). Another criticism is that the role of imitations and repetitions cannot be wholly denied or disregarded in such areas like learning vocabulary and sentences structures. In addition, language learning is also a learn-by-doing activity because at each learning stage, the child forms up a hypothesis, tests it, recognizes that his/her hypothesis falls short, then makes necessary modifications. All of this indicates that the child still learns by doing. Therefore, language learning is basically a mentally-oriented verbal behavior (Wilkins, 1972).

A few scholars have also critiqued the situated cognition theory. For example, Anderson, Reder and Simon (1996) argued that action is not necessarily grounded in the concrete situation in which it occurs. It is true that Brazilian street vendors, who correctly calculate the cost of items which they sell in the streets, are unable to answer similar questions at school. But this is a demonstration that skills practiced outside of schools do not generalize to schools, not that arithmetic procedures taught in the classroom cannot used by shop keepers. Indeed, skills like reading clearly transfer from one context to another. Anderson, Reder and Simon also debated the claim that training in abstraction is of little use. When introducing real-world-like problems to situate high school algebra, they felt much class time was wasted on such clerical tasks as tabling and graphing, while relatively little time was spent relating algebraic expressions to the real-world situations.

\section{My Conceptual Framework}

Form-oriented approaches, such as guided/controlled approaches, see learning L2 writing as the acquisition of language and form while process-oriented approaches view learning L2 writing as the acquisition of successful writing strategies, such as planning, 
drafting and revising (Barkaoui, 2007). In my opinion, L2 writing development is not only the learning of content, form and writing strategies but also the learning of the genres, values, and practices of the target community. In this perspective, proficient writers should be those who can "act effectively in new cultural settings" (Hyland, 2003, p.60). Such an orientation should emphasize the role of context and audience in learning L2 writing. Based on the literature reviewed above, my thirty-odd years' EFL teaching experience, Chinese EFL students' learning characteristics and in association with the status quo of China's EFL writing instruction, I came up with a context-based conceptual framework, which was used to guide my study. In my conceptual framework, I integrated behaviorism, mentalism, constructivism and situated cognition as its major theoretical foundation. The rationale for such an integration of the four learning theories was threefold. First, these four learning theories cannot be totally divorced from each other, for they are complementary to each other, serving different types of learners or representing different cases or phrases of second language learning. They are viewed as fundamental pillars of foreign/second language learning whose relevance to China's EFL writing education is apparent. Second, my assumption in this study is that in EFL writing instruction, what teachers teach or what students learn should be contextualized, and contextualization is a key factor contributing to EFL learners' writing skill development, and students' adequate comprehensible input of authentic materials will be a breakthrough in the issue of contextualization. Mentalism, constructivism and situated cognition provide a good theoretical foundation for such an assumption. Third, basic strategies of language learning within the scope of behaviorist theory are imitation, 
reinforcement, and rewarding. In terms of foreign/second language learning, there is a threshold level, which means that learners must learn consciously supported by repetition and drilling to build up an effective linguistic intuition, acquisition of which marks the establishment of threshold level. Before obtaining the threshold level in writing, the language learner is not creative, cannot use the target language properly in new situations in a real sense. As for China's first/second year EFL students at the tertiary level, they generally learn English for five to seven years before they go to college, who tend to have an intermediate English level of proficiency. Students with an intermediate level of proficiency are considered to be in their initial stage in English writing development, which means they still need to be provided with models of the target language and supported by imitation and repetition of language models from textbooks and other authentic materials. Therefore, the role of imitations and repetitions cannot be totally denied or disregarded in learning vocabulary and sentences structures in EFL students' initial stage of writing development. As was previously reviewed, approximation, as one of the three important components of social constructivism, is a process in which English language learners imitate the language behaviors of their models. As they test hypothesis about their new language acquisition, they grow more proficient. Approximation is dependent on oral and written opportunities within the context of authentic wholes. In view of this, apart from the other learning theories, behaviorism is also integrated into my conceptual framework. My conceptual framework, also called the Write-to-learn Model, is further presented and discussed in detail in Chapter 3. 


\section{Review of the Methodological Literature}

Research methodology is a philosophical stance of worldview that underlies and informs the style of research (Sapsford \& Jupp, 2006). In another view, Creswell (2003) considered research methodology as the overall approach to the design process of conducting research including all phases from the theoretical underpinning to the collection and analysis of data. Therefore, one of the critical decisions that we need to make in designing our research is the paradigm(s) within which we situate our work. Using an established paradigm allows us to "build on a coherent and well-developed approach to research rather than having to construct all of this ourselves" (Maxwell, 2005, p.36). Each paradigm involves "a basic set of beliefs and assumptions that guide action and research" (Guba, 1990, p.17). Creswell (2003) identifies four paradigms that shape and guide researchers' notions of truth and knowledge: positivism/post-positivism, constructivism, transformative, and pragmatism. Although different research paradigms are used to explore this research problem, three research paradigms are involved in this study: positivism, constructivism and pragmatism.

\section{Positivism}

Positivism, also referred to as scientific method, reflects "a deterministic philosophy in which causes probably determine effects or outcomes" (Creswell, 2003, p.7). In a positivist view of the world, science is seen as the way to get at truth, to understand the world well enough so that we may predict and control it. Science is largely a mechanistic or mechanical affair. We use deductive reasoning to postulate theories that we can test. Based on the results of our studies, we may learn that a theory does not fit the facts well 
and so we need to revise it to better predict reality. Positivists believe in empiricism and aim to test a theory or describe an experience "through observation and measurement in order to predict and control forces that surround us" (O’Leary, 2004, p. 5). The key approach of the scientific method is the experiment, the attempt to discern natural laws through direct manipulation and observation.

Positivists think that research is the process of making claims and then refining or abandoning some of them for other claims more strongly warranted. Data, evidence, and rational considerations shape knowledge. In practice, the researcher collects information on instruments based on measures completed by the participants or by observations recorded by the researcher. Thus, in the scientific method, a researcher begins with a theory, collects data that either supports or refutes the theory, and then makes necessary revisions and conducts additional tests. In the positivist world, researchers are objective and strive to minimize sources of bias wherever they can. Research is true and the best research is quantitative. The positivist research paradigm typically employs the use of quantitative research methods which, in this case, serve as an effective method to explore the outcome of adding context to EFL teaching and learning of writing at China's tertiary level.

\section{Constructivism}

One of the goals of this research is to understand the perceptions and attitudes of students towards contextualization of EFL writing instruction. Guba and Lincoln (1985) suggested that the constructivist research paradigm is useful for exploring the types of varied and complex perceptions of experiences involved in this type of research problem 
because constructivism regards the nature of reality and perceptions of reality as complex and multidimensional. The paradigm explicitly states that new knowledge is not constructed in a vacuum, but rather the ability to construct new meaning is dependent upon existing foundations of knowledge.

The constructivist research paradigm tends to rely on the "participants' views of the situation being studied" (Creswell, 2003, p.8) and recognizes the impact on the research of their own background and experiences. This paradigm is most likely to rely on qualitative data collection methods and analysis or a combination of both qualitative and quantitative methods. Quantitative data may be utilized in a way, which supports or expands upon qualitative data and effectively deepens the description.

\section{Pragmatism}

This research paradigm involves utilitarian research that explicitly promotes acceptance and understanding relevance (Vogt, Gardner, \& Haeffele, 2012). It is appropriate for this research because it "is not committed to any one system of philosophy or reality" (Creswell, 2003, p. 39) and "is oriented toward solving practical problems in the real world" (Feilzer, 2010, p. 8) rather than on assumptions about the nature of knowledge. The pragmatic paradigm stresses that multiple realities exist in any given proviso, and that, the researcher's choice of paradigm is dependent on the research question the study is trying to solve. In addition, the pragmatic research paradigm is multi-purpose in nature; and therefore, a good tactic that will allow questions to be addressed that do not sit comfortably within a wholly quantitative or qualitative approach to research design and methodology. This research paradigm also perceives issues 
differently in different scenarios and permit different views and interpretation of the world.

The pragmatic paradigm helps to provide a grounding where the research avoids engaging in issues of insignificance rather than issues of truth and reality and as such is intuitively appealing (Creswell, 2009; Tashakkori \& Teddlie, 2003). The pragmatic paradigm provided a basis for practical research by integrating different perspectives which help to elucidate the data interpretation process in research. Therefore, a pragmatic approach helps to understand the assumptions that underpin the knowledge and inquiry. In addition, it does not classify the research as purely quantitative or qualitative in nature with either a positivist or interpretive philosophy. Hence, a pragmatic approach provides a balanced point between the deductive and inductive perspectives of thinking which offers practical answers for merging different paradigms. As a result, Creswell (2009) suggested that a pragmatic research approach seemed to be the most prominent paradigm with a strong philosophical relationship for a mixed method approach.

\section{Research Approach}

The purpose of this study was to examine how Chinese EFL students respond to changes in their writing instruction that pays attention to the context of EFL teaching and learning. I used the mixed methods approach to conduct this study. I considered it well suited to my study. Chen (2007) defined mixed methods research this way: "Mixed methods research is a systematic integration of quantitative and qualitative methods in a single study for purposes of obtaining a fuller picture and deeper understanding of a phenomenon; mixed methods can be integrated in such a way that qualitative and 
quantitative methods retain their original structures and procedures (pure form mixed methods). Alternatively, these two methods can be adapted, altered, or synthesized to fit the research and cost situations of the study (modified form mixed methods)" (Johnson, Onwuegbuzie, \& Turner, 2007, p. 119). According to Creswell (2009), mixed methods involves combining or integration of qualitative and quantitative research and data in a research study. Qualitative data tends to be open-ended without predetermined responses while quantitative data usually includes closed-ended responses such as found on questionnaires or psychological instruments.

The rationale for adopting such a research method was twofold. First, as Creswell (2003) asserted, a research problem or an issue that needs to be addressed determines what kind of research method needs to be undertaken, not the other way around. Morgan (2013) also noted that qualitative methods have strengths useful for inductivesubjective-contextual research, while quantitative methods are well-suited to deductive-objective general research. Thus, the integration of qualitative and quantitative research provides well-developed matches between a set of research purposes. As the mixed methods research involves both collecting and analyzing quantitative and qualitative data, it is far more comprehensive than understanding a problem from only one point of view, and with the emergences of strategies and tools for blending these different types of data. Therefore, the mixed methods design employing both quantitative and qualitative approaches was more appropriate for this study as this better helped me answer my research questions. It also enabled me to look at the 
contextualization of EFL teaching and learning at the tertiary level from more than one perspective.

Second, the multiple measures to explore the effect of context on EFL college student achievement helped ensure the validity of both quantitative and qualitative findings. In fact, the use of a variety of data sources in a study such as this was a means of data triangulation. This triangulation of data integrated with methodological triangulation - the use of multiple methods to study a single problem - is considered essential to verify and cross-check the research findings in a study (Creswell, 2003; Morgan, 2013).

\section{Summary}

My primary purpose of reviewing the literature was to explore the relationships between EFL/ESL writing and context. Based on my assumptions and research questions, I first reviewed context, which covers three aspects: lexical context, syntactic context and cultural context. I also touched upon written corrective feedback, which is considered an important element of ESL/EFL writing. Then I discussed four learning theories in relation to China's EFL education. Then, I examined four major writing approaches used in the ESL/EFL classroom. Finally, I synthesized and critiqued the literature in relation to EFL writing instruction, and came up with my hypothesized Write-to-learn Model, which was used to guide this study. In the next chapter, Chapter 3, I will discuss the research methodology used in this study, and explain the methods of and procedures for data collection and data analysis. 


\section{Chapter 3: Methods}

Chinese students learning English as a foreign language seem to get good marks in tests, but are poor or limited in their ability to write in English. This dilemma of China's EFL writing instruction was assumed to be related to the decontextualization of practices for teaching writing in EFL classes. The purpose of this study was to examine how Chinese EFL students respond to changes in their writing instruction that pays attention to the context of EFL teaching and learning. This chapter delineates the research methodology employed in this study. I first describe the mixed methods approach. Then I continue on to discuss the strategies used in the selection of participants and describe the profiles of the participants. I next explain the research procedures, the interview protocols, the instruments and measures used in the study, data collection procedures and data analysis methods. Finally, I deal with validity issues and confidentiality.

\section{Research Methods}

This study used the mixed methods approach to explore the impact of context on EFL college student writing achievement (Creswell, 2009; Morgan, 2013). My motivation for integrating multiple methods was "to produce convergent findings across different methods that each address the same research question" (Morgan, 2013, p.11). The research design in this study adopted a mixed methods approach based on an "equalstatus concurrent triangulation" strategy, symbolized as "QUAN + QUAL", illustrated in Figure 3 (Creswell, 2009). In the design of this study, both quantitative and qualitative phases were integrated into the overall research, and each of the methods was given equal status. In other words, I collected both quantitative and qualitative data, using both 
methods but at different phases of the study. Equal priority was given to each method in data collection and data analysis. Only when I interpreted the data were the findings from the two methods brought together. I then highlighted the convergence of the findings to strengthen the knowledge claims of the study or explain any lack of convergence that may result (Creswell, 2009). After using data of different forms in this design, I expected the findings of the study to be validated and well-substantiated. Figure 3 presents the research design of this study.

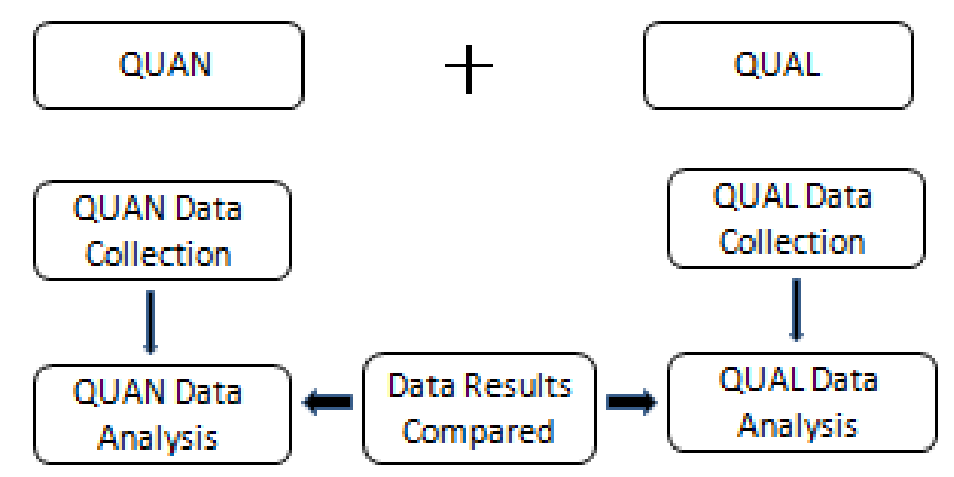

\section{Figure 3. Equal-status concurrent triangulation design from Creswell (2009)}

Note: 1. A plus sign "+" indicates a concurrent collection of data. 2. An arrow sign " $\rightarrow$ " indicates a sequential collection of data.

3. "QUAN" and "QUAL" stand for quantitative and qualitative research respectively.

Figure 3 shows the "equal-status concurrent triangulation" strategy used in this study. This design had the following characteristics. First, both quantitative and qualitative methods were equally important in the research design. There was no priority of one method over the other. Data from each method were collected at different phases of the study. Second, data analysis was undertaken only after all data were collected. Third, the 
research findings were verified and cross-validated through the use of quantitative and qualitative methods as well as through the triangulation of data within the study (Creswell, 2009; Morgan, 2013).

With the goal of examining how Chinese EFL students respond to changes in their writing instruction that pays attention to the context of EFL teaching and learning, three research questions were designed to explore the impact of context on EFL students' writing achievement. The three research questions were as follows:

1. How does adding context create different writing outcomes for Chinese EFL students?

2. How do Chinese EFL students imagine/reflect the ways of developing writing skills and the use of English writing skills?

3. How do Chinese EFL students compare/contrast writing in Chinese and in English?

\section{Participants}

The study was divided into two sub-studies, which were conducted separately. The participants of the two sub-studies were as follows.

Participants in Sub-study 1 (S1). The participants in Sub-study 1 were two classes of 60 second-year undergraduate students in a university in Guangzhou, China. There were 30 students in each class. These students majored in English for International Business. Before they were admitted into this university, they had studied English in middle school and high school for at least six years and passed the college entrance examination. Based on their curricula, these students focus on English courses in the first 
two years and specialized courses in the last two years. In the first two years, these students take such English courses as Listening Comprehension, Speaking, Intensive Reading, Extensive Reading and Writing. They take English writing course in the $2^{\text {nd }}$ year, which takes place once a week and lasts two hours. After completing the English courses, they are required to take College English Test Band 4. To engage these students in this study, I first gave them a presentation about this study, and then asked them to sign the consent form (see Appendix C).

Participants in Sub-study 2 (S2). The participants in Sub-study 2 were five Chinese students studying in their second year in a joint program in a university in Oregon, United States. These students had spent their first two years studying in a university in Guangzhou, China before they came to the United States. These students will receive a Bachelor's degree if they complete their two-year study in the university in the US. To engage these five students in Sub-study 2, I first communicated with the Chinese teacher who was the representative of the Chinese university at the university about my study and my intention to invite five second-year Chinese students to participate in the study. Considering that some candidates might decline to participate in this study for some reason, I requested a name list of about 10 potential candidates. I then sent the letter of information and the consent form (see Appendix C) to five potential candidates. They were requested to send back their signed consent forms in a week. Luckily, within a week, I received a reply from the five students respectively, who all agreed to participate in this study. They sent back their signed consent forms in time as requested. 


\section{Write-to-learn Model}

Recall that based on the literature review in Chapter 2, my teaching experience and in association with the status quo of the EFL writing instruction in China, I developed a conceptual framework called the Write-to-learn Model to guide this study, as Figure 4 shows.

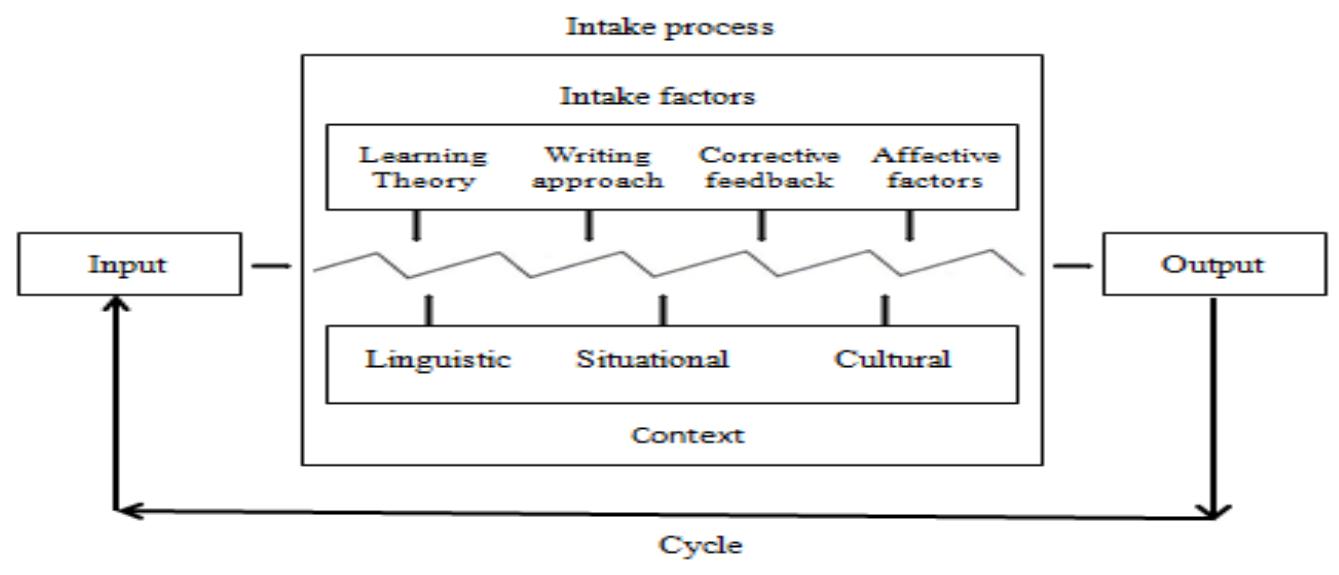

Figure 4. The Write-to-learn Model

The model starts with input because I think it important for learners to be provided with the opportunities to make sense of what they see and to notice the contexts in which the samples of the target language are used. Input here refers to comprehensible input, which should be meaningful and interesting. In order for available data in the learner's environment to be better absorbed and used in building the learner's interlanguage system, a few factors need to work together to make input become intake, and intake into output. These factors include context, learning theory, writing approach, authentic materials and written corrective feedback. Of these factors, context functions as the foundation of the intake process, supported by writing approach(es), authentic materials, corrective feedback and affective needs. Hill (2002) argued that learning theories are conceptual 
frameworks that describe how information is absorbed, processed and retained during learning, they can provide us with vocabulary and a conceptual framework for interpreting the examples of learning that we observe and suggest where to look for solutions to practical problems. Therefore, I consider it important to combine the four learning theories as the theoretical foundation of my context-based framework. Behaviorism provides the theoretical foundation of learning through imitation, repetition and reinforcement (Skinner, 1957; Ellis, 1985) while mentalism, constructivism and situated cognition furnish theoretical support for my assumption that EFL writing instruction should take place in context (Vygotsky, 1978; Bauersfeld, 1995; Brown, Collins \& Duguid, 1989; Schell \& Black, 1997), and sufficient exposure to authentic materials is central to the issue of contextualization. Then each theory is translated into appropriate methodologies and put to work in classrooms. In this process, appropriate written corrective feedback also plays a role in bringing students' initiatives into play and meeting their affective needs.

To operationalize this hypothesized model for China's EFL writing instruction at the tertiary level, I conducted an experiment in Sub-study 1. The experiment involved two classes of second- year undergraduate students in English Writing Course in a university in Guangzhou, China. Of these two classes, one class of 30 students served as the experimental group (EG) and the other class of 30 as the control group (CG). The experiment lasted for one semester (about five months). Both groups were taught by the same teacher, who adopted two different writing approaches. All the other courses taken by the two classes were kept the same. For the CG, the teacher stuck to the time-honored 
teaching approach in the university: traditional-current approach. This approach focuses on helping students develop effective paragraphs through the creation of topic sentences, supporting sentences and transitions. Students are guided to produce connected sentences according to different types of texts such as descriptions, narratives, definitions, exemplification, classification, comparison and contrast, cause and effect, and generalizations. The CG used the textbook entitled "A Handbook of English Writing" by Wangdao Ding (2000).

The EG followed the procedures of my operationalized model, called the Write-tolearn Model. No textbook was used in the EG. The major strategies employed in this new approach included the following (Tang, 2004; Wang et al., 2000), with the mixed use of the learning theories reviewed in the literature review chapter as their theoretical foundation and points of support.

1) Designing an appropriate task (constructivism). In designing a task, we took into consideration these three points: a) it could arouse students' intrinsic interest and their desire to express themselves; b) it was suited to students' level of English proficiency; c) it was relevant to students' life experiences so that they could have a lot to write about.

\section{2) Manipulating the length of writing by adjusting the scoring scheme}

(constructivism). We assumed that one effective way to encourage more writing was to adopt a scoring scheme that puts a premium on length. A marking scheme could be so devised that it divided a percentage score into four components: length (40\%), organizational structure (20\%), content (20\%) and language accuracy (20\%), with length 
carrying the heaviest weight. When students were used to writing long compositions, and the teacher would like the students to pay attention to organizational structure of a composition, then the percentage scoring for this component could be increased from $20 \%$ to $40 \%$, vice versa. The scoring scheme was detailed in Table 1.

Table 1. Scoring scheme of the new teaching model

\begin{tabular}{cccc}
\hline Length & Organizational Structure & Content & Language Accuracy \\
\hline $40 \%$ & $20 \%$ & $20 \%$ & $20 \%$ \\
\hline
\end{tabular}

3) Providing relevant input in class (behaviorism). Class hours focused on two activities: a) analytically reading materials selected from books or magazines that are relevant to the task at hand; b) critically evaluating one or two best-written compositions selected from students' work. These two activities were conducted under the teacher's guidance. In the process of the analytical reading, some essentials of writing techniques could be instilled such as how to construct good sentences and how to achieve coherence and cohesion in a discourse. The best-written composition(s) were printed out and distributed to every student. Then the class were asked to mark all good points and errors in the composition(s). By so doing, students noticed the gap between their own compositions and the good example set by their peers. The good points could serve as peer pressure motivating the students to learn further while the weak points in the best composition enabled the students to learn from errors and at the same time did not hurt its writer, who usually took pride in his or her writing as a whole.

4) Marking good points (behaviorism). Instead of correcting errors, the teacher only marked good points in students' compositions. I assumed that the benefits of so 
doing lay in the fact that it could satisfy students' affective needs. My experience indicated that language learning, especially second language learning, was not always a pleasant experience for students, who tended to have a stronger desire for encouragement than for criticisms. One way to satisfy this psychological need was to provide positive feedbacks by highlighting good points in their compositions. Positive feedback could help build up students' confidence while negative feedbacks (correcting errors) tended to dampen students' enthusiasm. What's more, marking good points was much easier than correcting mistakes, particularly for non-native teachers of English.

5) Encouraging students to 'copy' good sentences and structures (behaviorism). Imitation is an important step in language learning. To master a language, a foreign language learner needs to imitate native speakers in terms of speaking and writing in the initial stage. To let the students express themselves in a more native like way and avoid Chinglish, it is necessary for the students to become familiar with Western culture and make use of the authentic expressions or structures that they have learned from books in their compositions. The students were asked to underline the good sentences or structures that they 'borrow' from books or magazines in the original. There were 5 credit points for these good sentences or structures used in compositions. The aim of this is to encourage students to use English more authentically and accurately.

6) Addressing errors with care (constructivism). Teachers using the conventional method believe that error-correction is an effective way to help students improve their English level and writing skills. Therefore, they think it essential to correct or point out all the errors with red ink pens. Thus, students' compositions are always full of teachers' 
corrections. In our opinion, errors are simply a natural part of the second language learning process just like children learning to walk. Tumbles and falls are inevitable. When most English learners are in the process of writing, they tend to think in Chinese and then translate their mind into English. In this code-switching process, due to their insufficient English input, the students commit syntactic errors or create Chinese English. Sometimes, teachers find it so hard to correct these errors that they have to rewrite the sentences. This is because many errors are beyond students' ability to understand, and they tend to make the same errors again in their future writing. On the other hand, teachers find it so hard and time-consuming to teach writing. So many teachers think that teaching writing is arduous and fruitless. Based on the new teaching model, there is no need for teachers to correct all the errors. With increasing exposure to comprehensible input, many errors will disappear by themselves.

This does not mean that the students' errors are ignored. It occurred to us that errors could be eliminated through means rather than explicit correction. The measures taken include (a) providing students with appropriate input such as reading materials containing useful expressions relevant to the current writing task; (b) raising consciousness of such expressions of their uses; (c) explaining how to use dictionaries to clarify uncertain uses; (d) evaluating good compositions from students with a focus on the errors made; (e) selfcorrecting or group-correcting errors; (f) paying attention to cultural factors; (g) While marking the good points, the teacher underlined about 5-8 common errors that secondyear students should be able to avoid. Then the students were required to identify and 
self-correct the errors by themselves and in groups in class. By so doing, students could better realize their errors and avoid making the same errors.

7) Having students revise their compositions (constructivism). The students were required to keep their marked compositions in a portfolio and revise them twice, and turn the portfolios in at the end of the semester. The aim of this was to allow the students to have opportunities to reevaluate their own compositions.

8) Encouraging free write and journal keeping (constructivism and situated cognition). The students free wrote for about 5-8 minutes at the beginning or at the end of each class. In addition, the students were required to keep journals in English on a daily basis and hand them in at the end of each term for the teacher to check in.

\section{Research Procedures}

As was previously mentioned, in Sub-study 1, of the two classes of second-year undergraduate students, one class of 30 students served as the experimental group (EG) and the other class of 30 students as the control group (CG). These two classes of students took two tests at the beginning of the experiment: a cloze test (see Appendix E) and a timed writing test. The group that had the higher average scores in the two tests was selected to be the control group so that the two groups could be more effectively compared. The experiment lasted for about five months. Both groups were taught by the same teacher. The EG followed the new teaching model procedures. For the CG, the teacher stuck to the time-honored teaching practice in the university: traditional-current approach. Except for the use of different writing approaches in the English Writing Course, all the other courses taken by the two classes were kept the same. 
The participants in the EG took a pre-questionnaire and a post-questionnaire (see Appendix D) to see if there were changes in their attitudes towards the new teaching model that paid attention to the context of EFL writing. To evaluate the effectiveness of context, pre-and post-testing was conducted at the beginning and at the end of the experiment for both groups in the form of cloze test. A cloze test with 25 blanks (see Appendix E) was administered as an indicator of the participants' general English proficiency. In addition, a pre-writing test and a post-writing test were designed to evaluate the participants' English writing ability in both groups. To ensure the validity and reliability, two teachers were invited to double-mark each participant's composition to yield an average score representing the participant's English writing ability. At the end of the experiment, we interviewed the participants in the EG with 12 questions (see Appendix F) concerning context, teaching methods, authentic materials, written corrective feedback and affective factors. For the participants in the CG, they did a prewriting test and a post-writing test, the data of which was used to compare those of the participants in the EG. In addition, the participants in the CG were required to write a reflection on their ways of developing writing skills and their use of English writing skills at the end of the term. The reason why they were asked to do so instead of being interviewed was that it would be too time consuming to conduct interviews with both groups. The following table is a summary of the research procedures in Sub-study 1. 
Table 2. Summary of the Research Procedures in Sub-study 1

\begin{tabular}{cccccccc}
\hline & \multicolumn{3}{c}{ At the beginning of the } & \multicolumn{4}{c}{ At the end of the experiment } \\
experiment & $\begin{array}{c}\text { Pre- } \\
\text { test }\end{array}$ & $\begin{array}{c}\text { Pre- } \\
\text { writing } \\
\text { test }\end{array}$ & $\begin{array}{c}\text { Pre- } \\
\text { questionnaire }\end{array}$ & $\begin{array}{c}\text { Post- } \\
\text { test }\end{array}$ & $\begin{array}{c}\text { Post- } \\
\text { writing } \\
\text { test }\end{array}$ & $\begin{array}{c}\text { Post- } \\
\text { questionnaire }\end{array}$ & Interviews \\
\hline $\begin{array}{c}\text { EG } \\
\begin{array}{c}\text { Write-to- } \\
\text { learn Model) }\end{array}\end{array}$ & $\mathrm{X}$ & $\mathrm{X}$ & $\mathrm{X}$ & $\mathrm{X}$ & $\mathrm{X}$ & $\mathrm{X}$ & $\mathrm{X}$ \\
\hline $\begin{array}{c}\text { CG } \\
\text { (Traditional- } \\
\text { current } \\
\text { Approach) }\end{array}$ & $\mathrm{X}$ & $\mathrm{X}$ & & & & & \\
\hline
\end{tabular}

Note: $\mathbf{E G}=$ Experimental Group, $\mathbf{C G}=$ Control Group

In Sub-study 1, the 30 students in the EG were named EG-Student 1 to EG-Student 30 while the 30 students in the CG were named CG-Student 1 to CG-Student 30. The experiment started in September 2015 and ended in April, 2016. The interview with the 30 students in the EG was conducted from February 2016 to April 2016.

In Sub-study 2, for the sake of confidentiality, I named the five students Student A, Student B, Student C, Student D and Student E respectively. I scheduled interviews for the five participants after I received their signed consent forms. The interviews were scheduled in August and September, 2015 (see Table 3). The interviews took place in their university or any public place that was convenient and safe for the participants. I prepared 15 interview questions beforehand (see Appendix G). I interviewed them on a one to one basis. Each interview lasted 40 - 60 minutes. To help them relieve anxiety and nervousness, I started with a ten-minute warm-up practice session by asking them some questions about their daily life. When the interviewees felt at ease with the interview, I began to interview them. The interview was conducted in both English and Chinese. Of the five interviewees, two interviewees had trouble making themselves understood in 
English at some point, they chose to do it in Chinese. All the interviews were recorded and then transcribed into English for data analysis.

Table 3. Schedule for the interview with the five students in the joint program

\begin{tabular}{cll}
\hline Name & \multicolumn{1}{c}{ Date } & Note \\
\hline Student A & August 20 (10:00 a.m. - 11:15 a.m.) & \\
Student B & August 21 (10:00 a.m. - 11:15 a.m.) & \\
Student C & August 24 (10:00 a.m. - 11:15 a.m.) & \\
Student D & September 8 (10:00 a.m. - 11:15 a.m.) & \\
Student E & September 10 & Preferred to answer the \\
& & interview questions in writing \\
\hline
\end{tabular}

\section{Research Timeline}

The timeline of activities for this research is described in Table 4. Overall, my study lasted approximately nine months. I successfully defended the dissertation research proposal in the spring of 2015, acquired IRB approval in June 2015, collected and analyzed the data in September, 2015 and March, 2016, completed the manuscript, and planned to defend the dissertation in the fall, 2016.

\section{Table 4. Research Timeline}

\begin{tabular}{ll}
\hline $2 / 1 / 15$ & Defend proposal \\
$2 / 1 / 15$ to $3 / 15 / 15$ & Revise proposal \\
$4 / 1 / 15$ & Complete proposal revision \\
$4 / 15 / 15$ & Submit proposal to IRB \\
$5 / 10 / 15$ & Return proposal from IRB for revision \\
$6 / 5 / 15$ & Resubmit proposal to IRB \\
$6 / 18 / 15$ & IRB approves proposal and advances to candidacy \\
$7 / 10 / 15$ to $9 / 15 / 15$ & Contact participants and conduct interviews
\end{tabular}




\begin{tabular}{ll}
\hline $10 / 20 / 15$ to $4 / 25 / 16$ & Transcribe and analyze data \\
$5 / 5 / 16$ to $6 / 15 / 16$ & Revise and write results \\
$7 / 1 / 16$ to $9 / 20 / 16$ & Edit and format dissertation \\
$11 / 2 / 16$ & Submit final draft to committee members \\
$11 / 18 / 16$ & Defend dissertation
\end{tabular}

\section{Instruments and Measures}

In this study, I mainly used three types of instruments to collect data. They were interviews, questionnaire surveys and tests.

Interviews. Interviews are often considered to be an effective instrument to collect data in the mixed methods design. Burns (1999) contended that interviews are a popular and widely used means of collecting qualitative data. To this end, researchers intend to "obtain a special kind of information" (Merriam, 1998, p. 71) and investigate what is going on in the respondents' mind. As researchers cannot observe the participants' feelings and thinking, interviewing is a key to understanding what and how people perceive and "interpret the world around them" (ibid, p. 72). Flick (2006) added that the purpose of interview is to reveal existing knowledge in a way that can be expressed in the form of answers and so become accessible to interpretation.

I employed semi-structured interviews in this study (Merriam, 2009; Creswell, 2009). The rationale for using this type of interview was that semi-structured interviewing is flexible and allows the interviewee to provide more information than the other ones. This form of interview is neither too rigid nor too open. It is a moderate form in which a great amount of data can be elicited from the interviewee. Merriam (2009) noted that semi- 
structured interviewing "allows the researcher to respond to the situation at hand, to the emerging worldview of the respondent, and to new ideas on the topic" (p. 91).

This instrument used in the interviews with the 30 participants in the EG and the five Chinese students in the joint program followed what Patton (2002) refers to as the interview guide approach. In this approach, I listed the questions explored in an interview and used the list as a guide to "ensure that the same basic lines of inquiry are pursued with each person interviewed" (p. 343). I did not follow these questions in any particular order during the interviews. Rather, the interview guide provided the topic dimensions within which I was "free to explore, probe, and ask questions that will elucidate and illuminate that particular subject" (Patton, 2002, p.343).

The interview protocols for this study were divided into six dimensions as Figure 5 shows. Twelve interview questions (see Appendix F) were prepared for the participants in the EG and fifteen interview questions (see Appendix G) were prepared for the five participants in the joint program.

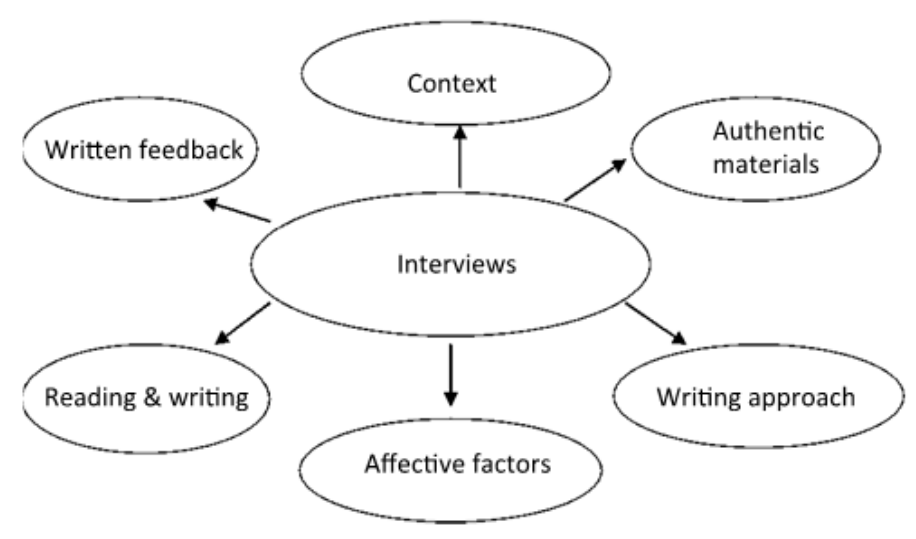

Figure 5. Six dimensions of the interview questions 
My role as a researcher during the interview was to explain the purpose of the research, what the interview would involve, ask the questions and audio record what each participant had to say during this conversation.

Prior to the beginning of each interview, I introduced the Consent Form (see Appendix C) to the participants. I read and explained each paragraph to the participant in both English and Chinese, checking frequently to ensure understanding and clarifying any points as necessary.

Questionnaire Surveys. Questionnaire surveys, as a method of collecting information from people about their ideas, feelings, beliefs, attitudes, needs, motivations, and behavior, have been widely used in social science research (Fink, 2002; Gray \& Guppy, 1999) as well as in the field of English as a second or foreign language education (Gorsuch, 2000; Stoller, 1994). Researchers choose to employ surveys as a research method because it is an effective way to get the required information from a large number of individuals (Alreck \& Settle, 1995). I chose to use a questionnaire survey as one of the research instruments primarily because the purpose of this study was to examine how Chinese EFL college students responded to changes in their writing instruction that paid attention to the context of EFL teaching and learning. By using the questionnaire survey in the EG at the beginning and at the end of the experiment respectively, I could examine the changes of the participants in terms of their feelings, attitudes, beliefs, perceptions and motivations about EFL writing.

To this end, I designed a content structure for the questionnaire survey based on my hypothesized framework: Write-to-learn Model. Given that the purpose of the 
questionnaire was to explore the changes of the participants in the experimental group in terms of their attitudes, feelings, motivations and perceptions in relation to EFL writing when a new teaching model, the Write-to-learn Model, was adopted, the questionnaire was designed to address the first and second research questions. The questionnaire focused on six issues: (1) whether the students accepted the new teaching model, (2) whether their confidence increased in their ability to write in English after the new teaching model was adopted, (3) whether their English writing improved, (4) whether they were positive about the marking scheme, (5) whether they liked to write compositions outside class, and (6) whether authentic materials helped improve their writing. Considering that the participants were second-year undergraduate students, to avoid misunderstandings, the instrument was designed and written in Chinese. The questionnaire consisted of six sections, with a total of 50 items (see Appendix D). All the 50 items were designed on a 5-point Likert scale to obtain the respondents' degree of agreement or disagreement. The response scale was as follows: $5=$ Strongly Agree, $4=$ Agree, $3=$ Neutral (neither agree nor disagree), 2 = Disagree, 1 = Strongly Disagree.

Tests. Tests, as a method of collecting data in quantitative research, provide a way to assess subjects' knowledge and capacity to apply this knowledge to new situations. According to Guba and Lincoln (1981), tests are used when researchers want to gather information on the status of knowledge or the change in status of knowledge over time. They may be to determine whether the test taker qualifies in terms of some standard of performance. Changes in test performance are frequently used to determine whether a project has been successful in transmitting information in specific areas or influencing the 
thinking skills of participants. In this study, I chose two types of test: cloze test and writing test. A cloze test is an assessment consisting of a portion of text with certain words removed (cloze text), where the participant is asked to replace the missing words. The rationale for my choosing this type of test was that cloze tests require the ability to understand context, vocabulary and grammar in order to identify the correct words or type of words that belong in the deleted passages of a text. Porter (1976) and Oller (1979) concluded from their studies of cloze tests that these tests are quite valuable to the fields of language learning in general and language testing in particular. Filling in a gap in a cloze exercise is not just a matter of perceiving local redundancy but rather involves an awareness of the flow of discourse across sentences. In fact, to complete a cloze passage correctly requires the learners to have linguistic, textual and sometimes world knowledge. Generally, a cloze test consists of a passage of 250-500 words in which words are deleted at standard intervals and replaced by standard blank spaces. In this study, I selected a passage of 344 words with 25 blanks (see Appendix E). In addition to the cloze test, both classes of students took a timed writing test at the beginning and at the end of the experiment respectively in an attempt to evaluate the effectiveness of the new teaching model - the Write-to-learn Model.

\section{Role of the Researcher}

I worked to maintain impartiality with all participants (Vogt et al., 2012). Before the study was conducted, it occurred to me that it would be potentially hard to maintain impartiality and neutrality because of my ethnicity as Chinese and shared culture. As the contact with the interviewee was limited, the shared culture made it easier for me to build 
positive rapport with the interviewees during the brief conversations. With this rapport, the respondents felt less nervous and intimidated to answer each question, thus ensuring a free flowing conversation with them. In addition, the interviewees could choose to answer the questions in Chinese. The use of Chinese language during the interviews made sure that the interviewees were able to express their thoughts more freely, completely and accurately.

Throughout the interviews, I maintained my impartiality by refraining from asking questions only in Chinese or only in English and talking about my own experiences as a former student and teacher in the Chinese university where the interviewees spent their first two years. I also maintained the use of formal, respectful language and demeanor rather than that of informal language during the conversations.

My personal experiences as a former student and teacher from the same university may have led to biases. However, as Creswell (2003) stated, having shared the participants' view as an insider, my emic perspectives served as a benefit to the study. Instead, the meticulous use of well-designed research questions, interview questions and appropriate coding protocols served to control potential threats to validity and raised my awareness of potential bias.

\section{Data Collection and Analysis}

As the study used the mixed methods approach, there were two types of data: data from the quantitative research method and data from the qualitative research method. I first collected all the data from Sub-study 1 and Sub-study 2. Then I conducted data analysis and interpreted the results in relation to the three research questions. 
Quantitative Data Collection and Analysis. The data I gathered by using the quantitative approach included questionnaires, cloze tests and writing tests in Sub-study 1. After receiving all the data from these three sources, I coded and entered the quantifiable data into a computer file employing SPSS 14.0 version. As I mainly looked at the differences between two groups of students, the $t$-test was considered appropriate to obtain statistics for analysis (Field, 2011). Specifically, I used the independent $t$-test to obtain statistics for the two groups and the dependent $t$-test to produce statistics for the students in the experimental group. The statistics from the $t$-test included mean, standard deviation and the value of $t$ and $p$. In the process of the quantitative data analysis, I used both descriptive and inferential statistics analysis. The rationale for using both descriptive and inferential statistics analysis was twofold. First, according to Krathwohl (2009), researchers collecting data that is quantified are often faced with a large amount of raw data that must be organized and summarized because there are too many pieces of information to understand at face value. Descriptive statistics analysis can help describe, show or summarize data in a meaningful way, from which we can see patterns and draw conclusions. Generally, there are two general types of statistic that are used to describe data: measures of central tendency and measure of spread. Second, inferential statistics analysis "permits us to infer the characteristics of a population from a representative sample. Applying inferential statistics to data from a sample, we can estimate the size of a population characteristic of interest, such as the mean of population. By using the data of the sample and setting the level of certainty, we construct an interval that tells the range within which the population value lies. Based on this, we can determine whether an 
effect other than that of sampling and chance error exists in a study" (Krathwohl, 2009, p. 433). In other words, inferential statistics analysis allows us to use samples to make generalizations about the populations from which the samples were drawn.

Qualitative Data Collection and Analysis. The data I gathered by using the qualitative approach included interviews and documents (Merriam, 2009). All the interviews were audio-recorded. In addition to the interviews, I also tried to collect such documents as the students' writing assignments, drafts of texts, course syllabi, certificates, honor rolls and report cards. These data could be used for the purpose of data triangulation. When I finished collecting all the data from the interviews, I listened to the recordings, translate and transcribe them. To make sure that I translated and transcribed as accurately and truthfully as possible, I asked one of my colleagues, who is a fluent speaker of both Chinese and English to check my interview data. After all the data were organized and prepared, I proceeded to coding the data and categorizing them based on themes or topics. In the coding process, I adopted the thematic networks analysis proposed by Attride-Stirling (2001). This analysis process, according to Attride-Stirling, goes through three stages: (1) the reduction or breakdown of the text; (2) the exploration of the text; and (3) the integration of the exploration. The detailed six steps are illustrated in Figure 6. 
ANALYSIS STAGE A: REDUCTION OR BREAKDOWN OF TEXT

Step 1. Code Material

(a) Devise a coding framework

(b) Dissect text into text segments using the coding framework

Step 2. Identify Themes

(a) Abstract themes from coded text segments

(b) Refine themes

Step 3. Construct Thematic Networks

(a) Arrange themes

(b) Select Basic Themes

(c) Rearrange into Organizing Themes

(d) Deduce Global Theme(s)

(e) Illustrate as thematic network(s)

(f) Verify and refine the network(s)

ANALYSIS STAGE B: EXPLORATION OF TEXT

Step 4. Describe and Explore Thematic Networks

(a) Describe the network

(b) Explore the network

Step 5. Summarize Thematic Networks

ANALYSIS STAGE C: INTEGRATION OF EXPLORATION

Step 6. Interpret Patterns

Figure 6. Steps in analyses employing thematic networks

(Attride-Stirling, 2001, p. 391)

\section{Coding Methods}

In association with my hypothesized framework, the Write-to-learn Model and the research questions of this study, I used two coding methods for coding the data gathered from the qualitative approach, as illustrated in Figure 7. 


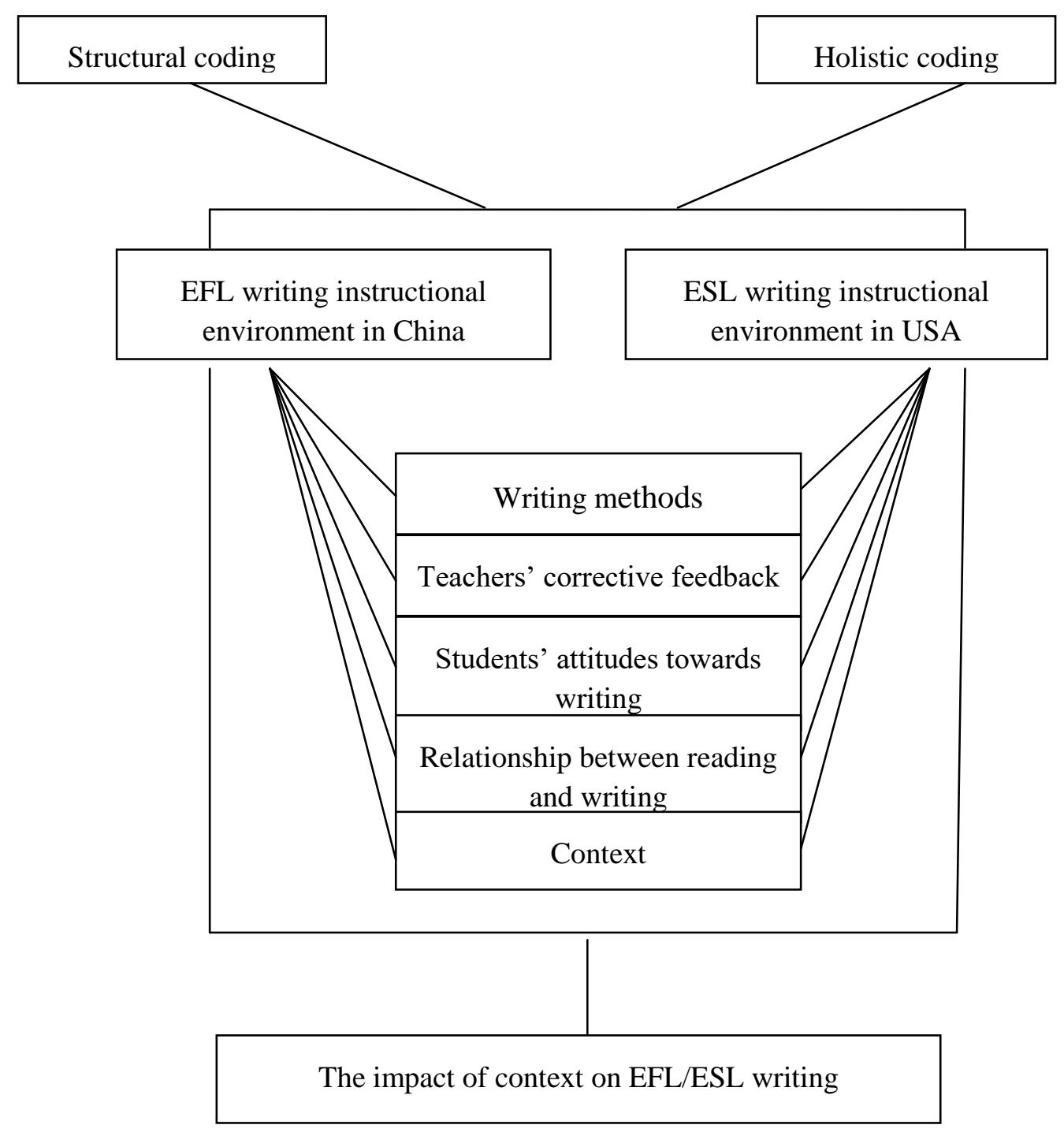

Figure 7. Coding methods for this study

Structural Coding. The application of structural coding method had something to do with the nature of the data collected through interviews. Structural coding is considered suitable for interview transcripts because it "applies a content-based or conceptual phrase representing a topic of inquiry to a segment of data to both code and categorize the data corpus" (Saldana, 2011, p. 66). MacQueen and Guest (2008) also 
pointed out, "Structural coding generally leads to the identification of large segments of text on broad topics that can form the basis for an in-depth analysis within or across topics" (p. 125). Based on the research questions, the data gathered through the interviews were coded under two categories: EFL writing instructional environment in China and ESL writing instructional environment in the US. The comparison and contrast of the coded data in terms of the five subcategories would lead to our understanding of the impact of context in EFL writing in some ways.

Holistic coding. The second coding method used to code the data gathered for this study was holistic coding method. Holistic coding, according to Saldana (2011), is an attempt to grasp basic themes or issues in the data by absorbing them as a whole rather than analyzing them line by line. This method is applicable when the researcher already has a general idea of what to investigate in the data or to chunk the text into broad topic areas, as a first step to seeing what is there. As Dey (1993) put it, the benefit of holistic coding lies in the fact that all the data for a category can be brought together and examined as a whole before deciding upon any refinement. This study attempted to address five major issues: (1) the role of context in EFL writing; (2) the relationship between reading and writing; (3) the impact of teachers' feedback on students' writing development; (4) the writing approaches; (5) students' attitudes towards writing. This coding method enabled us to see "what is there" in terms of the three issues the study attempted to address. 
When all the data from both Sub-study 1 and Sub-study 2 were collected, they were analyzed in relation to the three research questions addressed in this study, detailed as follows:

1. How does adding context create different writing outcomes for Chinese EFL students?

In this study, I argued that the dilemma of China's EFL writing instruction is related to the decontextualization of practices for teaching writing in EFL classes. Therefore, I contended that what teachers teach or what students learn should be contextualized. Again, decontextualization here means that practices for EFL writing instruction take place out of context. Context in this study include three aspects: linguistic level, situational level and cultural level. To explore how context impacted EFL writing, in Sub-study 1 of this study, I conducted an experiment with two classes of second-year undergraduate students in a university in China, with one group of 30 serving as the experimental group (EG) and the other group of 30 as the control group (CG). The experiment lasted five months, and the mixed methods approach was adopted. In Substudy 2 of this study, I used the qualitative research method. I interviewed five Chinese undergraduate students studying in a joint program in a university in Oregon, US. The data from both Sub-study 1 (S1) and Sub-study 2 (S2) were used to answer this question.

\section{How do Chinese students imagine/reflect the ways of developing writing skills and} the use of English writing skills?

Recall that in the experiment in Sub-study 1, a new teaching model called the Writeto-learn Model (refers to Figure 4, p. 80) was used with the experimental group. At the end of the experiment, I interviewed the 30 participants in the experimental group mainly 
from the six dimensions (see Figure 5, p. 91). In addition, in Sub-study 2, five students in a joint program were interviewed for their experiences and perceptions in relation to their English writing in China and in the US respectively. The data from the interviews of both sub-studies were used to answer this question.

3. How do Chinese EFL students compare/contrast English writing in Chinese and in English?

To address this question, I interviewed the five Chinese students who are now studying in their second year in a joint program in a university in Oregon, US. These five students had studied at a university in China for two years before they came to the United States. When they complete another two years' study in the university in Oregon, U.S., they will obtain a BA degree. During my interviews with them, I asked them to share their English writing experiences, and compare and contrast the differences and similarities between writing in Chinese and in English in terms of the six dimensions (see Figure 5, p. 91).

Validity

In the whole process of the mixed methods research, I paid close attention to two validity threats: researcher bias and reactivity. According to Pannucci and Wilkins (2010), bias means any tendency that prevents unprejudiced consideration of a question. In research, bias occurs when systematic error is introduced into sampling or testing by selecting or encouraging one outcome or answer over others. Bias can occur at any phase of research, including research design or data collection, as well as in the process of data analysis and publication. Reactivity here refers to the effect of the researcher on the 
individuals studied (Maxwell, 2005). To rule out these two threats, I adopted the following strategies:

1. In Sub-study 1, the same teacher taught the two groups of second-year undergraduate students. Two different teachers were asked to mark the students' compositions. The group that had the higher average scores in the first two tests was selected to be the control group so that the two groups could be more effectively compared.

2. The five Chinese students in the joint program was randomly selected. All the interviews were recorded and transcribed. This could avoid reactivity.

3. I used the triangulation of data for discussion and analysis. This strategy helped "reduce the risk of chance associations and of systematic biases due to a specific method, and allowed a better assessment of the generality of the explanations that one develops" (Maxwell, 2005, p.112).

In spite of the above strategies used to rule out validity threats in this study, some validity threats still might be unavoidable. Due to the nature of this study, I found it hard to have a bigger sample. The results of a relatively small sample might not provide credibility to generalization.

\section{Confidentiality}

In the process of the study, confidentiality was emphasized and guaranteed. Pseudonyms were used to replace the participants' real names. The name of the participants' school or university was simply identified as a university in Guangzhou, China or a university in Oregon, US. All data are kept in a safe place. Access to the data 
is strictly restricted to the researcher. I report the results of the study in my doctoral dissertation and may also report in publications of various types, conference presentations, journal articles, professional publications, and books. However, I will only report them as group data. Under no circumstance will the participants' names be released to anyone or appear in any publication created as a result of the study.

\section{Summary}

This chapter discussed the research methodology used in the study. First, I described the mixed methods approach to be employed in this study, in which research questions, the conceptual framework for this study, rationale for the choice of the approach, and the research design were presented. I then discussed the sampling strategies in the selection of participants. I also explained the interview protocols, the instruments used in the study and the research procedures. After that, I provided a detailed explanation of data collection procedures and a discussion of data analysis methods for interviews. Finally, I touched upon validity issues and confidentiality. 


\section{Chapter 4: Results and Analysis}

Chinese students learning English as a foreign language seem to get good marks in tests, but are poor or limited in their ability to write in English. This dilemma of China's EFL writing instruction was assumed to be related to the decontextualization of practices for teaching writing in EFL classes. This study aimed to examine how Chinese EFL students respond to changes in their writing instruction that pays attention to the context of EFL teaching and learning. This study addressed three questions: 1) How does adding context create different writing outcomes for EFL students? 2) How do Chinese students imagine/reflect the ways of developing writing skills and the use of English writing skills?

3) How do Chinese EFL students compare/contrast English writing in English and in Chinese? The mixed methods approach was used in the study.

This chapter starts with the analysis of data. Then it presents the research results. Next, it interprets the findings of the study in relation to the three research questions posed in the study. Finally, it addresses the limitations of the study.

\section{Analysis of Data}

As mentioned in Chapter 3, this study consisted of two sub-studies. So there were two data sources for this study. The first source of data collection for analysis from Substudy 1 was the two types of tests of the two classes of undergraduate students, and the questionnaires and interviews with the participants in the EG and the reflections in the CG. The second source of data collection for analysis from Sub-study 2 was the interviews with the five Chinese students in the joint program. 


\section{Analysis of Data from Sub-study 1}

Questionnaire Survey. Recall that the 30 students from the EG took the questionnaire survey at the beginning of the experiment (September, 2015) and at the end of the experiment (February, 2016) respectively. When the two questionnaire surveys were completed, all the quantifiable data were coded and entered into computer files (see Appendix I). Then I employed the SPSS to obtain statistics for analysis according to six issues I designed to investigate: (1) whether the students accepted the new teaching model, (2) whether their confidence increased in their ability to write in English after the new teaching model was adopted, (3) whether their English writing improved, (4) whether they were positive about the marking scheme, (5) whether they liked to write compositions outside class, and (6) whether authentic materials helped improve their writing (see Appendix I). As I mainly looked at the differences between the first questionnaire survey and the second questionnaire survey, I used the dependent $t$-test to produce statistics. The statistics from the $t$-test included mean, standard deviation and the value of $t$ and $p$. In the process of this quantitative data analysis, I used both descriptive and inferential statistics analysis.

Cloze Test and Writing Test. Recall that both EG and CG took a cloze test and a writing test at the beginning of the experiment (September, 2015) and at the end of the experiment (February, 2016) respectively. 30 students from the EG and 30 from the CG took the tests respectively. After receiving all the raw data of these tests (see Appendices $\mathbf{J}$ and K), I coded and entered the data into a computer file employing SPSS. As I chiefly explored the differences between the EG and the CG, the independent $t$-test was used to obtain statistics for analysis. The statistics from the $t$-test also included mean, standard 
deviation and the value of $t$ and $p$. In the process of the quantitative data analysis, I used both descriptive and inferential statistics analysis.

Interviews. Recall that 12 interview questions were prepared (see Appendix F). After interviewing each participant, I listened to the recording and translated it from Chinese to English. Then I asked a native Chinese speaker to double-check the translation to ensure the accuracy of the translation. Then I transcribed the response by using structural coding and holistic coding methods (Saldana, 2011). When analyzing the interview transcripts, I examined the participants' responses and created sets of thematic categories by using thematic networks analysis (Attride-Stirling, 2001). The process allowed me to listen to each conversation in its entirety and identify patterns to develop thematic categories. An initial set of thematic categories was developed by paying close attention to the common patterns of perceptions described by the participants. After each interview was assigned sets of labeling codes, all the coded responses were added to tables (see Appendix L).

\section{Analysis of Data from Sub-study 2}

Five students in the joint program were involved in Sub-study 2. The interviews were used to elicit their perceptions and attitudes about their English writing experiences in China and in the United States. 15 research questions (see Appendix G) were prepared concerning six dimensions (refer to Figure 5 on p. 91). The five interviews were conducted on a one-to-one basis in August and September, 2015. When interviewing each participant, I followed the same procedures as I did with the 30 students in the EG. For the key data from Sub-study 2, you can refer to Appendix M. 


\section{Analysis of Data from Sub-study 1 and Sub-study 2}

Recall that to answer the third research question, I also asked the 30 participants in the CG to write a reflection concerning their ways of their developing writing skills and their use of writing skills at the end of the experiment (February, 2016) so as to compare and contrast their ways of developing English writing skills and their use of English writing skills with the 30 participants in the EG and the five participants in the joint program. All the 30 participants in the $\mathrm{CG}$ wrote a reflection. After receiving all the reflections, I examined their responses and those from the interviews of the 30 participants in the EG and the five participants in the joint program. After each participant was assigned sets of labeling codes, all the coded responses were added to tables based on two thematic categories: ways of developing writing skills and use of writing skills (see Appendix N).

When all the data from both sub-studies were collected, I analyzed them in relation to the three research questions posed in this study. To have a clearer picture of how the data were used to answer the research questions, I created a research questions matrix (Morgan, 2013) as follows:

Table 5. Research Questions Matrix

\begin{tabular}{|c|c|c|c|c|c|c|}
\hline \multicolumn{7}{|c|}{ Data Sources } \\
\hline & $\begin{array}{c}\text { S1 } \\
\text { Questionnaires }\end{array}$ & $\begin{array}{c}\text { S1 } \\
\text { Pre-test }\end{array}$ & $\begin{array}{c}\text { S1 } \\
\text { Post-test }\end{array}$ & $\begin{array}{r}\text { S1 } \\
\text { In }\end{array}$ & $\begin{array}{l}\text { S2 } \\
\text { ews }\end{array}$ & $\begin{array}{c}\text { S1 } \\
\text { Writing tests }\end{array}$ \\
\hline $\begin{array}{l}\text { 1. How does } \\
\text { adding context } \\
\text { create different } \\
\text { writing outcomes } \\
\text { for EFL students? }\end{array}$ & that & $X$ & $X$ & $X$ & $X$ & 0.0 \\
\hline $\begin{array}{l}\text { 2. How do Chinese } \\
\text { students } \\
\text { imagine/reflect the } \\
\text { ways of developing } \\
\text { writing skills and }\end{array}$ & $X$ & & & $X$ & $X$ & \\
\hline
\end{tabular}




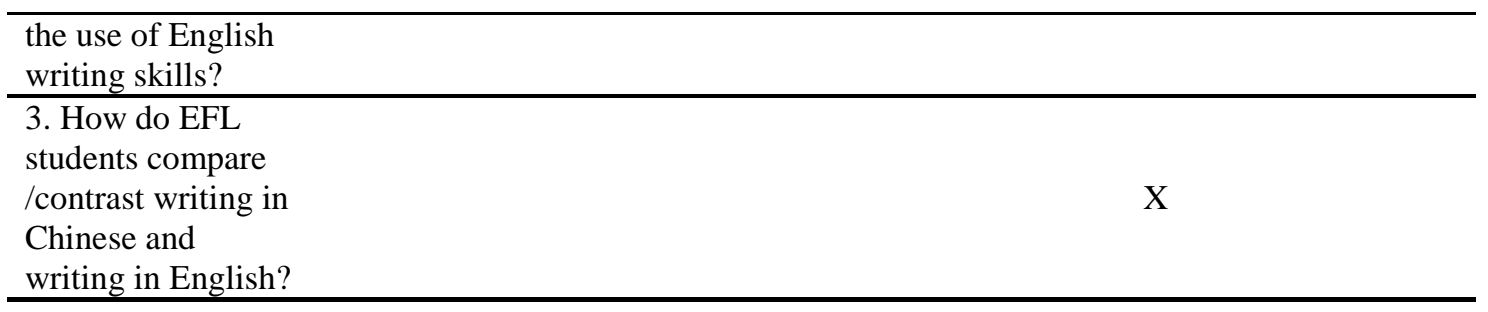

Note: S1= Sub-study1; S2= Sub-study 2

\section{Presentation of Results}

In this section, I present the results of this study based on the two sub-studies. As was previously mentioned, in Sub-study 1, I conducted an experiment to explore the effect of contextualized writing practices on EFL college student writing achievement; in Sub-study 2, I used interviews to elicit five students' perceptions and reflections about writing instruction in China and in the US. The results of the study are presented in relation to the three research questions as follows:

\section{Results of Sub-study 1}

The questionnaire in Sub-study 1 was designed to look into six issues: acceptance of the new teaching model, confidence in EFL writing, English improvement in writing, scoring scheme, writing out of class and use of authentic materials. To see if changes concerning the six issues occurred due to the new teaching model, the same questionnaire was taken at the beginning and the end of the semester. The participants were asked to make judgments by circling one appropriate number that reflected their opinion on a statement. Below are the SPSS tables containing the results of this group. Their judgments are summarized in Table 6, which shows that differences in the responses before and after the training are highly significant with respect to the six issues. 
Table 6. Differences in questionnaire responses $(\mathbf{N}=30)$

\begin{tabular}{lcccccc}
\hline \multicolumn{1}{c}{ Issues } & \multicolumn{2}{c}{ At the beginning of the experiment } & \multicolumn{4}{c}{ At the end of the experiment } \\
& Mean & SD & Mean & SD & t & P \\
\hline $\begin{array}{l}\text { Acceptance of Write-to- } \\
\text { Learn Approach }\end{array}$ & 3.05 & .76 & 4.15 & .46 & 6.486 & $.000^{*}$ \\
$\begin{array}{l}\text { Confidence in EFL writing } \\
\text { English improvement in }\end{array}$ & 3.35 & & & & & \\
writing & 3.47 & .62 & 4.19 & .39 & 6.176 & $.000^{*}$ \\
Scoring scheme & & .86 & 4.12 & .53 & 3.841 & $.000^{*}$ \\
Writing out of class & 3.54 & .69 & 4.32 & .43 & 5.253 & $.000^{*}$ \\
Use of Authentic materials & 3.96 & .42 & 4.59 & .47 & 2.047 & $.021^{*}$ \\
\hline
\end{tabular}

$* \mathrm{p}<.05$

The results of the cloze test are summarized in Table 7, which shows that the EG performed the test numerically better than the $\mathrm{CG}$, although the difference does not reach the .05 significance level.

Table 7. Differences in cloze test scores

\begin{tabular}{lcccccc}
\hline & \multicolumn{5}{c}{ Cloze Test } \\
& Pre-test & Post-test & Mean Diff. & SD & T & P \\
\hline EG $(\mathrm{N}=30)$ & 10.70 & 17.03 & 6.28 & 3.10 & & \\
CG $(\mathrm{N}=30)$ & 11.43 & 16.92 & 4.96 & 2.59 & 1.698 & .095 \\
\hline
\end{tabular}

The results of the writing test are summarized in Table 8, which also shows that the EG performed the test numerically better than the CG. The difference was significant, with $\mathrm{t}=4.314, \mathrm{p}<.05$.

Table 8. Differences in writing tests

\begin{tabular}{lcccccc}
\hline & \multicolumn{5}{c}{ Writing Tests } \\
& Pre-test & Post-test & Mean Diff. & SD & T & P \\
\hline EG $(\mathrm{N}=30)$ & 45.60 & 49.00 & 3.60 & 2.69 & & \\
CG $(\mathrm{N}=30)$ & 46.80 & 47.00 & .56 & 2.53 & 4.314 & $.000^{*}$ \\
\hline$* p<05$ & & & & &
\end{tabular}

$* \mathrm{p}<.05$

Results of the Interviews from the 30 students in the EG. These students went 
through the Write-to-learn Model training were interviewed for their perceptions and reflections on the new approach. Table 9 is a summary of the key data from the interviews of the 30 students. The interviews include five themes: Writing approaches, attitudes towards writing, relationship between reading and writing, corrective feedback and context. 
Table 9. Summary of the key data about the five themes of the 30 students in Sub-study 1

\begin{tabular}{|c|c|c|c|c|}
\hline Writing approach & $\begin{array}{l}\text { Attitudes towards } \\
\text { writing }\end{array}$ & $\begin{array}{l}\text { Relationship } \\
\text { between reading \& } \\
\text { writing }\end{array}$ & $\begin{array}{l}\text { Corrective } \\
\text { feedback }\end{array}$ & Context \\
\hline $\begin{array}{l}\text { - Is an effective teaching } \\
\text { method; } \\
\text { Drives us to read } \\
\text { books, articles and } \\
\text { magazines in the } \\
\text { original; } \\
\text { - } \text { Is a catalyst for } \\
\text { extensive reading and } \\
\text { "good medicine" for } \\
\text { broadening our } \\
\text { horizons; } \\
\text { Helps enlarge our } \\
\text { vocabulary and } \\
\text { expressions; } \\
\text { Learns to use a variety } \\
\text { of structures; } \\
\text { Helps improve our } \\
\text { writing proficiency. }\end{array}$ & $\begin{array}{l}\text { Writing is becoming } \\
\text { more fun and } \\
\text { enjoyable; } \\
\text { - } \text { Removes our fear or } \\
\text { EFL writing; } \\
\text { - Enhances our } \\
\text { confidence in } \\
\text { writing; } \\
\text { Develops a sense of } \\
\text { achievement in EFL } \\
\text { writing; } \\
\text { Brings my writing } \\
\text { initiatives into full } \\
\text { play; } \\
\text { Wants to write } \\
\text { instead of needing to } \\
\text { write; } \\
\text { Writing is a pleasure } \\
\text { to express our life } \\
\text { experiences, feelings } \\
\text { and opinions. }\end{array}$ & $\begin{array}{l}\text { Writing should not } \\
\text { be separated from } \\
\text { reading; } \\
\text { Reading is the } \\
\text { foundation of writing; } \\
\text { The more you read, } \\
\text { the more ideas you } \\
\text { have; } \\
\text { Reading authentic } \\
\text { materials enables us } \\
\text { to express ourselves } \\
\text { more fluently, clearly } \\
\text { and accurately. }\end{array}$ & $\begin{array}{l}\text { - New scoring scheme } \\
\text { arouses my writing } \\
\text { enthusiasm; } \\
\text { Pointing out } \\
\text { "shining points" is a } \\
\text { stimulus to my } \\
\text { writing; } \\
\text { - Underlining errors } \\
\text { and self-correction } \\
\text { make me better } \\
\text { aware of my errors; } \\
\text { Peer review is a } \\
\text { good way to give } \\
\text { feedback to each } \\
\text { other; } \\
\text { Teacher's in-class } \\
\text { comments on good } \\
\text { compositions } \\
\text { enables me to } \\
\text { understand my } \\
\text { weaknesses. }\end{array}$ & $\begin{array}{l}\text { Extensive exposure to } \\
\text { authentic materials } \\
\text { enables us to think and } \\
\text { express ideas in English; } \\
\text { Imitating good } \\
\text { expressions from } \\
\text { books/magazines is a } \\
\text { good way to avoid } \\
\text { Chinglish; } \\
\text { Extensive reading puts } \\
\text { our learning in context; } \\
\text { Cultural knowledge leads } \\
\text { to my better } \\
\text { understanding of the } \\
\text { mindset of native } \\
\text { speakers. }\end{array}$ \\
\hline
\end{tabular}


Positive comments from the interviews about the new teaching model were abounding and three comments are cited below as examples of the results of Substudy 1 .

After writing long compositions and free writing for one semester, I find my writing improved. In the beginning I was not used to writing long compositions. I was worried about getting ideas to write. What's more, it took too much time to write. Gradually I find the approach helpful. It forces me to search for English reading materials relevant to the writing tasks. The Write-to-learn Model has not only fueled my interest in writing English but also expanded my English vocabulary (EG-Student 3).

Because writing long compositions and free write provide me with much more opportunities to express myself in English, I have to rack my brains to differentiate sentence structures and phrases and use different wording so that my compositions will not sound monotonous and verbose (EG-Student 8).

I have to say the Write-to-learn Model must go with reading. In order to be able to come up with ideas for a long composition, I need to do a lot of reading. Writing long compositions makes me aware of my own weaknesses in using English and gives me an urge to read more books. The more books in the original I read, the more authentic expressions I can use in my writing (EG-Student 10).

\section{Results of Sub-study 2}

In Sub-study 2, five students in the joint program were interviewed according to the five themes related to the contextualization of EFL writing practices: writing 
approaches, attitudes towards writing, relationship between reading and writing, corrective feedback and context. Table 10 is a summary of the key data from the interviews of the five students in the joint program. 
Table 10. Summary of the key data from the interviews of the five students in the joint program

\begin{tabular}{|c|c|c|c|c|c|}
\hline & Writing approaches & $\begin{array}{l}\text { Attitudes towards } \\
\text { writing }\end{array}$ & $\begin{array}{l}\text { Relationship between } \\
\text { reading \& writing }\end{array}$ & Corrective feedback & Context \\
\hline Student A & $\begin{array}{l}\text { Encourages } \\
\text { students to write } \\
\text { through reading } \\
\text { and learn writing } \\
\text { techniques from } \\
\text { the authors; } \\
\text { Basic writing } \\
\text { techniques are not } \\
\text { difficult; } \\
\text { developing ideas is } \\
\text { more important and } \\
\text { more difficult. }\end{array}$ & $\begin{array}{l}\text { English writing is } \\
\text { not as hard as we } \\
\text { imaged as long as } \\
\text { you get used to it; } \\
\text { Writing is } \\
\text { becoming more } \\
\text { enjoyable. }\end{array}$ & $\begin{array}{l}\text { Writing ought to be } \\
\text { integrated with } \\
\text { reading so as to } \\
\text { develop a better } \\
\text { English language } \\
\text { awareness; } \\
\text { Writing and reading } \\
\text { are just like water } \\
\text { and fish. }\end{array}$ & $\begin{array}{l}\text { Pay more attention } \\
\text { to ideas than to } \\
\text { syntactic errors; } \\
\text { - } \\
\text { Peer review is } \\
\text { encouraged; } \\
\text { - } \\
\text { Rubric also serves } \\
\text { as a guide for my } \\
\text { writing. }\end{array}$ & $\begin{array}{l}\text { Have made great } \\
\text { progress in writing } \\
\text { because there's an } \\
\text { environment where } \\
\text { I'm exposed to } \\
\text { English every day; } \\
\text { - I attributed }\end{array}$ \\
\hline Student B & $\begin{array}{l}\text { Peer review is a } \\
\text { great approach } \\
\text { used in the writing } \\
\text { classes in the US. } \\
\text { Through reading } \\
\text { my peers' writing } \\
\text { and giving } \\
\text { feedback to it, I } \\
\text { learn about } \\
\text { different styles of } \\
\text { writing, the ways } \\
\text { of thinking of } \\
\text { native English } \\
\text { speakers and how } \\
\text { these ways are } \\
\text { different from } \\
\text { mine; }\end{array}$ & $\begin{array}{l}\text { Enjoy free write; } \\
\text { the more I write, } \\
\text { the more } \\
\text { confidence I have } \\
\text { in writing; } \\
\text { Writing is } \\
\text { becoming part of } \\
\text { my life and is the } \\
\text { reflection of my } \\
\text { life and study. }\end{array}$ & $\begin{array}{l}\text { Reading and writing } \\
\text { are highly related. } \\
\text { Writing starts from } \\
\text { imitation. I think } \\
\text { and learn when I } \\
\text { read, and then I } \\
\text { write down what I } \\
\text { think; } \\
\text { Reading broadens } \\
\text { my mind and gives } \\
\text { me more space to } \\
\text { write about. }\end{array}$ & $\begin{array}{l}\text { Professors work } \\
\text { with students on } \\
\text { ideas and suggest } \\
\text { using short and } \\
\text { simple sentences; } \\
\text { Professors help } \\
\text { students with how } \\
\text { to structure } \\
\text { sentences and how } \\
\text { to make paragraphs } \\
\text { coherent. }\end{array}$ & $\begin{array}{l}\text { I do feel my English } \\
\text { writing skills } \\
\text { improved a lot. The } \\
\text { most important factor } \\
\text { is the environment } \\
\text { where everyone } \\
\text { speaks English and I } \\
\text { read extensively. }\end{array}$ \\
\hline
\end{tabular}




\begin{tabular}{|c|c|c|c|c|c|}
\hline & $\begin{array}{l}\text { Language learning } \\
\text { process is more } \\
\text { than to study } \\
\text { grammar, and it is } \\
\text { to important to } \\
\text { learn the culture. }\end{array}$ & & & & \\
\hline Student C & $\begin{array}{l}\text { Journaling is a } \\
\text { good way to } \\
\text { improve your } \\
\text { writing. The more } \\
\text { you journal, the } \\
\text { better you can } \\
\text { write. } \\
\text { Writing originates } \\
\text { from life. Record } \\
\text { what happens to } \\
\text { your life. Your } \\
\text { writing inspiration } \\
\text { comes from life. }\end{array}$ & $\begin{array}{l}\text { - It has become my } \\
\text { habit to journal in } \\
\text { English; } \\
\text { - Developing a } \\
\text { sense of } \\
\text { achievement in } \\
\text { writing; } \\
\text { - Am able to } \\
\text { express my } \\
\text { thoughts more } \\
\text { fluently and } \\
\text { clearly. }\end{array}$ & $\begin{array}{l}\text { Reading should not } \\
\text { be separated from } \\
\text { writing. Writing } \\
\text { cannot be improved } \\
\text { without reading } \\
\text { extensively. The } \\
\text { relationship between } \\
\text { reading and writing } \\
\text { is like input and } \\
\text { output. }\end{array}$ & $\begin{array}{l}\text { Pay more attention } \\
\text { to the organization } \\
\text { of an essay and the } \\
\text { development of } \\
\text { ideas. }\end{array}$ & $\begin{array}{l}\text { My writing ability } \\
\text { has improved } \\
\text { considerably. I think } \\
\text { the major reason is } \\
\text { the change of the } \\
\text { environment where } \\
\text { I'm exposed to } \\
\text { English every day. }\end{array}$ \\
\hline \multirow[t]{2}{*}{ Student D } & $\begin{array}{l}\text { Practice writing } \\
\text { every day. Free } \\
\text { write is a good } \\
\text { way; } \\
\text { Read extensively } \\
\text { and you'll get good } \\
\text { ideas and imitate } \\
\text { good expressions. }\end{array}$ & $\begin{array}{l}\text { - Writing is } \\
\text { becoming } \\
\text { increasingly easy } \\
\text { for me with } \\
\text { constant practice } \\
\text { and extensive } \\
\text { reading; } \\
\text { - It's amazing that } \\
\text { I'm able to use a } \\
\text { variety of } \\
\text { structures. }\end{array}$ & $\begin{array}{l}\text { Writing is based on } \\
\text { reading. Reading } \\
\text { can widen my mind } \\
\text { and enables me to } \\
\text { write in a more } \\
\text { authentic manner. }\end{array}$ & $\begin{array}{l}\text { - } \begin{array}{l}\text { Stress is laid on } \\
\text { structure, ideas and } \\
\text { details; }\end{array} \\
\text { Work with a tutor } \\
\text { from the writing } \\
\text { help center; } \\
\text { - } \begin{array}{l}\text { Peer review is also } \\
\text { helpful. }\end{array}\end{array}$ & $\begin{array}{l}\text { All our course books } \\
\text { are in English. The } \\
\text { more we read, the } \\
\text { more we understand } \\
\text { and master English } \\
\text { expressions and } \\
\text { culture, and are able } \\
\text { to write more fluently } \\
\text { and clearly. }\end{array}$ \\
\hline & $\begin{array}{ll} & \text { Reading } \\
& \text { extensively helps }\end{array}$ & $\begin{array}{l}\text { Writing is a } \\
\text { process that calls }\end{array}$ & $\begin{array}{l}\text { Reading skills, } \\
\text { which are different }\end{array}$ & $\begin{array}{l}\text { Positive comments } \\
\text { are given; }\end{array}$ & $\begin{array}{l}\text { - I find my writing is } \\
\text { improving quickly }\end{array}$ \\
\hline
\end{tabular}




\begin{tabular}{|c|c|c|c|c|c|}
\hline Student E & $\begin{array}{l}\text { improve my } \\
\text { writing; } \\
\text { - Free write and } \\
\text { journaling are two } \\
\text { good methods; } \\
\text { Teaching some } \\
\text { writing techniques } \\
\text { is also necessary. }\end{array}$ & $\begin{array}{l}\text { for extensive } \\
\text { reading and } \\
\text { constant practice; } \\
\text { It's more } \\
\text { important to } \\
\text { develop in-depth } \\
\text { ideas than to learn } \\
\text { only writing } \\
\text { techniques. }\end{array}$ & $\begin{array}{l}\text { from writing skills, } \\
\text { can be taught } \\
\text { separately; } \\
\text { Reading is input } \\
\text { while writing is } \\
\text { output. Extensive } \\
\text { reading is the basis } \\
\text { of writing. }\end{array}$ & 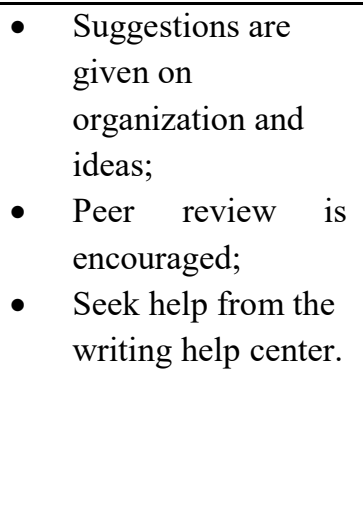 & $\begin{array}{l}\text { because we have } \\
\text { much more authentic } \\
\text { input and practice } \\
\text { writing more often; } \\
\text { There is a good } \\
\text { environment here } \\
\text { where we are } \\
\text { exposed to English. } \\
\text { The more you hear } \\
\text { and read, the more } \\
\text { you understand. }\end{array}$ \\
\hline
\end{tabular}


The analysis of the five students' interview data reveals that all the five students felt they had made great progress in their English writing. The major factor contributing to their achievement in writing was the change of the learning environment. In the United States, they lived in an environment where they were exposed to the English language every day. Contextualized learning and sufficient authentic materials input enabled them to have a better understanding of American culture, different ways of thought of English native speakers and correct English expressions. Student D was cited as saying, "All our course books are in English. The more we read, the more we understand and master English expressions and American culture, and are able to write more fluently and clearly. $"$

In terms of the writing approaches, the five students all reported that the writing approaches used in their US classes led to their improvement in writing. The professors did not correct each and every grammatical error in the students' writing. Instead, they paid more attention to helping the students with how to organize paragraphs and develop ideas in their essays or compositions. In addition, the professors encouraged the students to read extensively to develop their English language awareness. Extensive reading helped the students enlarge vocabulary and master sentence structures and writing techniques. In the writing process, the students were encouraged to review each other's work. All the students did feel that peer review was an effective method to help each other. As Student B commented, "Peer review is a great approach used in the writing classes in the US. Through reading my peers' writing and giving feedback to it, I learn 
different styles of writing, the ways of thinking of native speakers and how these ways are different from mine." What's more, the students could also seek help from the Writing Help Center, where they could discuss with a tutor about ideas, sentence structures and some other details. All the five students found it easier to communicate with a tutor from the Writing Help Center. Student E was cited as saying: "He/She is nice, friendly and helpful, and doesn't have the authority of a professor."

As for what kind of feedback they expected to receive from the professors, the five students unanimously preferred positive feedback with constructive suggestions. They found that the major difference between the EFL teachers in China and the professors in the United States lay in the fact that the former paid more attention to syntactic errors than to ideas and organization. Another difference was that the EFL teachers in China told students to use complex sentence structures while the professors in the United States encouraged students to use simple and short sentences to be easily understood and avoid ambiguity. The following was the comment given by Student B:

The professors here often work with students on ideas and suggest using short and simple sentences in our essays. They help us with how to structure sentences and how to make paragraphs coherent. They seldom correct our grammatical mistakes. Instead, they encourage us to do more extensive reading. The more we read, the bigger vocabulary we develop. In this way, we will use correct and appropriate language to express our ideas. In addition, the professors encourage us to make full use of the Writing Help Center. I think the tutors with the Writing Help Center are very nice and helpful. 
While asking whether reading and writing should be treated as independent courses, four of the five students thought that writing should be integrated with reading. Student B put it, " My writing experience in the United States lets me know that reading and writing are highly related. Writing starts from imitation. I think and learn when I read, and then I write down what I think. In the meanwhile, reading broadens my mind and gives me more space to write about. However, one student, Student E, thought that reading skills were quite different from writing skills and could be taught separately if one wanted to prepare for such tests as TOEFL or GRE. But she also mentioned that when it came to writing, it was a good idea to combine writing with reading, adding that reading was input while writing was output and extensive reading was the foundation of writing.

The analysis of the data from the five students in the joint program also demonstrates that the five students show a positive change of attitude towards English writing. The five students felt that English writing was hard and boring in their first two years of study in China. It seemed to them that they practiced English writing mainly for tests and had to follow the format required for tests and took plenty of simulation tests. However, after one year of study in the United States, they had different perceptions about writing. They all felt that English writing was not as hard as they imagined and was becoming increasingly easy and enjoyable with constant practice and extensive reading; for they were able to express their thoughts and ideas more freely, clearly and logically. Two students' comments were cited as evidence of their positive change of attitudes towards writing.

I enjoy free write; the more I write, the more confidence I have in my writing. 
Writing is becoming part of my life and is the reflection of my life and study (Student D).

It has become my habit to free write and keep a journal in English every day. Ideas flow from mind when I write; I don't get stuck with words and sentence structures as I did in my first two years' study in China. I really have a sense of achievement in writing when I read the professors' positive comments about my essays (Student C).

\section{Interpretation of Findings}

In this section, I interpret the findings of this study in relation to the three research questions. The findings are interpreted in the following three aspects:

\section{Outcome of Adding Context to Learning and Teaching of Writing}

Table 6 shows that, following the 5-month training with the new teaching model, the participants felt more confident in their ability to learn English, believed their English had improved, preferred to write outside class, and liked the approach along with its marking scheme. On the whole, the learners were very positive about the Write-to-learn Model after it was introduced.

The cloze results in Table 7 reveals that the EG performed the cloze test numerically better than the CG although the score difference does not reach the .05 significance level. Table 8 unequivocally demonstrates that the EG improved significantly more than the CG with respect to English writing. In short, the EG enjoyed the Write-to-learn Model and, following the five-month training with the new teaching model, wrote English better and exhibited considerable improvement in English writing. The results of Tables 7 and 8 demonstrate that the participants' actual writing performance matches their perceptions 
reflected in Table 6 . The quantitative results of Sub-study 1 imply that adding context to the teaching and learning of writing created a positive outcome for ELF students.

The quantitative results of Sub-study 1 were also supported by the interviews of the 30 students in the EG. Besides the key data in Table 9, two more comments from the interviews are cite as evidence in support of this finding.

English writing used to be a hard nut to crack for me. Every time we were assigned a writing task, it was a mental torture to me. It often took me one or two days to complete a 300-word composition. I was so scared when the Write-to-learn Model was introduced in our writing class. I had trouble writing a 200/300-word composition, let alone a 500/1000-word composition or longer. But after five months' training with this approach, I find I've benefited a lot from this new teaching model. I feel comfortable and at ease to write a 500/600-word composition. Compared to our first-year writing method, the Write-to-learn Model stresses writing at length. To write at length, we're forced to read extensively in the target language to get ideas, vocabulary, idiomatic expressions and sentence structures. For example, we were once asked to write a composition about air pollution. I didn't know much about this. I borrowed a few books about air pollution from the library and visited such websites as European Environmental Protection Agency, United States Environmental Protection Agency and Chinese Environmental Protection Bureau. Through these readings, I got a lot of information about environmental pollution and learned to express myself in English. As a Chinese proverb goes, "Even the cleverest housewife can't cook a meal without rice." The greatest benefit of the Writeto-learn Model is to encourage us to read English magazines, newspapers and novels and imitate the good expressions. This process enables us to know how to express our ideas in more authentic English instead of Chinglish, and enrich our knowledge. I speak highly of this new teaching 
model used in EFL writing class. As I see it, the Write-to-learn Model is not only a teaching method, but also a project requiring a lot of "bricks and tiles" (EG-Student 17).

Constant dripping wears away the stone. Such can be said of EFL writing, which cannot be achieved in one day. Through five months of training with the Write-to-learn Model, I'm becoming aware that extensive reading is a breakthrough in our EFL writing abilities. Only through extensive reading can we widen our horizons and enrich our English knowledge. The reading of the books, magazines and newspapers in the original immerses our learning in terms of vocabulary, sentence structures and culture (EG-Student 25).

\section{Ways of Developing Writing Skills and Use of English Writing Skills}

Table 11 is a summary of the key data from the interviews of Sub-study 1 and Substudy 2 regarding the ways of developing writing skills and the use of English writing skills. 
Table 11. Summary of the key data from the interviews of Sub-study 1 \& Stub-study 2 regarding the ways of developing writing skills and the use of English writing skills

\begin{tabular}{|c|c|c|c|c|}
\hline & \multicolumn{2}{|c|}{ Sub-study 1} & \multicolumn{2}{|c|}{ Sub-study 2} \\
\hline & $\mathbf{C G}$ & $\mathbf{E G}$ & $\begin{array}{l}\text { First two years } \\
\text { in China }\end{array}$ & $\begin{array}{c}\text { Last two years } \\
\text { in the US }\end{array}$ \\
\hline $\begin{array}{l}\text { Ways of developing } \\
\text { writing skills }\end{array}$ & 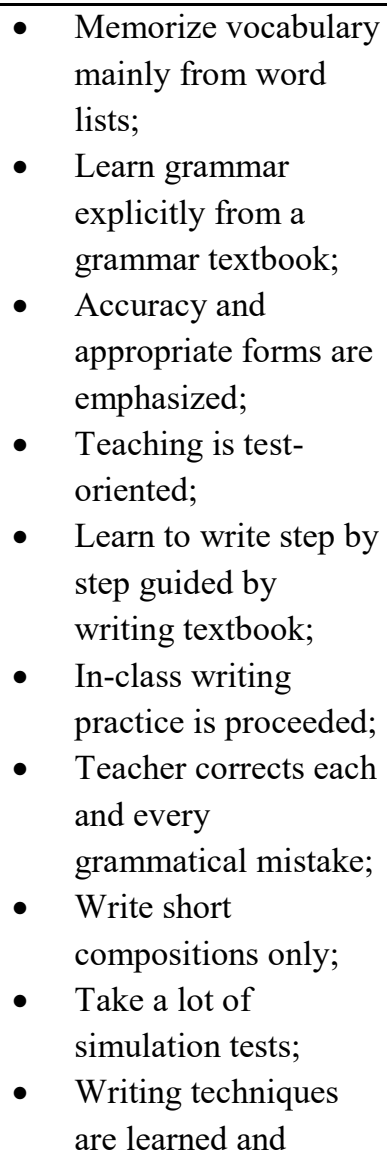 & 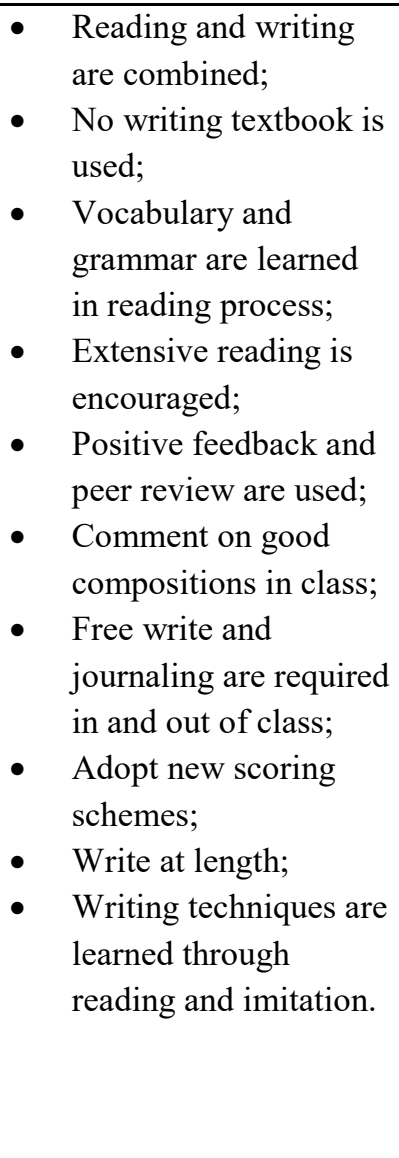 & 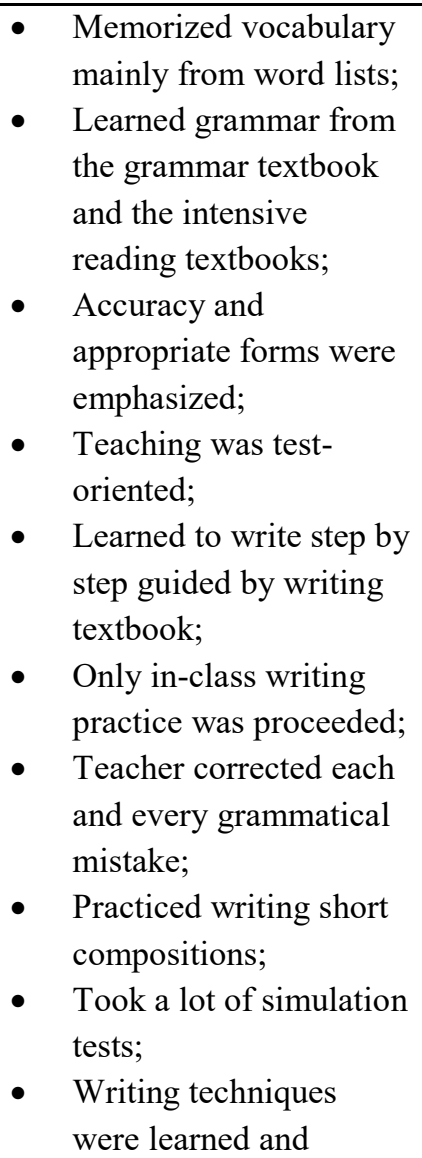 & $\begin{array}{l}\text { - } \begin{array}{l}\text { Reading and writing are } \\
\text { - }\end{array} \text { No writing textbook is } \\
\text { used; } \\
\text { - } \quad \text { Vocabulary and grammar } \\
\text { are implicitly learned in } \\
\text { association with reading } \\
\text { materials; } \\
\text { - } \quad \text { Extensive reading is } \\
\text { encouraged; } \\
\text { Positive feedback and } \\
\text { peer review are used; } \\
\text { Free write and journaling } \\
\text { are encouraged in and out } \\
\text { of class; } \\
\text { Write essays often; } \\
\text { Writing techniques are } \\
\text { learned through reading } \\
\text { and imitation; } \\
\text { Seeking help from } \\
\text { Writing Help Center. }\end{array}$ \\
\hline
\end{tabular}




\begin{tabular}{|c|c|c|c|c|c|c|}
\hline & & $\begin{array}{l}\text { developed through } \\
\text { textbook. }\end{array}$ & & & $\begin{array}{l}\text { practiced in class } \\
\text { through the teacher and } \\
\text { the textbook. }\end{array}$ & \\
\hline $\begin{array}{l}\text { Use of English writing } \\
\text { skills }\end{array}$ & $\bullet$ & $\begin{array}{l}\text { Writing skills are } \\
\text { mainly used for } \\
\text { taking tests, esp. } \\
\text { CETB-4 or CETB-6. }\end{array}$ & $\begin{array}{l}\text { Writing is an } \\
\text { important tool for } \\
\text { communication; } \\
\text { Writing enhances } \\
\text { English proficiency; } \\
\text { - Writing is developed } \\
\text { as one of the four } \\
\text { skills for future } \\
\text { academic pursuit. }\end{array}$ & $\bullet$ & $\begin{array}{l}\text { Writing skills were } \\
\text { mainly used for taking } \\
\text { tests, such as TOEFL or } \\
\text { IELTS. }\end{array}$ & $\begin{array}{l}\text { - Writing is an important } \\
\text { tool for communication; } \\
\text { - Writing is developed as } \\
\text { one of the four skills for } \\
\text { academic purpose or } \\
\text { pursuit. }\end{array}$ \\
\hline
\end{tabular}


It can be seen from Table 11 that the CG and the five students in the first two years in China developed their writing skills in a similar way. As mentioned in Chapter 3, the EFL teachers mainly adopted the two writing approaches: the Guided Approach and the Functional Approach in the CG and other normal writing classrooms. The textbook they used in the writing classes was "A Handbook of English Writing" by Wangdao Ding. The key data from Table 10 shows that the writing practices were summarized as (1) acquiring grammatical knowledge mainly from the grammar textbook and ; (2) learning vocabulary from the word lists of the textbook; (3) developing writing skills step by step in the order of words, sentences, paragraphs, passages and compositions; (4) emphasizing language accuracy; (5) practicing writing short essays or compositions in class; (6) correcting each and every grammatical error; (7) ignoring extensive reading. The data from Table 10 also shows that the students in the CG used their writing skills mainly for taking CETB-4/6 tests while the five students in the first two years in China aimed at the TOEFL and ILETS tests. As a result, EFL writing practices in the EFL writing classes were mainly test-oriented. The format and the requirements of tests were used as a guide for writing instruction and the students took plenty of simulation tests to prepare for the CETB-4/6 tests. All the students interviewed in both sub-studies shared similar opinions and reflections about their writing practices in the EFL classes. Two students' reports were cited as follows to show evidence in support of this finding:

I used to think that English writing was very time-consuming and boring. During the first two years of study in the university in China, I was so scared of English writing. When the teacher gave us a topic and asked us to write a 300- 
word essay, I was at a loss about what to write about and how to start. I racked my brains and managed to complete it. What scared me most was the teacher's negative comments in red about my English expressions and grammar. I hated to read these comments. In most cases, they dampened my enthusiasm about writing. I didn't realize I made so many grammatical mistakes although I did good jobs in grammar tests. What also frustrated me was that I made the mistakes again and again unawares. Additionally, we were asked to take many simulation tests. I think this practice was of some help to take tests, but I didn't see much help in improving my writing (CG-Student 1).

I have to say that English writing is quite different from Chinese writing. So it's quite important for us to learn some English writing techniques, such as how to structure an essay and how to make paragraphs coherent. However, after a few years' English learning, I still have struggle with English writing. In writing classes, we have learned how to make sentences, how to write paragraphs and how to organize ideas. I'm also familiar with the format of an English essay. I don't think my English grammar is bad. I don't know why English writing still seems to be so hard for me. In many cases, I find I lack ideas. Even though I have ideas, words often fail to get these ideas across. The comment or feedback that I often receive from my teacher is about my Chinglish expression. Maybe this has something to do with my insufficient knowledge about the topics and unfamiliarity with proper English expressions (CG-Student 9).

However, the analysis of the data from Table 11 shows a great difference for the EG and the five students in the last two years in the United States in terms of their ways of developing writing skills and use of English writing skills. The biggest difference lies in the writing approaches. The new teaching model, the Write-to-learn Model, was used 
with the EG while the Process Approach seemed to be mainly adopted with the five students in the joint program in the last two years in the United States. The similar practices of these two approaches lie in the integration of writing with reading. In addition, no textbook was used in writing classes. Students were encouraged to read extensively out of class to enlarge their vocabulary, acquire grammatical knowledge and learn writing techniques. Free write and journaling were an important part of their writing practice. Positive written feedback and peer review were used as the major feedback. Two students' reports are cited as follows to give a glimpse of the students' perceptions about English writing:

I find I benefit a lot from the Write-to-learn Model. On one hand, my writing skills are improving in terms of language usage and sentence structures. In a long composition, I try to avoid using the same words, the same phrases and the same sentence structures all the time. Instead, synonyms or different phrases with similar meanings are often used in my compositions. On the other hand, the new teaching model forces me to read more extensively so as to come up with novel ideas (EG-Student 16).

I feel that I'm quite lucky to have an opportunity to experience higher education in both China and the United States. I see big differences between the two. The major difference lies in the use of English writing skills. In the first two years, I learned to write mainly for passing the ILETS test. I did many simulation tests. Although I passed the test, I still had a struggle in my essay writing in my first year in the United States. In the United States, we use our writing skills for communication and academic purpose. This difference determines our ways in which we develop my writing skills. In the United States, the professors don't focus on semantic or syntactic errors as the EFL 
Chinese teachers did. They pay more attention to your ideas and some other details, such as how to use coherent words to organize your ideas or paragraphs and how to avoid ambiguity. Generally, we can use rubric to guide our writing. What's more, the professors encourage us to read extensively so that we can get in-depth ideas, build a larger vocabulary and learn writing techniques from our readings. Of course, it is easier to develop our English writing skills here simply because we are able to access to more resources, such as native speakers, tutors at schools, and English readings and entertainments. In other words, there is an environment where we are exposed to English. Another thing that I want to note is that a good understanding of culture and ways of thoughts can also contribute to our improvement in writing. I'm coming to realize that a lack of culture often results in Chinglish (Student C).

Based on the above analysis of the data in Table 11, it can be seen that the CG and the five students in the joint program in the first two years in China shared many similarities in terms of the ways of developing writing skills and the use of English writing skills. By contrast, the EG were similar to the five students in the joint program in the last two years in the United States in terms of their use of English writing skills and their ways of developing English writing skills.

\section{Students' Comparison of Writing in Chinese and Writing in English}

Table 12 is a summary of the key data from the interviews of the five students in the joint program regarding differences and similarities between writing in Chinese and writing in English. As only a few similarities between Chinese writing and English writing were mentioned during the interviews, I focused on the differences in an attempt to better understand the challenges of the students in English writing and the possible 
causes of the Chinglish phenomenon. It is noted here that the interviewees enumerated many differences between writing in Chinese and writing in English and only the common or similar ones were listed in Table 12. For the sake of clarity, the differences are categorized in terms of semantics, syntax and culture as shown in Table 12. 
Table 12. Summary of the key data from the interviews of the five students in the joint program regarding the differences between writing in Chinese and writing in English

\begin{tabular}{|c|c|c|}
\hline & Writing in Chinese & Writing in English \\
\hline Semantics & 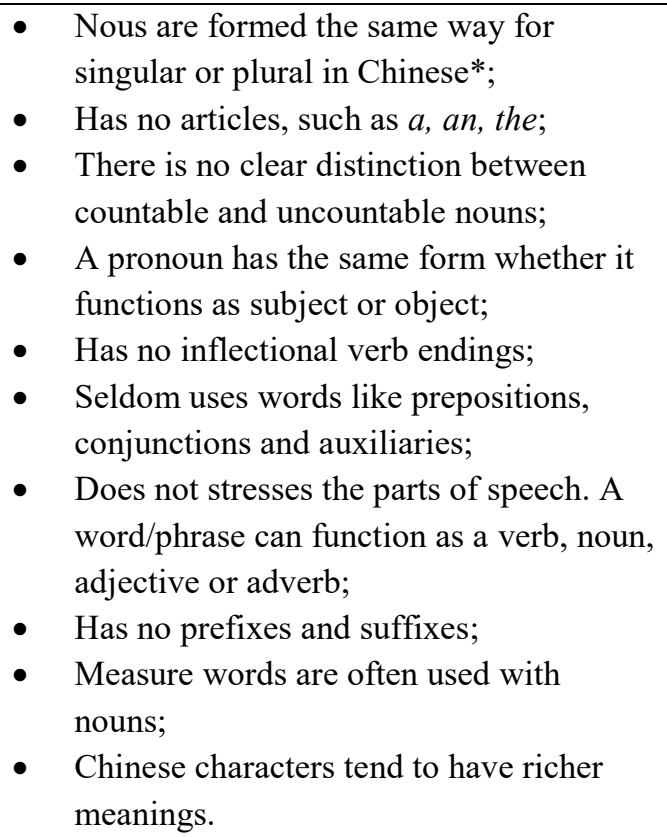 & $\begin{array}{l}\text { - There is the singular-plural distinction; } \\
\text { - } \quad \text { There is the subject/object case distinction; } \\
\text { - Has inflectional verb endings; } \\
\text { - Has articles, such as a, an, the; } \\
\text { - } \quad \text { There is the distinction between countable and } \\
\text { - } \text { uncountable nouns; } \\
\text { - } \quad \text { Often uses words like prepositions, } \\
\text { - } \quad \text { Hanjunctions and auxiliaries; } \\
\text { - Emphasizes and suffixes; }\end{array}$ \\
\hline Syntax & 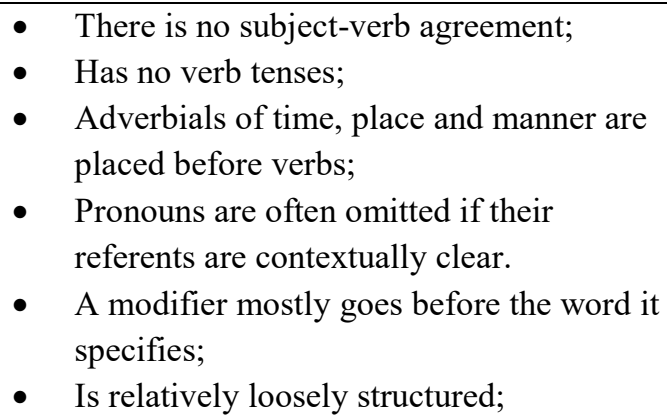 & $\begin{array}{l}\text { - There is subject-verb agreement; } \\
\text { - } \quad \text { Has verb tenses; } \\
\text { - } \text { Adverbials of time, place and manner are often } \\
\text { placed at the end of a sentence; } \\
\text { Pronouns cannot be omitted even if their } \\
\text { referents are contextually clear. } \\
\text { The core structure of a sentence should stand } \\
\text { closely together, with other parts going before } \\
\text { or after the core sentence; }\end{array}$ \\
\hline
\end{tabular}


- Emphasizes meaning: a sentence is usually short with few modifiers or the meaning will be confusing;

- The active voice is much more widely used.

- Words contains different connotations;

- Using definite and concrete things to express abstract ideas, such as idioms and proverbs;

Culture

Visualizing \& generalizing thinking;

- Tortuous thinking.
- Is more strictly structured;

- Emphasizes structure: a complicated sentence can express several meanings clearly;

- The passive voice is often used, especially in scientific articles.

- Using abstract words to express ideas;

- Analytic \& logical thinking;

- Straightforward thinking.

Note: Some Chinese pronouns referring to people sometimes do make a distinction between singular and plural by adding the morpheme 们 (men), such as teachers (老师们) and students (同学们). 
Differences in Semantics. Chinese and English use different writing systems.

Written Chinese is logographic while written English is alphabetic. The analysis of the data from Table 12 also shows some key differences between Chinese and English in writing in terms of semantics, syntax and culture. Semantically, out of the total differences, the five differences that every interviewee mentioned include singular and plural distinction, the use of articles, subject/object pronouns, inflectional verb endings and distinction between countable and uncountable nouns. Four interviewees reported that form words are seldom used in Chinese, such as prepositions, conjunctions and auxiliary words while three mentioned the parts of speech are not so important as those in English. Interestingly, three interviewees touched upon word prefixes and suffixes and measure words. In addition, two interviewees said that they often used the wrong words in English writing because a Chinese character tends to have richer meanings. The example that Student C gave was "看" (kàn), which can mean "look at", "read", "watch" or "see". Another example given by EG-Student J was "在" (zài), which can mean "in, at or on", depending on different situations: 在六点 (at six o'clock), 在波特兰 (in Portland), 在星期六 (on Saturday).

Differences in Syntax. Syntactically, eight key differences were pointed out. Of all the eight differences, the two differences mentioned by all the five interviewees include verb tenses and subject-verb agreement. Four interviewees realized that in Chinese, pronouns are often omitted if their referents are contextually clear while pronouns cannot omitted even if their referents are contextually clear. For example, to express the English 
meaning "I think I will go to the library to borrow some books after class," the Chinese would say, "I think today after class go to library borrow some books." Four interviewees found that Chinese writing is quite loosely structured while English writing is much more strictly structured. What's more, Chinese sentences tend to be short with few modifiers or the meaning will be confusing whereas English sentences can be long with a few clauses. For example, EG-Student 6 stated, "I find that the basic word order of Chinese and English is similar: subject-verb-object (SVO). Although both languages use SVO word order as their basic sentence structure, if a sentence grows complex, its structure becomes quite different. One important difference is the position of modifiers. In Chinese, a modifier mostly goes before the word it modifies. So it sounds awkward even to the point of unintelligibility in English." He illustrated it by giving the following example:

English: The man whom we met yesterday was a professor who works at the Gorge Fox University.

Chinese: We met the man yesterday was at the Gorge Fox University works a professor.

What's more, two interviewees thought that there is also a difference in the active and passive voices. For instance, Student $\mathrm{C}$ commented, "In Chinese, the active voice is often used while in English, the passive voice is often used, especially in scientific articles. A good example of this was:

English: It is generally believed that ...

Chinese: People generally believe that ... 
Differences in culture. In addition to the differences in semantics and syntax, differences were also found in culture, especially in modes of thought, the differences of which often lead to different understanding and expression of meanings and ideas. Student A said, "English learning is not only the learning of vocabulary and grammar, but also the understanding of culture. What is appropriate in Chinese culture may not be appropriate in American or western culture. For example, last name +老师(lăo shī, teacher) is the right way to address a teacher in Chinese culture, but in American culture, you can address a teacher or a professor by his/her first name. What's more, some same words may contain different connotations in different cultures. In Chinese, "王八" (wáng bā, a popular name for turtle or tortoise) is often used as a curse while in English it does not contain this connotation. A professor once asked me what "a turtle's egg" meant, a phrase he came across while reading a book about China. When I told him that this was vulgar language in Chinese culture, he was so shocked with wide-opened eyes.

Student E recounted during her interview about the differences and similarities between writing in Chinese and writing in English, " Based on my two years' experiences in the US, Chinese people seem to use more definite and concrete things to express ideas. I feel that in Chinese we often use idioms or proverbs to express abstract ideas. By contrast, American people seem to use more abstract vocabulary to express ideas. In many cases, we cannot find the English equivalents. This may be one of the reasons we have to resort to Chinglish expressions in our English writing. One example of this was " 人山人海” (rén shān rén hái, people mountain people sea), an idiom used to express a 
large crowd of people. Another example is "滴水之恩，当涌泉相报" (dī shuǐ zhī ēn dāng yǒng quán xiāng bào, a drop of water shall be returned with a burst of spring), an idiom with the meaning "Even if it was just a little help from others, you should return the favor with all you can when others are in need." This idiom always occurs to me when I want to thank someone who helps me or does something for me, but I cannot find an English equivalent. Once, I used the Chinese idiom "画蛇添足" (huà shé tiān zú, to add legs when painting a snake, meaning in English "to gild the lily") in one of my English essays. The professor underlined the sentence and put a big question beside it. Apparently, he didn't understand what it meant.

What is particularly worth mentioning is that three students in the joint program reported that differences sometimes lie in modes of thoughts arising from culture. Student B stated that Chinese people paid close attention to human relationships. That was the reason why it was so complex to address family members, some of which we could not find the English equivalents . Student $C$ noticed that in English writing, important points are generally made at the very beginning of an essay and details and relevant situations are then given or presented while in Chinese writing, relevant information and details are presented before hitting upon the theme. He added by saying, "In my first year here, my professors suggested that I make the important points at the beginning of each paragraph so as to clarify my ideas." It seemed to her that Chinese people prefer a tortuous thinking mode while American people or Westerners prefer a straightforward and analytic thinking mode. Student E observed that Chinese people seem to stress entirety while 
American people like to emphasize components and specifics. He illustrated this with the expression of time, location and titles. When talking about time, the Chinese always start from greater units and move on to smaller units. This is also true of the expression of location. By contrast, the Americans always start from smaller units and proceed to greater units. In introductions, the Chinese list the titles first (normally from higher to lower) before referring to specific names while the Americans will do the opposite. Based on her experience, she felt that Chinese people tend to follow a generalizing thinking mode and American people or Westerners tend to take an analytic and logical thinking mode.

To sum up, based on the analysis of the data in Table 12, the participants reported some major differences between writing in Chinese and writing in English in three aspects: semantics, syntax and culture. These differences tended to result in students' Chinglish expressions and writing styles. The findings from the interviews of the five students in the joint program suggested that sufficient exposure to authentic materials was a remedy to the problems.

\section{Limitations of the Study}

The current study has some limitations. They involve the participants, the generalization of the study, and the language and cultural factors affecting the processes of data collection and interpretation. Each limitation is identified below.

\section{Participants}

The first limitation involves the participants of the study. The study consisted of two sub-studies: Sub-study 1 and Sub-study 2. The participants of the two sub-studies were 
two different groups. There would be a continuity if the participants were from the same group in the two sub-studies and the results would be more convincing and reliable. However, due to the time limit of the study and the actual circumstances of the participants, it would be almost impossible to find the same group of participants who studied for the first two years in the university in China and the last two years in the university in the US. In spite of this, the participants were carefully selected, who had studied for the first two years in the university and the same teaching methods and course books were adopted.

\section{Generalization of the Study}

The second limitation involves the generalization of the study resulting from a relatively small sample. As discussed in the methodology chapter, two sub-studies were conducted in the study. Sub-study 1 engaged two classes of 60 second-year students in a university in China, with one class of 30 students serving as the experimental group, the other class of 30 students as the control group. Sub-study 2 involved only five students in the joint program in a university in the US. The total number of the participants was 65 . In spite of the strategies used to rule out validity threats in this study, some validity threats still might be unavoidable. The results of a relatively small sample might not provide credibility to generalization.

\section{Language and Cultural Factors}

In both sub-studies, the language employed in the interviews with the participants was primarily Chinese. Although all the participants were students who had learned English since middle school and could speak fluent English, they unanimously chose to 
use Chinese as the main language in the interviews. In all of the interviews, we asked the questions in Chinese and emphasized some key words in the interview questions first in English and then in Chinese, to ensure that the interviewees understood what we referred to. The responses provided by the interviewees were mostly in Chinese, with occasional use of English to clarify some key terms or concepts. For example, the five students in the joint program mentioned the concepts of "writing help center", "peer review", "presentation", "subordinate clause" and "ESL", which have been extensively used in their English writing classes.

I translated and transcribed all the interview recordings. I am a native born Chinese, have mainly received my education in China, and taught English for over 20 years before pursuing my graduate studies in the US. However, my bilingual proficiency may not be equal in decoding these two languages. I have encountered difficulties in demonstrating the interviewees' unique styles of talking, their choice of words, and their distinctive way of expressing their view points. This, to some extent, may weaken the authenticity and vividness of the interview data collected during my translation.

\section{Summary}

This chapter has focused on the research results, data analysis and the interpretations of the findings of the study. Based on the data of the surveys, tests and interviews, this chapter has reported on the research findings of this study. The surveys, tests and interviews in Sub-study 1 and Sub-study 2 explored the impact of adding context to English writing. The interviews with the participants in Sub-study 1 and Sub-study 2 examined the Chinese students' imagination and/or reflections on their ways of 
developing English writing skills and the use of English writing skills. The interviews with the five students in the joint program in Sub-study 2 investigated how the Chinese students compare writing in Chinese and writing in English. The findings revealed that adding context to writing instruction created a positive outcome for EFL students. The findings also indicated a few similarities but more differences between writing in Chinese and writing in English in terms of semantics, syntax and culture, and differences between the $\mathrm{CG}$ and the EG, and the five students in the joint program in the first two years in China and the in the last two years in the United States regarding ways of developing English writing skills and use of English writing skills. At the end of the chapter, the limitations of the study were identified and addressed. The next chapter, Chapter 5, will focus on the discussion of the research findings and provide implications and conclusions. 


\section{Chapter 5: Discussion and Conclusions}

As stated in Chapter 1, Chinese students learning English as a foreign language seem to get good marks in tests, but are poor or limited in their ability to write in English. This dilemma of China's EFL writing instruction was assumed to be related to the decontextualization of practices for teaching writing in EFL classes. The purpose of this study was to examine how Chinese EFL students respond to changes in their writing instruction that pays attention to the context of EFL teaching and learning. This study addressed three questions: 1) How does adding context create different writing outcomes for Chinese EFL students? 2) How do Chinese students imagine/reflect the ways of developing writing skills and the use of English writing skills? 3) How do Chinese EFL students compare/contrast English writing in China and in the US? The mixed methods approach was used in the study.

This chapter synthesizes the research findings of the study in relation to the three research questions posed in this study. The discussion of the research findings focuses on six aspects. First, I discuss the new teaching model used to examine the outcome of adding context to English writing of teaching and learning for EFL students. Second, I talk about the relationship between reading and writing. Third, I discuss the teaching and learning of vocabulary and grammar. Fourth, I deal with the effectiveness of positive corrective feedback. Fifth, I focus on motivating students to write by meeting their affective needs. Finally, I discuss how the differences between Chinese and English may have affected students' English writing and the necessity of contextualizing writing practices. The discussion of the research findings helps probe how factors pertaining to 
context contribute to EFL writing instruction. Finally, I provide implications and conclusions based on the findings of the study.

\section{Synthesis of Findings}

In this section, I present and discuss the findings derived from the analysis of the results of the study. The major findings are as follows:

\section{Write-to-learn Model: A Well-received and Effective Teaching Model}

Recall that in this study, based on my context-based hypothesis, I developed a new teaching model called the Write-to-learn Model. This new writing approach was used with the EG while the traditional-current approach was used with the CG. The analysis of the quantitative data in Tables 7 and 8 shows that the EG performed numerically better than the $\mathrm{CG}$ in both tests in terms of average score, suggesting that adding context to English writing did contribute to the students' improvement in writing. Moreover, the analysis of the data from the surveys also reveals that the students in the EG showed a positive change in their perceptions and attitudes in the six issues: acceptance of Writeto-learn Model, confidence in EFL writing, English improvement in writing, scoring scheme, writing out of class, authentic materials. Specifically, in terms of whether you accept the Write-to-learn Model, the average score went up from 3.05 to 4.15, indicating that the participants accepted this new writing model. The average score for scoring scheme rose from 3.54 to 4.32 , implying that the students also accepted the scoring scheme of the new writing model. Following the five months training with the Write-tolearn Model, the students showed more confidence and improvement in English writing. 
With regards to the use of authentic materials in and out of class, all the students demonstrated a very positive change, with the average score of 3.71 going up to 4.75 . All this implies that the students accepted and enjoyed the new teaching model. The numerous positive comments in the interviews from the EG also lend support to the above result. All the interviewees commented that the Write-to-learn Model was an effective teaching method and this new writing model helped them improve their English writing. Most of the interviewees said that one of the benefits of this new teaching model was to "compel us to read books, articles and magazines in the original in order to write at length". EG-Student 3 used a metaphor to comment on the Write-to-learn Model: "It seems to me that the new teaching model is a catalyst for reading extensively and good medicine for broadening our horizons. It motivates me to write." Many interviewees reported in their interviews that they had changed their attitudes towards English writing. They felt that writing was a pleasure to express their life experiences, feelings and opinions. They weren't afraid of or bored of English writing. Instead, they wanted to write instead needing to write. The more they practiced writing, the more confidence they were enhancing in writing. The ability to write long compositions brought their writing initiatives into full play and helped them develop a great sense of achievement in English writing. In addition, a few interviewees also suggested that when the students be used to writing long compositions, they should also learn to condense long compositions so as to better prepare for tests. However, they also believed that if one could "do a one-thousandmeter race, he/she should be able to do a one-hundred-meter dash easily" (EG - Student 
20).

As can be seen in the interviewees' comments in Sub-study 1, the learners might not get used to writing at length to begin with, but they were coming to see the merits of the Write-to-learn Model as they proceeded. Under the pressure of the length requirement, they felt impelled to read extensively and think deeply. With plenty of authentic materials input and self-motivated writing practice, they were able to write in English more effectively. In the meanwhile, they enhanced their confidence in English writing and considered it a pleasure to write in English. This finding echoes Ackerman's (1996) view that an effective model of learning should attempt to enculturate students into authentic practices through activity and social interaction in a way similar to that evident, and evidently successful, in craft apprenticeship and also reinforces the result of Mayer's (2003) study that instructional methods cannot separated from the context in which they are used. This finding of the study shows that the new teaching approach, with its emphasis on contextualizing EFL writing practices, is a well-received and effective writing approach.

\section{Integrating Writing with Reading}

The data from the interviews of both Sub-study 1 and Sub-study 2 suggests that reading should not be separated from writing. The students from the EG in Sub-study 1 all shared the view that reading ought to be combined with writing. Most of them considered it their biggest problem to be "巧妇难为无米之炊" (qiăo fù nán wéi wú mĩ zhī cuī, a Chinese idiom used to mean that even the cleverest housewife cannot cook a meal without rice). They reported that in many cases, due to insufficient authentic 
materials input, they had to think in Chinese and express in Chinglish. After all, there were a lot of differences between Chinese and English. What made the new teaching model (the Write-to-learn Model) distinct from other writing methods was that it integrates writing with reading. As EG-Student 22 recounted, "Constant dripping wears away a stone. Such can be said of EFL writing, which cannot be achieved in one day. Through five months of training with the Write-to-learn Model, I'm becoming aware that extensive reading is a breakthrough in our EFL writing abilities. Only through extensive reading can we widen our horizons and enrich our English knowledge. The reading of the books, magazines and newspapers in the original immerses our learning in terms of vocabulary, sentence structures and culture and provides models of language for us." EGStudent 11 resonated with Student 19 by saying, "I have to say writing must go with reading. In order to be able to come up with ideas for a long composition, I need to do a lot of reading. Writing long compositions makes me aware of my own weaknesses in using English and gives me an urge to read books. The more books in the original I read, the more authentic expressions I can use in my writing."

The five students in the joint program shared the same view regarding the relationship between reading and writing. They noticed that reading and writing were treated as two independent courses in the English curriculums in the first two years in the university in China. Their learning experiences in the United States made them aware that it was necessary and important to integrate reading with writing. They found that reading extensively enabled them to think more deeply and express their ideas in a native-like way. They also realized that sufficient authentic materials input was an effective way to 
minimize or avoid Chinglish in English writing. Student C is cited as saying, "My learning experiences in the United States let me know that reading is the foundation of writing. The professors here don't talk too much about writing skills or techniques. Instead, they encourage us to read extensively and learn to use correct and appropriate forms of language and writing formats. It seems to me that reading authentic materials is a good way to put your learning in context and provides you with models of English language. I've benefited a lot from my extensive reading since I came to the United States. Through extensive reading, I've also learned to think in English and familiarized myself with Americans' thought patterns and writing styles. I attribute my great improvement in writing to my extensive reading and constant practice."

The data from the interviews of both Sub-study 1 and Sub-study 2 shows that all the students consider it important to integrate reading with writing. This finding aligns with those of the previous studies by Reid (1993), Nystrand (1986) and Esmaeili (2002) that reading and writing are integrally connected. This finding also supports Plakan's (2009) belief that reading ability facilitates writing by providing content.

\section{Combining Vocabulary and Grammar with Reading and Writing}

Mention has been made in Chapter 2 that vocabulary is mainly learned from the word lists of each unit of Intensive Reading Textbooks and grammar is learned in English grammar class in the curriculum of the Chinese university where Sub-study 2 was conducted. The data of the interviews from both Sub-study 1 and Sub-study 2 shows different opinions about how vocabulary and grammar are learned. In asking which was a better way of learning vocabulary and grammar, most interviewees from the EG in Sub- 
study 1 considered it a better way to learn vocabulary and grammar in context, i.e. to integrate vocabulary and grammar with reading and writing. After five months' training with the Write-to-learn Model, they were coming to realize the importance of learning vocabulary and grammar in context. However, five interviewees considered it easier and helpful to learn vocabulary from word lists of the textbooks or vocabulary books and to learn grammar from grammar books, especially when they were preparing for tests. They felt that they couldn't learn vocabulary and grammar in the way that native speakers do and the explicit learning of grammar helped them master English grammar more effectively and do better jobs in tests. But they also added that although they knew grammar rules very well, they did not know for certain how to use them appropriately and correctly. This seems to resonate with the findings of the studies conducted by Martinsen (2000) and Frodesen and Holten (2003) that if learners are taught rules explicitly, they will perform better in grammar tests, but there is little evidence that they will perform better in less structured production tasks.

The data of the interviews from Sub-study 2 demonstrates the five students in the joint program and most interviewees in Sub-study 1 shared their view in that vocabulary and grammar ought to be integrated with reading and writing. They all felt that learning vocabulary and grammar with reading enabled them to know better how to use the vocabulary and grammar correctly and appropriately. Student A 's description was cited as a good example to support this. In replying to the question "Which is a better way to acquire vocabulary and grammar?", she stated:

In the first two years in China, I mainly learned vocabulary from the word lists of our Intensive Course Textbooks. As for grammar, I chiefly 
learned it from a grammar textbook entitled "A Handbook of English Grammar" by Bo Bing. We started with parts of speech, then went on to learn tenses, voice, subjunctive mood, non-infinitive verbs, finally proceeded to complex sentences. In class, the teacher explicitly explained grammar rules and illustrated with some examples. Then we were required to learn by heart the grammar rules and given some worksheets to practice after class. The exercises were mostly in the form of sentences focusing on a specific grammar point. At that time, it occurred to me that learning English was equivalent to memorizing grammar rules. Trained in this way, I found that I knew all the grammar rules and was also able to do good jobs in grammar tests, but when it came to English writing, I still made a lot of syntactic errors. Not until I came to study in the United States did I realize that it was far from enough to merely memorize vocabulary and grammar rules. The most important thing is that you need to know how to use them in a correct and appropriate manner. To this end, you have to be exposed to authentic materials. The benefit of doing this is to enable you to familiarize yourself with how vocabulary and grammar are used in context and acquire models of the target language. Imitating good models of the target language from books and magazines is a good way to express yourself in an authentic way, thus minimizing Chinglish expressions. After about two years' study in the United States, it dawns on me that good English writing is more than a large vocabulary and a lot of grammatical knowledge put together. What counts most is you need to know how to use them correctly and appropriately to express your ideas. To know how to use vocabulary and grammar correctly and appropriately, you have to learn them in context, i.e. reading authentic materials or communicating with native speakers. My suggestion for EFL students in China is: Don't learn words and grammar in isolation. Associate them with your reading and writing! 
The analysis of the data of the interviews from both sub-studies demonstrates that although a few interviewees felt that the explicit learning of vocabulary and grammar benefited in some ways, most interviewees favor the integration of vocabulary and grammar with reading and writing because they feel that learning vocabulary and grammar in discourse is a good way to minimize Chinglish expressions in their writing. This finding lends support to Krashen's (1989) view that acquiring vocabulary through massive reading for pleasure is more effective than learning words through purposeful vocabulary exercises. It also resonates with Martinsen's (2000) conclusion that that in L2 instruction, it is more effective to learn vocabulary and grammar in context.

\section{Effectiveness of Positive Corrective Feedback}

The findings of the study demonstrate that the students preferred positive corrective feedback to negative feedback and indirect feedback to direct feedback. Most interviewees from the EG reported that marking only good sentences and shining points in their compositions was really a stimulus to their writing. It was a great encouragement to them to see the teacher highlighting their shining points in their compositions instead of correcting each and every semantic or syntactic error in red. Previously, they were scared of reading the teacher's feedback or comments. Now they enjoyed reading the teacher's feedback or comments. They felt that the teacher's positive feedback let them see their "shining points" and recognize their "strengths in some ways", thus arousing their enthusiasm and enhancing their confidence. Student 8 recounted this way, "What I like most about the new teaching model is the way the teacher provides feedback and comments about our compositions. In high school and my first year in college, I was 
always scared of reading the teachers' feedback or comments on my English compositions. Every time I was given back my composition, I always found it full of the teacher's corrective feedback and comments in red. I always felt frustrated and sad because of so many grammatical mistakes that I had made in my composition. I doubted if I was able to write well in English. Sometimes the teacher felt angry and disappointed too because I made the same mistakes over and over again. It occurred to me that some corrective feedback was beyond my understanding at that time. By contrast, with the new teaching model, the teacher marks good points, including good sentences and good ideas instead of focusing on correcting each and every grammatical mistakes. What I also enjoy is that the teacher underlines five to eight grammatical errors that she thinks that could be avoided in the second year in college and encourages us to self-correct them. I feel I better understand why and where I made the mistakes and can avoid the same mistakes in the future. Another thing that I like is the teacher's in-class comments about one or two exemplary compositions. This way, I can see the gap between mine and my peers'."

In comparison with the students from the EG, the five students in the joint program reported that the professors in the US seldom corrected their syntactic errors as the EFL teachers did in China; instead they paid more attention to ideas, especially their own ideas. The professors often provided both positive and suggestive feedback. They focused on ideas, details and organization and suggested using simple and short sentences to express ideas clearly. One way they found helpful was rubric, which could serve as a guide for their writing. In addition, they all spoke highly of peer preview and tutoring with the Writing Help Center. 
These findings of this study concerning corrective feedback support that of the study by Cleary (1990) that the key to positive feedback is clear communication in which the teacher genuinely communicates his/her feedback in students' ability to do good work. Prolonged negative feedback, however, has a detrimental effect on writers' confidence and motivation. In addition, these findings may also provide evidence in support of my assumption that English writing is not always a pleasant experience for students, who tend to have a stronger desire for encouragement than for criticisms and one way to satisfy this psychological need is to provide positive feedbacks by highlighting good points in their compositions.

\section{Motivating Students to Write}

Writing is considered one of the most difficult skills that L2 learners are expected to acquire, requiring the mastery of a variety of linguistic, cognitive, and sociocultural competences (Barkaoui, 2007). To help students attain proficiency in L2 writing, motivating students to write frequently and automatically is an important task faced with EFL/ESL teachers. As Hyland (2003) emphasizes, teachers need to attend to both cognitive and motivational factors in the L2 writing classroom. Motivational/affective factors can include learners' beliefs about the nature and importance of writing, the differences between L1 and L2, their attitude to the L2, and about their writing competence, which in turn influence learners' engagement, effort, and learning in the L2 writing classroom (Dornyei, 2001). Teachers need to be aware of these affective factors and to help their students become more motivated. 
The findings of the study show that following the 5-month training with the new teaching model, the students' attitude toward EFL writing changed. They felt that writing was not so hard as they imagined; writing was becoming more fun and enjoyable; writing was a pleasure of expressing their life experiences, feelings and opinions. As they were motivated to write frequently, they were able to write at length, thus developing a sense of achievement and enhancing their confidence in writing. In time, they wanted to write instead of needing to write. The students' positive attitudes towards writing attribute to the strategies adopted in the new teaching model. First, the scoring scheme changed the way of the teacher corrective feedback. The teacher did not correct each and every syntactic error the student made. Instead, the teacher only marked good and shining points and good expressions. This practice "helps students see themselves as successful writers by providing them with positive experiences with writing activities; emphasizing that they can be successful in these activities through their own efforts; praising them on work well done; and helping them start seeing them as writers, rather than as students, who can get things done with written discourse" (Williams, 2003, p. 121). The teacher's in-class comments on students' exemplary works help ensure a pleasant and supportive atmosphere in the classroom where the students can feel safe and trusting. Designing appropriate tasks and selecting teaching materials takes the different backgrounds, experiences, and expectations that students bring to the writing classroom into account, thus making writing meaningful, relevant, and varied in terms of content and genre. Writing at length and encouraging students to imitate good expressions from their 
readings stimulate the students to read extensively and help them broaden their horizons and get models of the target language.

\section{Contextualizing Writing Practices}

Contextualization is viewed as a form of deep learning which happens through linking ideas and concepts across courses (Moltz, 2010). As far as language teaching is concerned, it refers to placing the target language in a realistic setting to make the learning process meaningful to students. Ellis (1994) asserted the effectiveness of contextualized tasks, implying that contextualization strategies work better for those learners who possess a fair level of second language knowledge. Mayer (2003) declared that contextualization plays a major role in instructional methods. Contextualization is generally divided into two types. The first type is on basic skills like reading and writing (Perin, 2011). It is also used in discipline area instruction without any focus on basic skills. Teachers present authentic materials related to the topics being taught to deepen domain knowledge (Cammarata, 2009). The second type is on problem-based learning in real life situations (Perin, 2011).

The findings of this study reveal that there exist major differences between writing in Chinese and writing in English. These differences are mainly reflected in three major areas: semantic, syntactic and cultural. As can be seen from the data in Tables 10, 11 and 12, the students in the CG and the five students in the first two years in China acquired vocabulary from word lists and grammar from a grammar textbook. Teaching and learning of writing were mainly test-oriented. As accuracy and appropriate forms are emphasized in the test, the students had to learn to write step by step guided by the 
textbook and the teacher had to correct each and every grammatical error.

Decontextualized writing practices in the writing classroom and insufficient input of authentic materials led to the negative transfer of the students' mother tongue in English writing, resulting in plentiful Chinglish expressions. By contrast, the students in the EG and the five students in the last two years in the US read extensively and wrote frequently. They acquired vocabulary and grammar in association with reading. They considered writing to be an important tool or skill for communication and academic pursuit. Taking simulation tests was on longer their focus of writing practices. Byram (1997) and Kramsch (2001) asserted that acquiring a new language means the manipulation of syntax, lexicon and culture. For EFL students, a good manipulation of syntax, lexicon and culture requires a good understanding of the differences between Chinese language and English language. To this end, EFL students have to be sufficiently exposed to authentic materials to obtain models of the target language and understand Westerners' thought patterns and English writing styles. The findings of this study align with the principle of constructivism about authentic learning that the problem and the situation should not be decontextualized since context provides necessary and relevant information for the learner to understand and construct his/her knowledge; for decontextualized knowledge does not give us the skills to apply our understandings to authentic tasks. The findings also support Brown, Collins and Duguid's (1989) assertion that knowing is inseparable from doing, and all knowledge is situated in activity bound to social, cultural and physical contexts. The findings of the study suggest that contextualization of writing practices is an indispensable part of writing instruction. 


\section{Situated in Larger Context}

The findings of the study show that following a 5-month training with the new teaching model, the experimental group improved significantly more than the control group with respect to English writing, indicating that adding context to EFL teaching and learning created positive writing outcomes for EFL students. In addition, the results of this study also demonstrate that the Chinglish phenomenon was related to decontextualized EFL writing practices and thought patterns resulting from culture. As the study lasted only about five months and the sampling was relatively small, two aspects need to be taken into consideration for future research into this topic. These two aspects will involve the continuation of the Write-to-learn Model and the impact of different mindsets on writing.

First, as has been noted in Chapter 3, a new teaching model called the Write-to-learn Model, was used in this study. This new teaching model, based on my context-based conceptual framework, places a focus on the contextualization of EFL writing practices. It aims to help learners improve their L2 English writing proficiency through reading authentic materials extensively and writing as long as their current level of L2 proficiency allows. Although it lasted about five months, Sub-study 1 showed positive results in favor of this new approach. However, this approach has still left some questions unanswered such as: Is the Write-to-learn Model effective with students preparing for CETB-4/6 tests? Are those better able to write at length good at writing short essays or compositions as well? Is the Write-to-learn Model more effective with learners of low writing proficiency than learners of high writing proficiency or the other way round? 
These questions are empirical issues that require further investigations and answers to them will undoubtedly contribute to a better understanding and more effective use of the Write-tolearn Model.

Second, future research should also be expanded to include the impact of different mindsets on thought patterns. As has been discussed in Chapter 4, the five students in the joint program noted that an important aspect that had a great impact on their English writing was culture. They were of the opinion that Chinese culture was the main cause of the Chinglish phenomenon because culture decided people's mindsets and thought patterns. To minimize or avoid Chinglish, it was of great importance for English learners to understand westerners' mindsets and thinking modes by frequently communicating with native speakers and extensively reading English books, magazines or newspapers in the original. It seems that very few empirical studies have been conducted to explore this issue so far. Further research into this empirical issue will lead to a better understanding of how Chinese culture impacts students' EFL writing.

\section{Implications}

To date, quite a few studies have theoretically touched upon the impact of context on EFL writing, but few empirical studies of contextualizing EFL writing within a new teaching model have been conducted in China. Therefore, this study has implications for EFL language education in China as well as in other EFL contexts. This section discusses implications of my study within the writing context in EFL education.

The findings of this study reveal that the problems and challenges of China's EFL writing instruction were related to the decontextualization of EFL writing practices. For 
EFL students to minimize Chinglish expressions and improve their comprehensive English writing, writing practices in the EFL classroom need to be contextualized. To this end, the following recommendations are made.

\section{Recommendations for EFL Policymakers}

1. As the College English Syllabus adopts the same requirements nationwide and, to some extent, fails to take into consideration the actual situations of different universities and colleges, some universities and colleges may find it hard to implement this policy. This policy ought to consider the specific situations of different universities and colleges, and adopts more flexible standards. Therefore, a more general, open-ended, and abstract EFL policy should be formulated to offer local colleges and universities and teachers some flexibility and autonomy.

2. The CET should not be used as the sole test to evaluate students' English proficiency. The CET ought to be designed to check students' ability to apply the English language to avoid the phenomenon of "high grade but low ability".

3. EFL teaching and learning should not be limited to the required textbooks only. More authentic materials should be used and students should be encouraged to read more English books in the original so that EFL teaching and learning take place in context.

\section{Recommendations for Administrators}

1. Students' pass rate of the CET is not to be used as the sole criterion for evaluating EFL teachers' teaching and academic achievement. Other evaluation mechanisms 
should be introduced to assess an EFL teacher's professional level and academic achievement in a more comprehensive manner.

2. Since reading is considered a prerequisite for writing, and reading is closely connected with writing, reading and writing should not be taught and learned separately. It is necessary that a curriculum be worked out that includes the development of reading and writing skills.

3. EFL teachers should be given more autonomy in terms of the use of teaching materials and the choice of teaching methods. Teachers are encouraged to adopt an eclectic range of methods that represent different learning perspectives, accommodating their practices to the constraints of their teaching situations and their beliefs about how their students learn to write.

\section{Recommendations for EFL Teachers}

1. It is essential that EFL teachers adopt a teaching approach that can help students become more competent L2 writers by describing and modeling for them the processes and strategies that underlie effective writing, encouraging them to read extensively, motivating them to write frequently and automatically and providing them with appropriate feedback on their performance until they are able to apply these processes and strategies independently and flexibly.

2. It may be hard to situate everything in a way that the five students in the joint program do in the United States. In spite of this, the findings of this study show that sufficient exposure to authentic materials is a remedy to contextualize the acquisition of vocabulary and grammar and familiarize themselves with English writing patterns 
and styles. Therefore, it is necessary and important for EFL teachers to contextualize their writing practices in EFL classes.

3. In terms of vocabulary acquisition, it is not enough for EFL students to acquire vocabulary from the word lists of the textbooks. EFL teachers should provide their students with as many opportunities as possible to be exposed to authentic materials, including newspapers, magazines and books so as to associate vocabulary acquisition with reading.

4. Since implicit instruction of grammar is more effective than explicit instruction of grammar, it is far from enough for students to merely memorize grammar rules and take simulation tests. The focus of grammar instruction is to be placed on helping students understand rules and transfer their grammatical knowledge to application in English writing. Accordingly, it is necessary to integrate grammar instruction with reading and writing.

5. The findings of this study show that EFL writing is part of cultural experiences. Different cultures lead to different thought patterns and different thought patterns result in differences between writing in Chinese and writing in English. In view of this, it is imperative to include a culture integrated course in China's EFL curriculums so as to acquaint students with the Western mindset and make the paradigm shift consciously in the process of writing in English. To achieve this, three aspects need to be taken into consideration:

1) Develop students' cross-cultural awareness. EFL teachers can include culture related content in reading to enable students to understand the differences 
between writing in English and writing in Chinese to improve their crosscultural awareness and cultivate their English cultural sensitivity, thus minimizing or avoiding the impact of Chinese thinking in English writing process.

2) As different modes of thought result in different writing styles, it is necessary that in addition to providing authentic materials for students, EFL teachers help students understand the differences between writing in Chinese and writing in English. To this end, EFL teachers can train students to develop English essay writing skills through extensive reading and detailed analysis of English discourse and writing styles. Well acquainted with the mindsets of Westerners and English writing characteristics, EFL students will be able to write more effectively in L2.

3) Characterized by dialectical thinking, Chinese students tend to write essays or theses with agreeing in opinion, lacking conjunctions between sentences and/or paragraphs. This Chinglish writing style often give readers a jumping and incoherent sense as to what is written. To help students solve this problem, ELF teachers should train their students to use appropriate conjunctions to express their ideas in a logical way. To do this, students will familiarize themselves with different functions of conjunctions, such as progressive, enumeration, transition, contrast, degree, causal relation, summary, analysis and conclusion. 


\section{Conclusions}

The current study examined how Chinese EFL college students respond to changes in their writing instruction that pays attention to the context of EFL teaching and learning. By using the mixed methods approach, I conducted the study by engaging two classes of second-year undergraduate students from a university in China and five Chinese students studying in a joint program in a university in the United States. A new teaching model, based on my context-based conceptual framework, was used with the EG in Sub-study 1. The major findings are summarized as follows.

First, the participants of the experimental group reported that adding context to the teaching and learning of writing created a positive outcome for their English writing proficiency. They noted that they had benefited a lot from the Write-to-learn Model. The biggest benefit they obtained from the new teaching model was that they were compelled to read extensively in order to write at length, the process of which helped contextualize the writing practices and also enabled them to draw upon good expressions and structures from their extensive reading. Following the 5-month training, they felt more confident in their ability to write in English, believed their English writing had improved, preferred to write outside class, and liked the approach along with its marking scheme.

As evidence to their perceptions and attitudes about their English writing improvement, the students in the EG performed all the tests numerically better than those in the $\mathrm{CG}$ and improved significantly more than the $\mathrm{CG}$ with respect to English writing. This finding was strongly supported by the results of the interviews from the five students in the joint program. All the five students felt they had made great progress in their 
English writing. The major factor contributing to their achievement in writing was the change of the learning environment, i.e. learning context.

Second, this study concludes that the Chinglish phenomenon in students' English writing was related to the differences between Chinese and English and China's on-going practices of EFL writing instruction. On one hand, there are major differences between Chinese and English in terms of semantics, syntax and discourse. Without a good manipulation of English vocabulary and grammar, linguistic patterns and rhetoric conventions from Chinese language often tend to transfer to English writing and cause interference. On the other hand, many EFL students learn English for the purpose of passing the tests. In their English learning process, EFL students rely primarily on textbooks, on which tests are based. The textbooks provide limited linguistic context in which students mainly acquire their vocabulary and grammar. In such a case, students may pass the test, but their ability to write in English is limited. They tend to resort to word to word translation of Chinese expressions or the negative transfer of their mother tongue in an attempt to produce meaningful performance, thus resulting in Chinglish expressions.

Third, this study reveals that cultures play an important role in EFL writing proficiency. For students with higher writing proficiency like the five students in the joint program in Sub-study 2, the main problem with their English writing seems to be more related to culture instead of vocabulary, grammar and discourse. Different cultures lead to differences between writing in Chinese and writing in English and different cultures give rise to different mindsets and thought patterns. In order to write well in English, EFL 
students need to understand westerners' mindsets and thought patterns. The experiences of the five students show that adequate comprehensible input of authentic materials provide an effective way to understand English native speakers' mindsets and thought patterns and a good remedy to provide linguistic, situational and cultural contexts where vocabulary, grammar, discourse and writing styles are used appropriately. 


\section{References}

Ackerman, E. (1996). Perspective-taking and object construction: Two keys to learning. In Y. Kafai \& M. Resnick (Eds.), Constructionism in practice: Designing, thinking, and learning in a digital world, pp. 25-35. Mahwah, NJ: Lawrence Earbaum Associates.

Alreck, P. L., \& Settle, R. B. (1995). The survey research handbook (2nd ed.). Chicago, IL: Irwin.

Anderson, J., Reder, L., \& Simon, H. (1996). Situated learning and education. Educational Researcher, 25(4), 5-11.

Attride-Stirling, J. (2001). Thematic networks: An analytic tool for qualitative research. Qualitative Research, 1(3), 385-405.

Bada, E. (2000). Culture in ELT. Cukurova University Journal of Social Sciences, (6), 100-110.

Bandura, A. (1986). Social foundations of thought and action: A social cognitive theory. Mahwah, NJ: Prentice-Hall, Inc.

Barkaoui, K. (2007). Teaching writing to second language learners: Insights from theory and research. TESL Reporter, 40(1), 35-48.

Bauersfeld, H. (1995). Language games in the mathematics classroom: Their function and their effects. In P. Cobb \& H. Bauersfeld (Eds.), The emergence of mathematical meaning: Interaction in classroom cultures, pp. 211-292. Hillsdale, NJ: Lawrence Erlbaum. 
Bekalo, S., \& Welford, G. (2000). Practical activity in Ethiopian secondary physical sciences: Implications for policy and practice of the match between the intended and the implemented curriculum. Research Papers in Education, 15(2), 185-212.

Biggs, J. (1998). Learning from the Confucian Heritage: So size doesn't matter? International Journal of Educational Research, 29(8), 723-738.

Blau, S. (1991). Thinking and the liberation of attention: The uses of free and invisible writing. In P. Belanoff, P. Elbow, \& S. I. Fontaine (Eds.), Nothing begins with N, pp. 283-299. Carbondale, IL: Southern Illinois University Press.

Bright, J., \& McGregor, G. (1970). Teaching English as a second language. London: Longman.

Brown, H. (1980). The optimal distance model of second language acquisition. TESOL Quarterly, (14), 157-164.

Brown, J. S., Collins, A., \& Duguid, P. (1989). Situated cognition and the culture of learning. Educational Researcher, 18(1), 32-42.

Bruner, J. S. (1978). The role of dialogue in language acquisition. In A. Sinclair, R. J. Jarvella, \&W. J. M. Levelt (Eds.), The Child's Conception of Language, pp. 241-256. New York, NY: Springer-Verlag.

Burkland, J., \& Grimm, N. (1984). Students' response to our response. Paper presented at the conference on College Composition and Communication, New York, NY.

Burns, A. (1999). Collaborative action research for English language teachers. Cambridge: CUP. 
Byram, M. (1997). Cultural studies and foreign language teaching. In Bassnett, S. (Ed.), pp. 53-65, Studying British Cultures. An Introduction. London: Routledge.

Byrd, P., \& Reid, J. (1998). Grammar in the composition classroom. Boston, MA: Heinle \& Heinle.

Campbell, C. (1998). Teaching second-language writing: Interacting with text. Boston, MA: Heinle \& Heinle.

Cammarata, L. (2009). Negotiating curricular transitions: Foreign language teachers’ learning experience with content-based instruction. The Canadian Modern Language Review, 65(4), 559-585.

CET Committee. (1999). The principles in designing the CETs. Shanghai: Shanghai Foreign Language Education Press.

Chandler, J. (2003). The efficacy of various kinds of error feedback for improvement in the accuracy and fluency of L2 student writing. Journal of Second Language Writing, (12), 267-296.

Chaudron, C. (1984). The effects of feedback on students' composition revisions. RELC Journal, (15), 1-15.

Chaudron, C. (1985). Intake: On methods and models for discovering learners' processing of input. Studies in Second Language Acquisition, (7), 1-14.

Chen, G. (2009). Foundation of intercultural communication. Shanghai: North-East China Normal University Press.

Chen, J. (2005). The research of English study in China. Beijing: Higher Education Press. 
Chlopek, Z. (2008). The intercultural approach to EFL teaching and learning. English Teaching Forum, (9), 19-27.

Chomsky, N. (1959). Review of verbal behavior by B. F. Skinner. Language, (1), 1-10. Chomsky, N. (1965). Aspects of the Theory of Syntax. Cambridge, MA: MIT Press.

Chomsky, N. (1966). Topics in the theory of generative grammar. The Hague: Mouton. Cleary, L. (1990). The fragile inclination to write: Praise and criticism in the classroom, English Journal, 79(2), 22-28.

College English Curriculum Requirements (for trial implementation). (2004). Shanghai: Shanghai Foreign Language Education Press.

College English Teaching Syllabus (for trial implementation). (1979). Shanghai:

Shanghai Foreign Language Education Press.

College English Teaching Syllabus. (1986). Shanghai: Shanghai Foreign Language

Education Press.

College English Syllabus Revision Team. (1999). College English syllabus. Beijing: Higher Education Press.

Connelly, F. M., \& Lantz, O. C. (1991). Definitions of curriculum: An introduction. In A. Lewy (Ed.), The international encyclopaedia of curriculum, pp. 15-18. New York, NY: Pergamon Press.

Corder, S. (1967). The significance of learners' errors. IRAL, (5), 161-170.

Cortes, V. (2004). Lexical bundles in published and student disciplinary writing: Examples from history and biology. English for Specific Purposes, (23), 397-423. 
Coxhead, A., \& Byrd, P. (2007). Preparing writing teachers to teach the vocabulary and grammar of academic prose. Journal of Second Language Writing, (16), 129-147.

Creswell, J. W. (2003). Research design: Qualitative, quantitative, and mixed methods approaches (2nd ed.). Thousand Oaks, CA: Sage Publications.

Creswell, J. W. (2009). Research design: Qualitative and quantitative approaches (3rd ed.). London: SAGE Publication.

Cumming, A. (2001). Learning to write in a second language: Two decades of research. International Journal of English Studies, 1(2), 1-23.

Demirezen, M. (1988). Behaviorist Theory and Language Learning. Retrieved 15, 2012, from http://www.efdergi.hacettepe.edu.tr/19883MEHMET\%20DEM\%C4\% B0REZEN.pdf.

Deng, Y. (1997). Language and Culture. Beijing: Foreign Language Teaching \& Research Press.

Di Vesta, F. (1987). The cognitive movement and education. In J. A. Glover \& R. R. Ronning (Eds.), Historical Foundations of Educational Psychology, pp. 203-233. New York, NY: Plenum Press.

Dodd, C. H. (1997). Dynamics of intercultural communication. McGraw-Hill Humanities. Dohrer, G. (1991). Do teachers' comments on students' papers help? College Teaching, (39), 48-54.

Dornyei, Z. (2001). Teaching and researching motivation. New York, NY: Longman. Duffy, T., \& Jonassen, D. (1992). Constructivism and the technology of instruction: A conversation. Mahwah, NJ: Lawrence Erlbaum Associates. 
Elbow, P. (1993). The war between reading and writing - and how to end it. Rhetoric Review (12), 5-24.

Ellis, R. (1985). Understanding second language. Oxford: Oxford University Press.

Ellis, R. (1994). The study of second language acquisition. Oxford: Oxford University Press.

Enginarlar, H. (1993). Student response to teacher feedback in EFL writing. System, (21), 193-204.

Ermma, B., \& Warren, B. (2000). The idiom principle and the open-choice principle. Text, (20), 29-62.

Esmaeili, H. (2002). Integrating reading and writing tasks and ESL students' reading and writing performance in an English test. The Canadian Modern Language Review, $58(4), 600-621$.

Feilzer, M. Y. (2010). Doing mixed methods research pragmatically: Implications for the rediscovery of pragmatism as a research paradigm. Journal of Mixed Methods Research, (4), 6-16.

Ferris, D. (1997). The influence of teacher commentary on student revision. TESOL Quarterly, (31), 315-339.

Ferris, D. (2003). Response to Student Writing: Implications for Second Language Students. Mahwah, NJ: Lawrence Erlbaum Associates.

Ferris, D., \& Hedgecook, J. (1998). Teaching ESL composition: Purpose, process, and practice. Mahwah, NJ: Lawrence Erlbaum Associates. 
Ferris, D., \& Roberts, B. (2001). Error feedback in L2 writing classes: how explicit does it need to be? Journal of Second Language Writing, (10), 161-184.

Field, A. (2011). Discovering statistics using SPSS (3rd ed.). Thousand Oaks, CA: SAGE Publications Ltd.

Fink, A. (2002). How to design survey studies (2nd ed.). Thousand Oaks, CA: Sage Publications.

Flower, L., \& Hayes, J. (1981). A cognitive process theory of writing. College Composition and Communication, 32(4), 365-87.

Fosnot, C.T. (1996). Constructivism: Theory, perspectives, and practice. New York, NY: Teachers College Press.

Fox, R. (2001). Constructivism examined. Oxford Review of Education, 27(1), 23-35.

Frantzen, D. (1995). The effects of grammar supplementation on written accuracy in an intermediate Spanish content course. Modern Language Journal, 79(3), 329-55.

Flick, U. (2006). An introduction to qualitative research. London: Sage.

Frodesen, J., \& Holten, C. (2003). Grammar and the ESL writing class. In B. Kroll (Ed.), Exploring the dynamics of second language writing, pp. 141-161. New York, NY: Cambridge University Press.

Gass, S. (1997). Input, interaction, and the second language learner. Mahwah, NJ: Lawrence Elrbaum.

Goodwin, C., \& Duranti, A. (1992). Rethinking context: Language as an interactive phenomenon. Cambridge: Cambridge University Press. 
Gorsuch, G. J. (2000). EFL educational policies and educational cultures: Influences on teachers' approval of communicative activities. TESOL Quarterly, 34(4), 675-710.

Gray, G., \& Guppy, N. (1999). Successful surveys: Research methods and practices (2nd ed.). Toronto: Harcourt Brace Canada.

Gu, X. (2005). Positive or negative? An empirical study of CET washback on college English teaching and learning in China. Unpublished PhD dissertation, Shanghai Jiaotong University, Shanghai, China.

Guba, E. G. (1990). The alternative paradigm dialog. InE. G. Guba (Ed.), The paradigm dialog, pp. 17-30. Newbury Park, CA: Sage.

Guba, E. G., \& Lincoln, Y.S. (1981). Effective evaluation. San Francisco, CA: JosseyBass.

Guiora, A., Beit-Hallahmi, B., Brannon, R., Duff, C., \& Scovel, T. (1972). The effects of experimentally induced changes in ego states on pronunciation ability in a second language: An exploratory study. Comprehensive Psychiatry, (13), 421-428.

Gumperz, J. (1982). Language and social identity. Cambridge: Cambridge University Press.

Harmer, J. (1991). The Practice of English language teaching. London: Longman.

Harmer, J. (2004). How to teach writing. Harlow, UK: Pearson Education.

Han, Y. (2005). Teaching writing in Chinese as mother tongue. InM. Shum \& D. Zhang (Eds.). Teaching writing in Chinese speaking areas, pp. 47-64. New York, NY:

Springer. 
Hill, W. F. (2002). Learning: A survey of psychological interpretation. Boston, MA:

Allyn \& Bacon.

Hitz, R., \& Discroll, A. (1989). Praise in the classroom. Eric Digest (ED313108). ERIC Clearinghouse on Elementary and Early Childhood Education Urbana IL. Retrieved April 24, 2007 fromhttp://www.ericdigests.org/pre-9213/praise.htm.

Holdaway, D. (1979). The foundations of literacy. Sydney: Ashton Scholastic.

Horowitz, D. (1986). What professors actually require: Academic tasks for the ESL classroom. TESOL Quarterly, 20(3), 445-482.

Hu, G. (2005). English language education in China: policies, progress, and problems. Journal Language Policy, 4(1), 5-24.

Huang, L. \& Wang, x. (2011). The influence of the different thinking patterns between Chinese and English on English writing. Theory and Practice in Language Studies, 1(4), 390-394.

Hutchinson, T., \& Torres, E. (1994). The textbook as agent of change. English Language Teaching Journal, 48(4), 315-328.

Hyland, K. (2003). Second language writing. Cambridge: Cambridge University Press. Hyland, K. (2007). Genre pedagogy: Language, literacy and L2 writing instruction. Journal of Second Language Writing, (16), 148-164.

Hymes, D. H. (1974). Foundations of sociolinguistics: An ethnographic approach. Philadelphia, PA: University of Pennsylvania.

Jin, L. X., \& Cortazzi, M. (1998). Dimensions of dialogue: large classes in China. International Journal of Educational Research, (29), 739-761. 
Johnson, B., Onwuegbuzie, A., \& Turner, L. (2007). Toward a definition of mixed methods research. Journal of Mixed Methods Research, (1), 112-133.

Judd, E. L. (1978). Vocabulary teaching and TESOL: A need for reevaluation of existing assumptions. TESOL Quarterly, 12(1), 71-76.

Kaplan, P. (1996). Cultural thought patterns in intercultural education. Language Learning, (16), 1-20.

Kitao, K. (2000). Teaching culture in foreign language instruction in the Unites States. Online documents at URL http://ilc2.doshisha.ac.jp/users/kkitao/library/article/ culture.htm.

Kramsch, C. (2001). Language and culture. Oxford: Oxford University Press.

Krashen, S. (1982). Principles and practice in second language acquisition. Oxford: Pergamon.

Krashen, S. (1985). The input hypothesis: Issues and implications. New York, NY: Longman.

Krashen, S. (1989). We acquire vocabulary and spelling by reading: Additional evidence for the input hypothesis. The Modern Language Journal, 73(4), 440-464.

Krathwohl, D. (2009). Methods of educational and social science research (3rd ed.). Long Grove, IL: Waveland Press, Inc.

Laufer, B., \& Nation, P. (1995). Vocabulary size and use: Lexical richness in L2 written production. Applied Linguistics, (16), 307-322.

Lave, J. (1988). Cognition in practice: Mind, mathematics, and culture in everyday life. Cambridge: Cambridge University Press. 
Lee, I. (2000). Exploring reading-writing connections through a pedagogical focus on coherence. The Canadian Modern Language Review, 57(2), 354-355.

Leki, I. (1990). Coaching from the margins: Issues in written response. In Kroll, B., (Ed.), Second language writing: research insights for the classroom, pp. 57-68, Cambridge: Cambridge University Press.

Lennberg, E. (1953). Cognition in ethnolinguistics. Language, Linguistic Society of America, 29(4), 463-471.

Li, Y., \& Curtis, A. (2010). English language assessment and the Chinese learner. New York, NY: Routledge.

Li, W. (1993). China English and Chinglish. Foreign Language Teaching and Research, (4), 18-24.

Liu, H. \& Matthews, R. (2005). Vygotsky's philosophy: Constructivism and its criticisms examined. International Education Journal, 6(3), 386-399.

Long, M. (1983). Input and second language acquisition theory. Paper presented at the Tenth University of Michigan Conference on Applied Linguistics.

Lybeck, K. (2002). Cultural identification and second language pronunciation of Americans in Norway. The Modern Language Journal, 86(2), 174-185.

McCarthy, M. (1990). Vocabulary. Oxford: Oxford University Press.

Macaro, E., \& Masterman, L. (2006). Does intensive explicit grammar instruction make all the difference? Language Teaching Research, 10(3), 297-327. 
MacQueen, K. M., \& Guest, G. (2008). An introduction to team-based qualitative research. In G. Guest \& K. M. MacQueen (Eds.), Handbook for team-based qualitative research, pp. 3-19. Lanham, MD: AltaMira Press.

Martinsen, A. (2000). The tower of Babel and the teaching of grammar: Writing instruction for a new century. English Journal, 90(1), 122-126.

Mayer, R. E. (2003). Learning and instruction. Upper Saddle River, NJ: Pearson Education.

Maxwell, J. A. (2005). Qualitative research design: An interactive approach (2nd ed.). Thousand Oaks, CA: Sage.

McDevitt, B. (2004). Negotiating the syllabus: A win-win syllabus. ELT Journal, 58(1), $3-9$.

McKay, S. (2003). Teaching English as an international language: Rethinking goals and approaches. Oxford: Oxford University Press.

Merriam, S. (1998). Qualitative research and case study applications in education. San Francisco, CA: Jossey-Bass.

Merriam, S. (2009). Qualitative research: A guide to design and implementation. San Francisco, CA: Jossey-Bass.

Mittan, R. (1989). The peer review process: Harnessing students' communicative power. In Johnson, D.H. \& Roen, D.H., (Eds.), Richness in writing: empowering ESL students, pp. 207 -219. New York, NY: Longman.

Moltz, D. (2010). Encouraging deep learning. Inside Higher Ed. Retrieved from http://www.insidehighered.com. 
Morillas, J. (2001). Developments in culture teaching theory, in García Sánchez, M. E., Present and Future Trends in TEFL, Almería, Servicio de Publicaciones de la Universidad de Almería.

Morgan, D. (2013). Integrating qualitative and quantitative methods. Thousand Oaks, CA: Sage.

Murray, D. (1985). A writer who teaches writing. Boston, MA: Houghton Mifflin.

Newman, F. M., \& Wehlage, G. G. (1993). Five standards of authentic instruction. Educational Leadership, (50), 8-12.

Nation, P. (2001). Learning vocabulary in another language. Cambridge: Cambridge University.

Nunan, D. (1989). Designing tasks for the communicative classroom. Cambridge: Cambridge University Press.

Nystrand, M. (1986). The structure of written communication: Studies in reciprocity between writers and readers. London: Academic Press.

Ochs, E. (1979). Introduction: What child language can contribute to Pragmatics. New York, NY: Academic Press.

Ochs, E. (1988). Culture and language development: Language acquisition and language socialization in a Samoan village. Cambridge: Cambridge University Press.

O’Leary, Z. (2004). The essential guide to doing research. London: Sage.

Oller, J. (1979). Cloze tests of second language proficiency and what they measure. Language Learning, 23(1),105-118. 
O’Sullivan, M. C. (2002). Reform implementation and the realities within which teachers work: A Namibian case study. Compare, 32(2), 219-237.

Oxford, R., \& Scarcella, R. C. (1994). Second language vocabulary learning among adults: State of the art in vocabulary instruction. System, (22), 231-243.

Pannucci, C., \& Wilkins, E. (2010). Identifying and avoiding bias in research. Plastic and Reconstructive Surgery, 126(2), 619-625.

Patton, M. Q. (2002). Qualitative research and evaluation methods (3rd ed). Thousand Oaks, CA: Sage.

Paulus, T. M. (1999). The effect of peer and teacher feedback on student writing. Journal of Second Language Writing, (8), 265-89.

Peacock, M. (1997). The effect of authentic materials on the motivation of EFL learners. ELT Journal, 51(2), 144-156.

Perin, D. (2011). Facilitating student learning through contextualization. CCRC working paper No. 29. Teachers College: Columbia University.

Pinker, S. (1994). The language instinct: How the mind creates language. New York, NY: Harper Perennial.

Pinkham, J. (2000). The translator's guide to Chinglish. Beijing: Foreign Language Teaching \& Research Press.

Plakans, L. (2009). The role of reading strategies in integrated L2 writing tasks. Journal of English for Academic Purposes, (8), 252-266.

Perlovsky, L. (2009). Language and cognition. Neural Networks, (22), 247-257. 
Porter, D. (1976). Modified cloze procedure: more valid re-test. English Language Teaching, (30), 151-155.

Radecki, P., \& Swales, J. (1988). ESL student reaction to written comments on their written work. System, (16), 355-365.

Reid, J. (1993). Teaching ESL writing. Eaglewood Cliffs, NJ: Prentice Hall Regents.

Reid, J. (1994). Responding to ESL students' texts: The myths of appropriation. TESOL Quarterly, (28), 273-92.

Reid, J. (2001). Writing. In: R. Carter \& D. Nunan. (Eds.). The Cambridge guide to teaching English to speakers of other languages, pp. 28-33. Cambridge: Cambridge University Press.

Richards, J. C. (1998). Beyond training: Perspectives on language teacher education. Cambridge: Cambridge University Press.

Saez, F. T. (2002). Towards interculturality through language teaching: Argumentative discourse. CAUCE, Revista de Filologia y su Didactica, (25), 103-119.

Saldana, J. (2011). The coding manual for qualitative researchers. Los Angeles, CA: Sage.

Sapsford, R., \& Jupp, V. (2006). Data collection and analysis (2nd ed.). London: SAGE.

Schell, J. W., \& Black, R. S. (1997). Situated learning: An inductive case study of a collaborative learning experience. Journal of Industrial Teacher Education, (34), 528.

Schouten-van Parreren, C. (1989). Vocabulary learning through reading: Which conditions should be met when presenting words in texts? AILA Review, (6), 75-78. 
Schumann, J. (1998). The neurobiology of affect in language. Malden, MA: Blackwell. Secondary English Syllabus. (1982). Shanghai: Shanghai Foreign Language Education Press.

Silva, T., \& Brice, C. (2004). Research in teaching writing. Annual Review of Applied Linguistics, (24), 70-106.

Silva, T. \& Matsuda. P. (2001). On Second Language Writing. Mahwah, NJ: Lawrence Erlbaum Associates.

Skinner, B. F. (1957). Verbal behavior. Englewood Cliffs, NJ: Prentice-Hall.

Skinner, B. F. (1969). Contingencies of reinforcement: A theoretical analysis. New York, NY: Appleton-Century-Crofts.

Snyder, J., Bolin, F., \& Zumwalt, K. (1992). Curriculum implementation. In P. Jackson (Ed.), Handbook of research on curriculum, pp. 402-435. New York, NY: Macmillan.

Stoller, F. (1994). The diffusion of innovations in intensive ESL programs. Applied Linguistics, 15(3), 300-327.

Tang, G. (2004). Length approach to EFL writing. Guide to English Writing, (1), 65-70. Tang, X. (2005). CET-4/6 and College English curriculum evaluation. Foreign Language Education, 26(1), 56-60.

Tashakkori, A., \& Teddlie, C. (2003). Handbook of mixed methods in social and behavioral research. London: SAGE.

Terhart, E. (2003). Constructivism and teaching: A new paradigm in general didactics? Journal of Curriculum Studies, 35(1), 25-44. 
Tribble, C. (1996). Writing. Oxford: Oxford University Press.

UNESCO. (2007). UNESCO Guidelines on Intercultural Education. Paris: UNESCO.

Vogt, W. P., Gardner, D. C, \& Haeffele, L. M. (2012). When to use what research design. New York, NY: Guilford Press.

Von Glasersfeld, E. (1989). Constructivism in education. In T. Husen \& N. Postlewaite (Eds.), International Encyclopedia of Education, pp. 162-163. Oxford: Pergamon Press.

Von Glasersfeld, E. (1995). Radical constructivism: a way of knowing and learning. London: Routledge Falmer.

Vygotsky, L. (1962). Thought and language. Cambridge, MA: MIT Press.

Vygotsky, L. (1978). Mind in society. London: Harvard University Press.

Wang, C., Niu, R., \& Zheng, X. (2000). Learning through writing. Foreign Language Teaching and Research, (3), 207-212.

Wang, E. (2003). American culture and society. Shanghai: Shanghai Foreign Language Education Press.

Wang, H. (2004). An implementation study of the English as a foreign language curriculum policies in the Chinese tertiary context. Unpublished $\mathrm{PhD}$ dissertation, Queen's University, Kingston, Ontario, Canada.

Wang, J. (2007). The college English test in China: challenges and suggestions. Asian Journal of English Language Teaching, (17), 137-144.

Wang, W. (2010). Evaluation on washback effects of College English Test Band 4. SinoUS English Teaching, 7(2), 35-40. 
Wang, Y. (1999). College English in China. English Today, 15(1), 45-51.

Watson, J. B. (1924). Behaviorism. Tucson, AZ: WEST Press.

Wertsch, J. V. (1997). Vygotsky and the formation of the mind. Cambridge: Cambridge University Press.

Widdowson, H. (1990). Aspects of language teaching. Oxford: Oxford University Press.

Wilkins, D. (1972). Linguistics in language teaching. London: Hodder \& Stoughton Educational.

Williams, J. D. (2003). Preparing to teach writing: Research, theory, and practice (3rd ed.). Mahwah, NJ: Lawrence Erlbaum.

Wilson, B., \& Myers, M. (2000). Situated cognition in theoretical and practical context.

In D. Jonassen, \& S. Land (Eds.). Theoretical Foundations of Learning Environments, pp. 57-88. Mahwah, NJ: Lawrence Erlbaum Associates.

Wray, A. (2002). Formulaic language and the lexicon. Cambridge: Cambridge University Press.

Yan, Y. (2010). Towards an eclectic framework for teaching EFL writing in a Chinese context. US-China Education Review, 7(3), 29-33.

Yang, J. (2011 Dec. 2). US students outperform Chinese in SATs. China Daily.

Yang, Y. (2000). History of English education in China (1919-1999). Cambridge, MA: Harvard School of Education.

Yang, Z. (2005). A historical review of CET 4/6. Modern Language Journal, 18(2), 100103. 
You, X. (2004). The choice made from no choice: English writing instruction in a Chinese university. Journal of Second Language Writing, (13), 97-110.

Zamel, V. (1983). The composing processes of advanced ESL students: Six case studies. TESOL Quarterly, 17(2), 165-187.

Zhang, Y., \& Mi, Y. (2010). Another look at the language difficulties of international students. Journal of Studies in International Education, 14(4), 371-388.

Zhu, W. (2001). Interaction and feedback in mixed peer response groups. Journal of Second Language Writing, (10), 251-76.

Ziv, N. (1984). The effect of teacher comments on the writing of four college freshmen. In R. Beach, \& S. Bridwell (Eds.), New directions in composition Research, pp. 362381. New York, NY: Guilford Press. 


\section{Appendices}

\section{Appendix A}

\section{A sample text of Intensive Reading in College English Course}

\section{READING-CENTERED ACTIVITIES $\quad$ LOVE

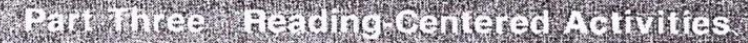

\section{A Good Heart to Lean On}

\section{Word List}

Directions: Memorize the words and phrases before class. You will benefit from your effort when you get the passage from your teacher and read it in class.

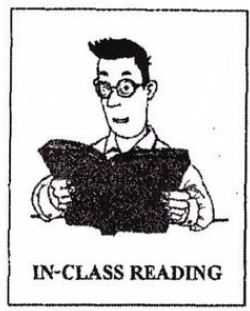

\section{New Words}

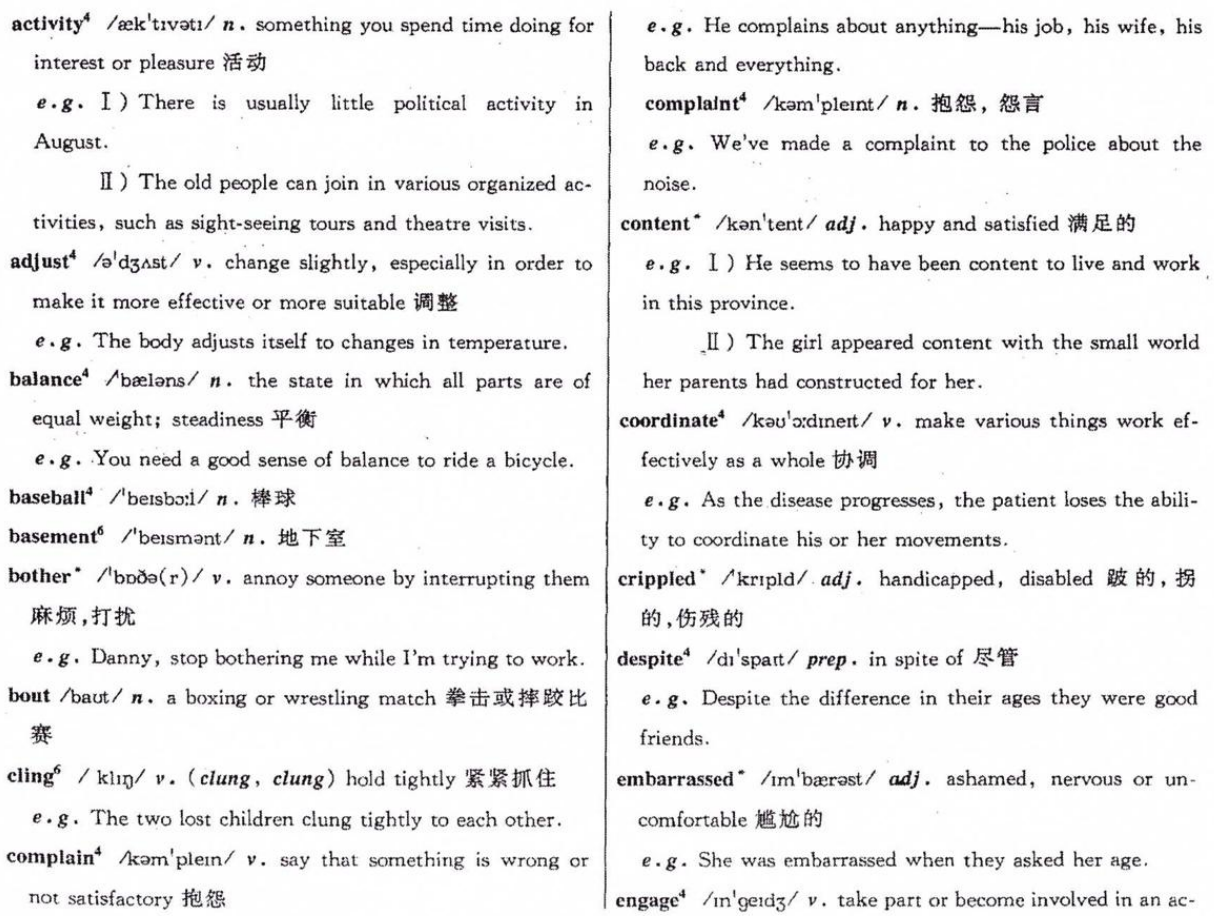




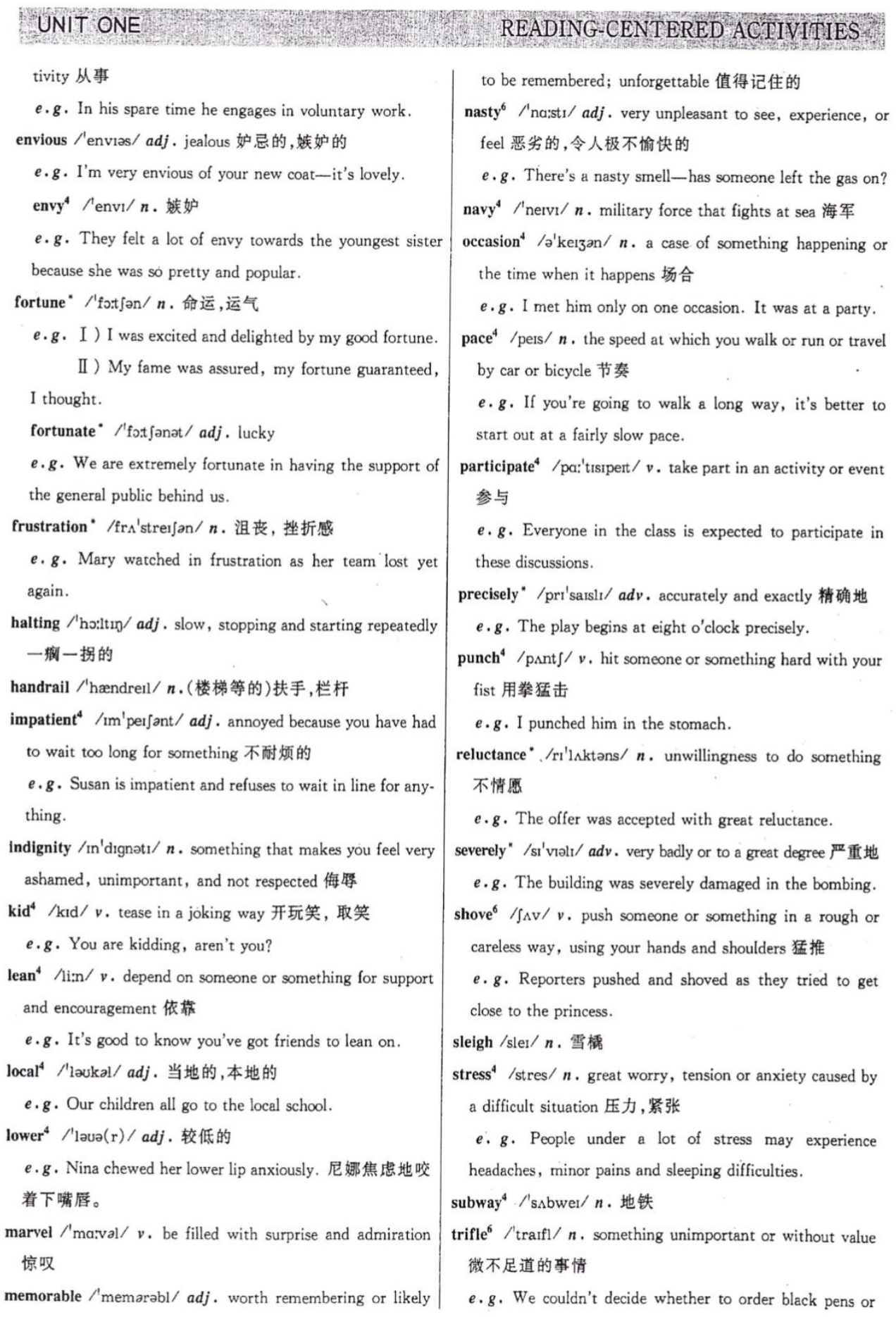




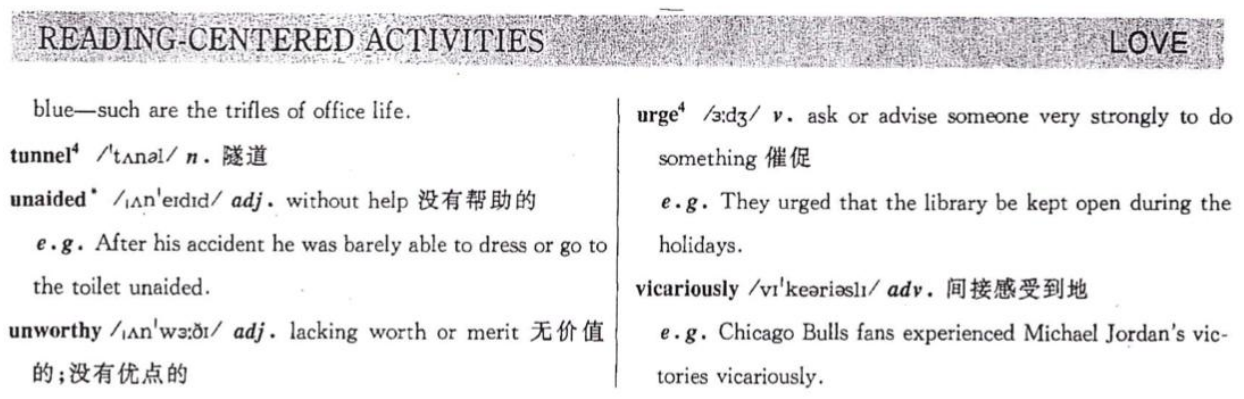

\section{Phrases and Expressions}

break out 爆发, 突然发生

$e . g$. A bad fire broke out in the supermarket.

engage in take part or become involved in an activity 从事, 参与

$e \cdot g$. If you engage in local politics, you cannot expect to have much time for your family.

let on tell someone something that was intended to be a secret; reveal 泄落秘密

$e \cdot g$. Don't let on that I told you.

make it to arrive somewhere in time for something 及时赶到

$e . g$. I just made it to the airport before the plane left.

我正好在飞机起飞之前赶到了机场。

now that 既然

$e \cdot g$. Now that dinner is ready, wash your hands.

on leave on holiday 休假

e.g. I ) He is home on leave from the Navy.

II ) He informed him that he was on sick leave from a government office.

see to it that 确保

e.g. I ) Catherine saw to it that the information went directly to Walter.

II) See to it that you are not late again.

set the pace 定速度

$e . g$. If we let the fastest runner set the pace the others will be left behind.

subject ... to make someone experience something, especially something unpleasant 使承受, 使进受

$e \cdot g$. He subjected us to a very difficult test.

\section{Pre-Reading}

Directions: Discuss the following questions in pairs.

1) How do you feel when you walk on the street and see a disabled person?

2) Do you know anyone who is disabled? If you do, talk about him/her. 


\section{Appendix B}

\section{A sample text of writing in English Writing Course}

\section{Part Three \\ The Sentence}

\section{Complete Sentences and Sentence Fragments}

A grammatically complete sentence is one that contains at least a subject and a predicate (or finite) verb; if the verb is transitive, there must be an object; if the verb is a link-verb, there must be a predicative or complement:

He came.

She wrote a letter.

Dr. Smith is a professor.

It is important to remember this basic structure of a sentence; otherwise, beginners might make sentences without a subject or a predicate verb or, both, like "Have done it," "Raining," and "How to use it?" instead of "I have done it," "It is raining," and "How do you use it?"

Attributes and adverbials, though they are not essential elements of a sentence, help to make the meaning clear or complete:

He came to the classroom very early.

She wrote a long letter to her parents.

Dr. Smith is a well-known professor of physics.

A complete sentence begins with a capital letter and ends with a period. Again, this simple rule is important for beginners to remember, for in Chinese writing commas may be used to separate complete sentences. The use of a comma in place of a period, a semicolon, a colon, or a dash in English writing is called the comma fault, which Chinese students should be on guard against.

Faulty: It was raining hard, they could not work in the fields.

Improved: It was raining hard; they could not work in the fields.

It was raining hard. They could not work in the fields.

It was raining so hard that they could not work in the fields.

They could not work in the fields because it was raining hard.

It was raining hard, so they could not work in the fields.

As it was raining hard, they could not work in the fields.

Faulty: I was born in a small town, in the town there was only one school, I studied there for six years. 
Part Three The Sentence

Improved: I was born in a small town. In it there was only one school. I studied there for six years.

In the small town where I was born, there was only one school, and I studied there for six years.

1 was born in a small town, where there was only one school. I studied there for six years.

I studied for six years at the only school in the small town where I was born.

The sentences marked "faulty" are not grammatically wrong: they are faulty because of the use of the commas. The two examples contain five short but complete sentences, each of which should have been closed with a period, or a semicolon.

It is easy to see that the improved sentences lay stress on different points. Which one is preferable depends on the context and on the writer's intention.

Here are examples with the semicolon, the colon and the dash:

Faulty: The essay is poorly organized, there is no central idea.

Improved: The essay is poorly organized: there is no central idea.

The essay is poorly organized; there is no central idea.

Faulty: There were people who would be glad to see him leave the place, he knew it.

Improved: There were people who would be glad to see him leave the place, and he knew it.

There were people who would be glad to see him leave the place-and he knew it.

Faulty: The principal of the school may do something to reduce the pupils' homework load, he may, for example, stop assigning homework for Saturday and Sunday.

Improved: The principal of the school may do something to reduce the pupils' homework load the may, for example, stop assigning homework for Saturday and Sunday.

In fiction, two short sentences closely connected in meaning are occasionally joined by a comma: in expository writing, however, the general rule is to use a period at the end of a complete sentence. whether it is long or short.

It has been said that students should make sentences that are grammatically complete and 
A Handbook of Writing 英语写作乎船

avoid making sentences without a subject or a predicate verb. But sometimes experienced writers use incomplete sentences for special effect.

It is hard to hear a new voice, as hard as it is to listen to an unknown language...

Why?-Out of fear. The world fears a new experience more than it fears anything. Because a new experience displaces so many old experiences. And it is like trying to use muscles stiff for ages. It hurts horribly.

-D. H. Lawrence

He was, I think, very handsome. I gather this from photographs and from my own memories of him, dressed in his Sunday best and on his way to preach a sermon somewhere, when I was little. Handsome, proud, and ingrown, "like a toe-nail," somebody said.

- James Baldwin

In the first passage three sentences are not complete in structure ("Why?" "Out of fear." and "Because a new experience...") and in the second one sentence ("Handsome, proud..."). We feel that these sentences are forceful: the main idea is made prominent because no other ideas are expressed. But such sentences should be used with care. One could try to use them after one has got some experience in writing.

Task 1 Read the following, point out the mistakes and make necessary corrections:

1. Our host entertained us with many interesting stories of adventure, he had been a member of an exploration team working in the Arctic.

2. When I woke up I saw him asleep in bed, I had not heard him when he came back. Because I had been sleeping soundly.

3. Liu always did his work a little better than his fellow workers, that was why he got higher pay than others.

4. No student could answer that question, even Yao, who was usually quick in answering questions, was silent.

5. Lin looks like Li, however, they are not related.

6. The old man hunched forward. His head tilted at an angle. His eyes half closed, looking very sleepy.

7. Their work was well planned, everybody worked with great enthusiasm, thus, they over fulfilled their quota.

8. Mark Twain, a well-known American writer, whose experience as a pilot on a steamboat was no doubt an important factor that helped him to become a famous writer. 


\section{Appendix C}

\section{Letter of Information and Consent Form}

\section{Letter of Information}

for

\section{Contextualization: An Experimental Model for EFL Writing Instruction in China}

I, Guimin Tang, a doctoral student at the Graduate School of Education, Portland State University in Portland, Oregon, United States, under the supervision of Dr. Yer Thao, Associate Professor in the School of Education, am inviting you to participate in the study entitled "Contextualization: an Experimental Model for EFL Writing Instruction in China." The purpose of my dissertation study is to examine how Chinese EFL college students respond to changes in their writing instruction that pays attention to the context of EFL teaching and learning.

I am inviting you to participate in an interview, which intends to explore the effect of context on EFL writing instruction in China. The interview will be arranged at a time and a location that is convenient and acceptable to you. It will be conducted in Chinese or in English (whichever you prefer) and will take about 60 minutes. Interview questions, letter of information, and consent form will be translated from English into Chinese and will be back-translated into English for verifying accuracy. With your permission, the interview may be audiotaped. I will also prepare pens and notebooks in case you feel uncomfortable to have the interview recorded. In both cases, I will send you a copy of the interview transcripts in order to insure the accuracy of the interview and to add or clarity any points that you wish. I will translate all the transcribed materials into English and Dr. Yer Thao, a faculty member at the School of Education, Portland State University will verify the English translation of the interview transcripts. Interview tapes will be erased after the dissertation is completed.

There are no known or foreseen risks in participating in this study. Your participation is entirely voluntary. You are free to choose to participate in the study. You may or may not wish to have your session audiotaped. You may withdraw from the study without reasons at any point, and you may request removal of all or part of your data. You are not obliged to answer any question that you find objectionable or that makes you feel uncomfortable. A pseudonym will replace your name on all data that you provide to protect your identity. No identification information will be included in the document. Your university will simply be identified as a university in China or a university in the USA. 
All data will be kept in a safe place and confidentiality is absolutely guaranteed. Access to the data is strictly restricted to the researcher. I will report the results of the study in my doctoral dissertation and may also report in publications of various types, conference presentations, journal articles, professional publications, and books. However, I will only report them as group data. Under no circumstance will your name be released to anyone or appear in any publication created as a result of the study.

If you want to obtain a copy of the findings of this study, you can contact me at my e-mail address: guimint@pdx.edu. or provide your email address at the bottom of the consent form in the space provided.

If you have questions about this study, please feel free to contact me, Guimin Tang at 503-828-1688 or at email: guimint@ pdx.edu. or my adviser, Dr. Yer Thao at thaoy@pdx.edu or at 503-725-8267.

\section{Consent Form}

for

\section{Contextualization: An Experimental Model for EFL Writing Instruction in China}

I have read, understood, and retained a copy of the Letter of Information concerning the study "Contextualization: an Experimental Model for EFL Writing Instruction in China." The purpose of the study is to examine how Chinese EFL college students respond to changes in their writing instruction that pays attention to the context of EFL teaching and learning in a city - Guangzhou, P. R. China. All the questions regarding the study have been sufficiently answered. I am aware that I will participate in a study. I will participate in interviews that will take about 80 minutes. I understand the purpose and data collection procedures of this study. I have been notified that my participation in this study is entirely voluntary. I may withdraw at any point during the study without any consequences to myself. I understand that I can choose to be or not to be audiotaped. I understand that I can choose not to answer any questions that I find objectionable or uncomfortable. I have been told the steps that will be taken to ensure confidentiality of all information. If I have questions about this study, I know that I am free to contact Guimin Tang at 503-828-1688 or at email: guimint@pdx.edu. For questions, concerns, or complaints about the research ethics of this study, I can also contact Dr. Yer Thao at thaoy@pdx.edu or 503-725-8267.

Participant's Name:

Signature: 
Date:

Please keep one copy of the Letter of Information and put the signed Consent Form into the envelope indicated as "Consent Form."

If you want to obtain a copy of a report of this study, please provide your e-mail address: 


\section{Appendix D}

\section{Questionnaire}

The questionnaire consists of 50 items. Each item is juxtaposed with a five-point Likert scale indicating different degrees of agreement and disagreement, with 5 standing for "strongly agree", 4 for "agree", 3 for "neutral", 2 for "disagree" and 1 for "strongly disagree".

\begin{tabular}{|c|c|c|c|c|c|}
\hline \multirow[b]{2}{*}{ 项目 } & \multicolumn{5}{|c|}{ 分值 } \\
\hline & \multicolumn{2}{|c|}{ 同意 } & \multicolumn{3}{|c|}{ 不同意 } \\
\hline $\begin{array}{l}\text { 1. 按长度、结构、内容、语言给作文分项评分使我明白自己在哪 } \\
\text { 方面不足。 }\end{array}$ & 5 & 4 & 3 & 2 & 1 \\
\hline $\begin{array}{l}\text { 2. 老师在课堂上讲评同学的优秀作文，我可以从中学到很 } \\
\text { 多东西。 }\end{array}$ & 5 & 4 & 3 & 2 & 1 \\
\hline 3. 我写完初稿之后反复修改。 & 5 & 4 & 3 & 2 & 1 \\
\hline $\begin{array}{l}\text { 4. 看到老师肯定我作文中的优点, 我写英语的兴趣就会提 } \\
\text { 高。 }\end{array}$ & 5 & 4 & 3 & 2 & 1 \\
\hline 5. 我不喜欢老师在课堂上讲评写得差的作文。 & 5 & 4 & 3 & 2 & 1 \\
\hline 6. 我不怕写英语作文。 & 5 & 4 & 3 & 2 & 1 \\
\hline 7. 我觉得我能够用英语写好作文。 & 5 & 4 & 3 & 2 & 1 \\
\hline 8. 阅读英语原版材料有助于学生用地道的英语表达思想。 & 5 & 4 & 3 & 2 & 1 \\
\hline $\begin{array}{l}\text { 9. 如果在课内写与课外写两者之间选择, 我更喜欢在课外 } \\
\text { 写作文。 }\end{array}$ & 5 & 4 & 3 & 2 & 1 \\
\hline $\begin{array}{l}\text { 10. 在批改错误与认可优点之间作选择，我宁愿老师肯定我 } \\
\text { 作文中的优点。 }\end{array}$ & 5 & 4 & 3 & 2 & 1 \\
\hline $\begin{array}{l}\text { 11. 阅读英语原版材料有助于整体提高学生英语写作的水 } \\
\text { 平。 }\end{array}$ & 5 & 4 & 3 & 2 & 1 \\
\hline $\begin{array}{l}\text { 12. 作文发回来再修改之后, 我作文的英语会比初稿要好很 } \\
\text { 多。 }\end{array}$ & 5 & 4 & 3 & 2 & 1 \\
\hline 13. 广泛阅读对提高我的写作有很大帮助。 & 5 & 4 & 3 & 2 & $\mathbf{1}$ \\
\hline 14. 我认为要提高英语水平, 必须在课外多写。 & 5 & 4 & 3 & 2 & 1 \\
\hline 15. 对我来说写长作文比写短作文困难。 & 5 & 4 & 3 & 2 & 1 \\
\hline 16. 我写英语作文最大的困难是无内容可写。 & 5 & 4 & 3 & 2 & 1 \\
\hline 17. 在批改错误与认可优点之间作选择, 我宁愿老师指出我 & 5 & 4 & 3 & 2 & 1 \\
\hline
\end{tabular}




\begin{tabular}{|c|c|c|c|c|c|}
\hline 作文中的错误。 & & & & & \\
\hline 18. 我喜欢把英语作文尽可能写长一些。 & 5 & 4 & 3 & 2 & 1 \\
\hline $\begin{array}{l}\text { 19. 我写英语作文最大的困难是不知如何用英语恰当表达意 } \\
\text { 思。 }\end{array}$ & 5 & 4 & 3 & 2 & 1 \\
\hline 20. 作文写长一些有助于我练好英语语言基本功。 & 5 & 4 & 3 & 2 & 1 \\
\hline 21. 我认为英语作文不应限字数, 而是越长越好。 & 5 & 4 & 3 & 2 & 1 \\
\hline $\begin{array}{l}\text { 22. 我希望老师带领大家在课堂上集体评论和分析学生的优 } \\
\text { 秀作文。 }\end{array}$ & 5 & 4 & 3 & 2 & 1 \\
\hline 23. 我认为按长度、结构、内容、语言分项评分明白易懂。 & 5 & 4 & 3 & 2 & 1 \\
\hline 24. 把作文长度作为评分的标准之一促使我多看书。 & 5 & 4 & 3 & 2 & 1 \\
\hline 25. 用英语写好作文我有信心。 & 5 & 4 & 3 & 2 & 1 \\
\hline 26. 我认为应该把作文长度作为评分的标准之一。 & 5 & 4 & 3 & 2 & 1 \\
\hline 27. 作文尽可能写长一些有助于打开我的思路。 & 5 & 4 & 3 & 2 & 1 \\
\hline $\begin{array}{l}\text { 28. 我认为作文发回来再修改, 英语的进步会比第一次写作 } \\
\text { 文时要大。 }\end{array}$ & 5 & 4 & 3 & 2 & 1 \\
\hline 29. 我感到写英语作文是一种乐趣。 & 5 & 4 & 3 & 2 & 1 \\
\hline 30. 我认为英语作文在课外完成比在课内完成好。 & 5 & 4 & 3 & 2 & 1 \\
\hline $\begin{array}{l}\text { 31. 课堂上听过优秀作文讲评之后再修改自己的作文, 我会 } \\
\text { 感到很有收获。 }\end{array}$ & 5 & 4 & 3 & 2 & 1 \\
\hline 32. 写长作文有助于我运用所见过的英语表达法。 & 5 & 4 & 3 & 2 & 1 \\
\hline 33. 我觉得用书面英语表达思想并不难。 & 5 & 4 & 3 & 2 & 1 \\
\hline 34. 多写长作文有助于我学好英语。 & 5 & 4 & 3 & 2 & 1 \\
\hline 35. 写长作文有助于纠正我的英语语言错误。。 & 5 & 4 & 3 & 2 & 1 \\
\hline 36. 我不喜欢老师多改我作文中的错误。 & 5 & 4 & 3 & 2 & 1 \\
\hline 37. 作文写得越长越有助于增强我使用英语的信心。 & 5 & 4 & 3 & 2 & 1 \\
\hline 38. 我感到每次把作文写长一些能够提高我的英语水平。 & 5 & 4 & 3 & 2 & 1 \\
\hline $\begin{array}{l}\text { 39. 我认为老师在课堂上讲评优秀作文会有助于提高我的英 } \\
\text { 语水平。 }\end{array}$ & 5 & 4 & 3 & 2 & 1 \\
\hline 40. 写长作文有利于我组织和表达思想内容。 & 5 & 4 & 3 & 2 & 1 \\
\hline $\begin{array}{l}\text { 41. 看到满篇作文都是老师划出的错误, 我写英语的兴趣会 } \\
\text { 降低。 }\end{array}$ & 5 & 4 & 3 & 2 & 1 \\
\hline 42. 我喜欢在课外写作文。 & 5 & 4 & 3 & 2 & 1 \\
\hline 43. 我认为应该按长度、结构、内容、语言分项评分。 & 5 & 4 & 3 & 2 & 1 \\
\hline
\end{tabular}




\begin{tabular}{|l|l|l|l|l|l|}
\hline 44. 老师给我的作文改得越细对我改进作文越有帮助。 & $\mathbf{5}$ & $\mathbf{4}$ & $\mathbf{3}$ & $\mathbf{2}$ & $\mathbf{1}$ \\
\hline 45. 我在课外写比在课堂上写更能写出好作文。 & $\mathbf{5}$ & $\mathbf{4}$ & $\mathbf{3}$ & $\mathbf{2}$ & $\mathbf{1}$ \\
\hline $\begin{array}{l}\text { 46. 每次把英语作文尽量写长一些能够增强我使用英英语 } \\
\text { 的信心。 }\end{array}$ & $\mathbf{5}$ & $\mathbf{4}$ & $\mathbf{3}$ & $\mathbf{2}$ & $\mathbf{1}$ \\
\hline $\begin{array}{l}\text { 47. 我不喜欢在写作课的当天完成老师布置的作文, 第二 } \\
\text { 天交。 }\end{array}$ & $\mathbf{5}$ & $\mathbf{4}$ & $\mathbf{3}$ & $\mathbf{2}$ & $\mathbf{1}$ \\
\hline 48. 加强英语写作训练有助于带动我听说读能力的提高。 & $\mathbf{5}$ & $\mathbf{4}$ & $\mathbf{3}$ & $\mathbf{2}$ & $\mathbf{1}$ \\
\hline 49. 我喜欢老师肯定我作文中的优点。 & $\mathbf{5}$ & $\mathbf{4}$ & $\mathbf{3}$ & $\mathbf{2}$ & $\mathbf{1}$ \\
\hline 50. 我感到很难把英语作文写长。 & $\mathbf{5}$ & $\mathbf{4}$ & $\mathbf{3}$ & $\mathbf{2}$ & $\mathbf{1}$ \\
\hline
\end{tabular}

\section{Questionnaire (English)}

\begin{tabular}{|l|c|c|c|c|c|}
\hline \multicolumn{1}{|c|}{ Item } & \multicolumn{3}{|c|}{ Score } \\
\cline { 2 - 6 } & Agree & $\mathbf{3}$ \\
\hline $\begin{array}{l}\text { 1. Scoring based on length, structure, content and language enables } \\
\text { me to understand where my weaknesses are. }\end{array}$ & $\mathbf{5}$ & $\mathbf{3}$ & $\mathbf{2}$ & $\mathbf{1}$ \\
\hline $\begin{array}{l}\text { 2. I benefit a lot from the teacher' s commenting on the good } \\
\text { compositions in class. }\end{array}$ & $\mathbf{5}$ & $\mathbf{4}$ & $\mathbf{3}$ & $\mathbf{2}$ & $\mathbf{1}$ \\
\hline 3. I keep revising the composition after finishing my first draft. & $\mathbf{5}$ & $\mathbf{4}$ & $\mathbf{3}$ & $\mathbf{2}$ & $\mathbf{1}$ \\
\hline 4. The teacher's positive feedback arouses my interest in writing. & $\mathbf{5}$ & $\mathbf{4}$ & $\mathbf{3}$ & $\mathbf{2}$ & $\mathbf{1}$ \\
\hline $\begin{array}{l}\text { 5. I don't enjoy the teacher' s commenting on poor compositions } \\
\text { in class. }\end{array}$ & $\mathbf{5}$ & $\mathbf{4}$ & $\mathbf{3}$ & $\mathbf{2}$ & $\mathbf{1}$ \\
\hline 6. I am not afraid of writing in English. & & & & \\
\hline 7. I think I am able to write well in English. & $\mathbf{5}$ & $\mathbf{3}$ & $\mathbf{2}$ & $\mathbf{1}$ \\
\hline $\begin{array}{l}\text { 8. Reading English authentic materials helps students express their } \\
\text { thoughts in an authentic manner. }\end{array}$ & $\mathbf{5}$ & $\mathbf{4}$ & $\mathbf{3}$ & $\mathbf{2}$ & $\mathbf{1}$ \\
\hline $\begin{array}{l}\text { 9. I prefer to write out of class if I can choose between writing in } \\
\text { class and writing out of class. }\end{array}$ & $\mathbf{5}$ & $\mathbf{4}$ & $\mathbf{3}$ & $\mathbf{2}$ & $\mathbf{1}$ \\
\hline $\begin{array}{l}\text { 10. I'd rather the teacher provided positive feedback if I can choose } \\
\text { between positive feedback and negative feedback. }\end{array}$ & $\mathbf{5}$ & $\mathbf{4}$ & $\mathbf{3}$ & $\mathbf{2}$ & $\mathbf{1}$ \\
\hline $\begin{array}{l}\text { 11. Sufficient exposure to authentic materials can improve students' } \\
\text { writing proficiency. }\end{array}$ & $\mathbf{5}$ & $\mathbf{4}$ & $\mathbf{3}$ & $\mathbf{2}$ & $\mathbf{1}$ \\
\hline $\begin{array}{l}\text { 12. After revising it based on the teacher's feedback, I find my } \\
\text { composition is better written than the first draft. }\end{array}$ & $\mathbf{5}$ & $\mathbf{4}$ & $\mathbf{3}$ & $\mathbf{2}$ & $\mathbf{1}$ \\
\hline
\end{tabular}




\begin{tabular}{|c|c|c|c|c|c|}
\hline 13. Reading extensively helps improve my English writing. & 5 & 4 & 3 & 2 & 1 \\
\hline $\begin{array}{l}\text { 14. I think that if I want to improve my English writing, I must } \\
\text { write often out of class. }\end{array}$ & 5 & 4 & 3 & 2 & $\mathbf{1}$ \\
\hline $\begin{array}{l}\text { 15. As for me, writing long compositions is more difficult that } \\
\text { writing short compositions. }\end{array}$ & 5 & 4 & 3 & 2 & 1 \\
\hline $\begin{array}{l}\text { 16. The biggest problem with my English writing is I have little to } \\
\text { write about. }\end{array}$ & 5 & 4 & 3 & 2 & 1 \\
\hline $\begin{array}{l}\text { 17. I'd rather the teacher pointed out my mistakes if I can choose } \\
\text { between the teacher pointing out good points and correcting } \\
\text { mistakes. }\end{array}$ & 5 & 4 & 3 & 2 & 1 \\
\hline 18. I like writing longer compositions. & 5 & 4 & 3 & 2 & 1 \\
\hline $\begin{array}{l}\text { 19. The biggest problem with my English writing is that I don't } \\
\text { know how to express myself clearly in English. }\end{array}$ & 5 & 4 & 3 & 2 & 1 \\
\hline 20. Writing longer compositions helps me practice my English skills. & 5 & 4 & 3 & 2 & 1 \\
\hline $\begin{array}{l}\text { 21. I don't think there should be a word limit to our compositions. } \\
\text { The longer we write, the better we improve our writing. }\end{array}$ & 5 & 4 & 3 & 2 & 1 \\
\hline $\begin{array}{l}\text { 22. I hope that the teacher can lead in-class discussions and analysis } \\
\text { of students' good compositions. }\end{array}$ & 5 & 4 & 3 & 2 & $\mathbf{1}$ \\
\hline $\begin{array}{l}\text { 23. I think scoring according to length, structure, content and } \\
\text { language makes a lot of sense. }\end{array}$ & 5 & 4 & 3 & 2 & 1 \\
\hline $\begin{array}{l}\text { 24. Using length as one of the scoring criteria forces me to read } \\
\text { more. }\end{array}$ & 5 & 4 & 3 & 2 & 1 \\
\hline 25. I have confidence in writing well in English. & 5 & 4 & 3 & 2 & 1 \\
\hline 26. I think length should be used as one of the scoring criteria. & 5 & 4 & 3 & 2 & 1 \\
\hline 27. Writing at length helps me broaden my horizons. & 5 & 4 & 3 & 2 & 1 \\
\hline 28. Revising my compositions helps me improve my English. & 5 & 4 & 3 & 2 & 1 \\
\hline 29. I feel it a pleasure to write in English. & 5 & 4 & 3 & 2 & 1 \\
\hline 30. I think it better to write out of class than to write in class. & 5 & 4 & 3 & 2 & 1 \\
\hline $\begin{array}{l}\text { 31. I feel I benefit greatly from in-class discussion of good } \\
\text { compositions. }\end{array}$ & 5 & 4 & 3 & 2 & 1 \\
\hline $\begin{array}{l}\text { 32. Writing at length helps me use the English expressions I have } \\
\text { learned. }\end{array}$ & 5 & 4 & 3 & 2 & $\mathbf{1}$ \\
\hline 33. I don't think it difficult to express my thoughts in written & 5 & 4 & 3 & 2 & $\mathbf{1}$ \\
\hline
\end{tabular}




\begin{tabular}{|c|c|c|c|c|c|}
\hline English. & & & & & \\
\hline 34. Writing at length frequently helps improve my English. & 5 & 4 & 3 & 2 & 1 \\
\hline 35. Writing at length helps me correct my errors. & 5 & 4 & 3 & 2 & 1 \\
\hline $\begin{array}{l}\text { 36. I don't like the teacher' s correcting mistakes in my } \\
\text { composition. }\end{array}$ & 5 & 4 & 3 & 2 & 1 \\
\hline $\begin{array}{l}\text { 37. Being able to write at length helps enhance my confidence in } \\
\text { writing in English. }\end{array}$ & 5 & 4 & 3 & 2 & 1 \\
\hline $\begin{array}{l}\text { 38. I feel whenever I am able to write longer, I can improve my } \\
\text { English in some ways. }\end{array}$ & 5 & 4 & 3 & 2 & 1 \\
\hline $\begin{array}{l}\text { 39. I think the teacher's in-class commenting on exemplary } \\
\text { compositions helps improve my English. }\end{array}$ & 5 & 4 & 3 & 2 & $\mathbf{1}$ \\
\hline 40. Writing at length helps me organize and express my thoughts. & 5 & 4 & 3 & 2 & 1 \\
\hline $\begin{array}{l}\text { 41. The teacher's correcting all my mistakes in red dampens my } \\
\text { enthusiasm for English writing. }\end{array}$ & 5 & 4 & 3 & 2 & 1 \\
\hline 42. I enjoy writing out of class. & 5 & 4 & 3 & 2 & 1 \\
\hline $\begin{array}{l}\text { 43. I think it a good way to score based on length, structure, content } \\
\text { and language. }\end{array}$ & 5 & 4 & 3 & 2 & 1 \\
\hline $\begin{array}{l}\text { 44. The more the teacher correct my composition, the more helpful } \\
\text { it becomes for me to improve it. }\end{array}$ & 5 & 4 & 3 & 2 & 1 \\
\hline 45. I am able to write better out of class than in class. & 5 & 4 & 3 & 2 & 1 \\
\hline $\begin{array}{l}\text { 46. Every time I am able to write a longer composition, I } \\
\text { enhance my confidence in using English. }\end{array}$ & 5 & 4 & 3 & 2 & 1 \\
\hline $\begin{array}{l}\text { 47. I don't like the teacher to give the writing topic in class and } \\
\text { have to complete the composition the next day. }\end{array}$ & 5 & 4 & 3 & 2 & 1 \\
\hline 48. English writing training helps improve my reading skills. & 5 & 4 & 3 & 2 & 1 \\
\hline 49. I enjoy the teacher' s positive feedback. & 5 & 4 & 3 & 2 & 1 \\
\hline 50. I feel it so hard to write well in English. & 5 & 4 & 3 & 2 & 1 \\
\hline
\end{tabular}




\section{Appendix E}

\section{Cloze test for the two groups of 2nd year undergraduate students Fill in each blank with an appropriate word.}

When a shared resource is in short supply, organisms compete, and 1 that are more successful survive. Within some plant and animal populations, all individuals 2 share the resources in such a way that none obtains sufficient 3 to survive as adults or to reproduce. 4 other plant and animal populations, dominant individuals claim access to the 5 resources and others are excluded. Individual plants tend to claim and hold onto a site 6 they lose vigor or die. These 7 other individuals from surviving by controlling light, moisture, and nutrients in 8 immediate areas.

Many animals have a highly developed social organization through 9 resources such as space, food, and mates are apportioned 10 dominant members of the population. Such competitive interactions may involve social dominance, in 11 the dominant individuals exclude subdominant individuals 12 the resource; or they may involve territoriality, in which the dominant individuals 13 space into exclusive areas, 14 they defend.

Subdominant or excluded individuals are forced to live in poorer habitats, do 15 the resource, or leave the area. Many of these animals succumb to starvation, exposure, and predation.

Competition among members of different species results in the 16 of resources in a community. Certain plants, for 17 , have roots that grow to different depths in the 18 Some have shallow roots that permit them to use moisture and nutrients near the surface. 19 more shallow, it encourages the invasion of floating plants such as pond lilies and emergent plants such as cattails. The pace 20 which succession proceeds depends on the competitive abilities of the species involved; tolerance 21 the environmental conditions brought about by changes in vegetation; the interaction with animals, particularly the grazing herbivores and fire. 22 the ecosystem arrives at a point called the climax, 23 further changes take place very slowly, and the site is dominated by long-lived, highly competitive species. 24 succession proceeds, however, the community becomes more stratified, enabling more 25 of animals to occupy the area. In time, animals characteristic of later stages of succession replace those found in earlier stages. 


\section{Appendix F}

\section{Interview questions for the participants in the experimental group}

1. How do you evaluate your current English writing ability compared with that in the $1^{\text {st }}$ year? What factors do you think have contributed to your improvement if you think you have made progress in your English writing?

2. Do you think it hard to write in English? Why?

3. What do you think of the Write-to-learn Model? As you see it, what are the merits and demerits of this approach?

4. With the Write-to-learn Model in writing classes, do you feel more motivated or demotivated to write? Please state your reasons.

5. What kind of teacher feedback would you like to receive? Do you expect your teacher to correct each and every error in your composition? Why?

6. What do you think is a better way of learning vocabulary and grammar? Do you like the way you are now learning vocabulary and grammar in class?

7. Do you think it a good idea to integrate writing into reading? How do you see the relationship between reading and writing?

8. How many English books have you read so far? In your opinion, what are the benefits of reading English newspapers, magazines and English books in the original?

9. In what ways can English learners avoid or minimize Chinglish expressions?

10. What do you suggest EFL teachers do to help students improve English writing? What do you suggest EFL students do to improve their English writing?

11. How are you developing your writing skills in the United States?

12. What is the major use of your English writing skills? 


\section{Appendix G}

\section{Interview questions for the five students in the joint program}

1. Do you think English writing is a difficult for you to develop? Why?

2. How do you evaluate your English writing ability during your first two years in the university in China?

3. Have you made any improvement in your English writing ability since you studied in the George Fox University? If yes, what do you think are the factors contributing to your improvement in your English writing?

4. What kind of corrective feedback do you expect from the teacher? Do you see any differences between EFL teachers in China and English writing teacher in terms of corrective feedback? Do you think it a good idea for the teacher to correct each and every error?

5. What writing approach is used in your writing classes in the United States? What approach do you prefer? Why?

6. Can you tell how you learn vocabulary and grammar in China and in the United States respectively?

7. Do you think reading and writing should be treated as independent courses or should they be combined as one course? Why?

8. Did you read English books in the original? How often did you do this? What are the benefits of doing this?

9. In your English learning experiences, do you see any differences between writing in Chinese and writing in English? If yes, in what aspects?

10. Chinglish is a common phenomenon in students' compositions. As you see it, what causes the Chinglish phenomenon and how can we avoid it?

11. Do you think it easier to develop your English writing skill in the United States? Why?

12. What challenges are EFL students faced with in terms of writing skill development?

13. How are you developing your writing skills in the United States?

14. What is the major use of your English writing skills?

15. What do you think of EFL writing instruction in China? 


\title{
Appendix H
}

\section{A sample essay written by a student in the EG during the experiment}

\author{
Standard of Beauty
}

Iane, a fat, low-paid shop assistant, took her routine walk from the shop to the market to buy some cheap sausage. Dlay by day. Year in yeav out, her life passed quietly like a lake without even a slight ripple. No love, no joy and no hope. One day, she, by an acidental chance, izan acceross a blind man in a flower shop, who was asking for help. They met. and they felt in love. The blind man touched her skin and alnays praised her for her delicate and soft skin. And fane was in full joy all the time. One day, the old man told fane that he had to go arcad to cure his eyes. On the news, fane had not the slightest delight, but sorrow and anxiety. She was in agonies all day lest the blind man would despise and desert her after he had knowbdge of her ill-built figure. At lengeh, she made up her mind to lose veight during the absence of the blind man. A long time had passed, and the flind man was back. Gane was as stim. if not slimmer than, the average ginl. sthe picked up her corcrage to knock on the blind man's door. To her great surpise, whe blind man's face was filled with a great deal of disappointment at the sight of hor. Pitifully this is not a happy ending. The flind mans disappointment reflected his bad affection for fanes change. It arouse me that it is not universally true that "Beauty lies in the eyes of the beholder". Whether it is beautifuel or not is actually up to everyone's set standards. Based on this understanding. I am sure nothing in the world could be refered to as ughy. The standards of beacty vary all the tine, particularly in this modern society. One thing may be much valued by this group, but it may be recognized as not worth a penny by the other group. This is not surprising at all if you take faskion for an example. In the old days, should women be thought good. the should dress in a simple, unaffected, and conservative 
way. Probably it will be most yleasing and decent for women to wear a dress. As to man. the requiement ioas not so cruel that men only had to dress in a clean and tidy way, which was auprtable by the majority. While in today's dimate, women and men are diverting their "original direction", and things are seemed in such a disorderly way that no one will suffer the pain of criticism for not having properly dressed himself, but the jeer of bing "out of date". In the faishion field. what is to be deemed as up-to-date? You'll see!'

Fivom the lateral pressrective, the two sexes are sometimes going extremes. The femine are on the way to the masculine, and vice versa. The old standards set up respectively for them would nevier work as strong as before.

From the vertical perspective, the standard of beauty is also differentiating greatly from the last several decades. "Lovely" or "prety." is no long the only qualified word to describe little girls, nor will "sexy", "noble", "graceful" on "dignified" do as to ladies. The connection now between them is w obrious and the distinction line is so vague that even the farhion designer sometimes doesn't know whether to follow the old vicle to make the mother sexy and the daughter precty. or to follow the nev standard of beauty to make the reserve come true. The outcome may bi the latter, for there's no accounts on preople's taste and rtandard of beauty at a age full of freedom atmosphere. To make some concessions, even if the designer doesn't make it appropriate. those who like to swin with the strean would still aupt it as creative for the reason of the change of the standard of beauty.

In addition, less and less attention has been praid to women's 
character. Women need not to live up to the standards in order to be looked on as beautiful that thoy should be tender, be considerato be in good figure, be good at reedlework and cooking, and assisting the husband and biinging up the children, ete. And men are not judged as "beautiful" from the storeotyped norms as strong. confident. effective or competint. Sometimes a merely foreign face can be deemed as beautiful, no matter how ignorant he is. It seems that modern preople like to see thing in i more direct way. And thus the standard of beautify lays greater stress on the outsider than the inside.

Last but not least, what deserves the priority over the obove is who changes the sule as for standard of beauty. I must say it is just we. Let me tell you a story. A blind man, with his friend. sound, went for a walk in a mountain for an hour. which had been with the blind man for ages. Back to the house, the blind man asked his friend whether he exyioyed the nice walk. To his great astonishment, his friend answered in a tired voice that it was just not too bad, and that there was nothing intoresting to see, besides rome trees and grasses. The blind man felt very soury for his having bored his friend and his friend's blindness. standard of beauty should consist in our heart. not our eyes. Walking around the mountain may sometimes be a sort of bore, seeing merely trees and grasses. But walk around along with our heart, we would find us indulging in the luxury of fresh air, pleasant singing of birds, breery wind, varm sunshine, smiling flowers ete. Eyes can only tell what is in the front. While heart can sparkle our life with wit. 
Life is all-embacing. To take it all as beautiful equals to take nothing of it. Life will have its sovnow without an eye for feauty. Without it, we are in blindness and life will be in dark. So, it is far better to setup our own standard of beauty and bighten up our short life period.

Time: about 6 hours

Words: about 1 hoo 


\section{Appendix I}

\section{Data of the five aspects in the questionnaire survey in Sub-study 1}

\section{Chinese}

\begin{tabular}{|c|c|c|}
\hline 六个部分 & 第一次 & 第二次 \\
\hline \multicolumn{3}{|l|}{ 1、你是否接受以写促学教学模式? } \\
\hline （1）作文写得越长越有助于增强我用英语写作的信心。 & 3.23 & 4.15 \\
\hline （2）我喜欢用英语写作文。 & 2.17 & 4.10 \\
\hline （3）多写长作文有助于我写好短作文。 & 3.21 & 4.05 \\
\hline （4）写长作文有利于我组织和表达思想内容。 & 3.6 & 4.46 \\
\hline （5）我喜欢把英语作文尽可能写长一些。 & 2.87 & 3.88 \\
\hline （6）作文尽可能写长一些有助于打开我的思路。 & 3.25 & 4.25 \\
\hline \multicolumn{3}{|l|}{ 2、你对英语写作是否有信心? } \\
\hline （1）我不怕写英语作文。 & 3.43 & 4.23 \\
\hline (2) 我觉得我能够用英语写好作文。 & 3.73 & 4.45 \\
\hline （3）我感到写英语作文是一种乐趣。 & 2.85 & 3.98 \\
\hline （4）每次把英语作文尽量写长一些能够增强我使用英英语的信心。 & 3.4 & 4.08 \\
\hline \multicolumn{3}{|l|}{ 3、你觉得写长作文是否有助于提高英语写作水平? } \\
\hline （1）多用英语写作有助于提高我的英语语言水平。 & 3.7 & 4.63 \\
\hline （2）写长作文有助于我运用所见过的英语表达法。 & 3.25 & 4.29 \\
\hline （3）写长作文有助于纠正我的英语语言错误。 & 2.58 & 3.85 \\
\hline (4) 加强英语写作训练有助于带动我听说读能力的提高。 & 3.6 & 4.2 \\
\hline $\begin{array}{l}\text { (5) 我认为作文发回来再修改, 英语的进步会比第一次写作文时要 } \\
\text { 大。 }\end{array}$ & 3.27 & 3.95 \\
\hline
\end{tabular}




\begin{tabular}{|c|c|c|}
\hline （6）多写长作文有助于我学好英语。 & 3.50 & 4.29 \\
\hline （7）我感到每次把作文写长一些能够提高我的英语水平。 & 3.20 & 4.17 \\
\hline $\begin{array}{l}\text { （8）我认为老师在课堂上讲评优秀作文会有助于提高我的英语水 } \\
\text { 平。 }\end{array}$ & 3.82 & 4.29 \\
\hline \multicolumn{3}{|l|}{ 4、你是否接受新的打分方法? } \\
\hline $\begin{array}{l}\text { (1) 按长度、结构、内容、语言给作文分项评分使我明白自己在哪 } \\
\text { 方面不足。 }\end{array}$ & 4.3 & 4.67 \\
\hline （2）我认为按长度、结构、内容、语言分项评分明白易懂。 & 3.45 & 4.63 \\
\hline (3) 把作文长度作为评分的标准之一促使我写长作文。 & 3 & 4.29 \\
\hline （4）我认为应该按长度、结构、内容、语言分项评分。 & 4.47 & 4.54 \\
\hline $\begin{array}{l}\text { (5) 老师在课堂上讲评同学的优秀作文, 我可以从中学到很多东 } \\
\text { 西。 }\end{array}$ & 4.17 & 4.5 \\
\hline （6）我写完初稿之后反复修改。 & 2.93 & 3.8 \\
\hline （7）看到老师肯定我作文中的优点，我写英语的兴趣就会提高。 & 3.87 & 4.42 \\
\hline （8）我不喜欢老师在课堂上讲评写得差的作文。 & 3.1 & 4.71 \\
\hline $\begin{array}{l}\text { (9) 在批改错误与认可优点之间作选择, 我宁愿老师肯定我作文中 } \\
\text { 的优点。 }\end{array}$ & 2.67 & 3.55 \\
\hline （10）我喜欢老师肯定我作文中的优点。 & 4.21 & 4.37 \\
\hline $\begin{array}{l}\text { (11) 课堂上听过优秀作文讲评之后再修改自己的作文, 我会感到很 } \\
\text { 有收获。 }\end{array}$ & 3.63 & 4.15 \\
\hline （12）看到满篇作文都是老师划出的错误，我写英语的兴趣会降低。 & 2.83 & 3.85 \\
\hline （13）我喜欢老师把上星期的作文发回来让我重新修改。 & 3.47 & 4.36 \\
\hline \multicolumn{3}{|l|}{ 5、你是否赞成课外写作文? } \\
\hline (1) 我认为在课外写比在课堂上写更能提高我的英语水平。 & 4.47 & 4.64 \\
\hline $\begin{array}{l}\text { (2) 如果在课内写与课外写两者之间选择, 我更喜欢在课外写作 } \\
\text { 文。 }\end{array}$ & 4.15 & 4.5 \\
\hline （3）我认为要提高英语水平，必须在课外多写。 & 3.78 & 4.48 \\
\hline （4）我认为英语作文在课外完成比在课内完成好。 & 3.47 & 4.63 \\
\hline
\end{tabular}




\begin{tabular}{|l|c|c|}
\hline (5) 我喜欢在课外写作文。 & 3.43 & 4.71 \\
\hline (6) 我在课外写比在课堂上写更能写出好作文。 & 4.43 & 4.54 \\
\hline 6、阅读英语原版材料是否有助于提高学生英语写作的水平? & \multicolumn{2}{|l|}{} \\
\hline (1) 阅读英语原版材料有助于学生用地道的英语表达思想。 & 3.62 & 4.65 \\
\hline (2) 阅读英语原版材料有助于整体提高学生英语写作的水平。 & 3.85 & 4.75 \\
\hline (3) 广泛阅读对提高我的写作有很大帮助。 & 3.65 & 4.82 \\
\hline
\end{tabular}

\section{English}

\begin{tabular}{|c|c|c|}
\hline Six aspects & 1st time & 2nd time \\
\hline \multicolumn{3}{|l|}{ 1. Whether you accept the Write-to-learn Model? } \\
\hline (1) Writing at length helps enhance my confidence in English writing. & 3.23 & 4.15 \\
\hline (2) I enjoy writing in English. & 2.17 & 4.10 \\
\hline (3) Writing at length often helps me write better short compositions. & 3.21 & 4.05 \\
\hline (4) Writing at length helps me organize and express my thoughts. & 3.6 & 4.46 \\
\hline (5) I like writing longer compositions. & 2.87 & 3.88 \\
\hline (6) Writing at length helps me open up my mind. & 3.25 & 4.25 \\
\hline \multicolumn{3}{|l|}{ 2. Whether you have confidence in English writing? } \\
\hline (1) I'm not afraid of writing in English. & 3.43 & 4.23 \\
\hline (2) I think I can write well in English. & 3.73 & 4.45 \\
\hline (3) I deem it a pleasure to write in English. & 2.85 & 3.98 \\
\hline $\begin{array}{l}\text { (4) Every time I can write a longer composition, I feel it can enhance my } \\
\text { confidence in using English. }\end{array}$ & 3.4 & 4.08 \\
\hline
\end{tabular}




\begin{tabular}{|c|c|c|}
\hline (1) Writing helps me improve my English proficiency. & 3.7 & 4.63 \\
\hline $\begin{array}{l}\text { (2) Writing at length helps me make use of the English expressions I } \\
\text { have learned. }\end{array}$ & 3.25 & 4.29 \\
\hline (3) Writing at length helps correct my English mistakes. & 2.58 & 3.85 \\
\hline (4) English writing practice helps improve my reading skills. & 3.6 & 4.2 \\
\hline $\begin{array}{l}\text { (5) I think I will improve my English when I keep revising my } \\
\text { compositions. }\end{array}$ & 3.27 & 3.95 \\
\hline (6) Writing at length helps me improve my English writing proficiency. & 3.50 & 4.29 \\
\hline $\begin{array}{l}\text { (7) I feel I can improve my English every time I can write a longer } \\
\text { composition. }\end{array}$ & 3.20 & 4.17 \\
\hline $\begin{array}{l}\text { (8) I think the teacher's in-class commenting on exemplary compositions } \\
\text { helps improve my English. }\end{array}$ & 3.82 & 4.29 \\
\hline \multicolumn{3}{|l|}{ 4. Whether you accept the marking scheme? } \\
\hline $\begin{array}{l}\text { (1) Marking based on length, structure, content and language makes me } \\
\text { understand where my weaknesses are. }\end{array}$ & 4.3 & 4.67 \\
\hline $\begin{array}{l}\text { (2) I think it makes more sense to mark based on length, structure, } \\
\text { content, and language. }\end{array}$ & 3.45 & 4.63 \\
\hline $\begin{array}{l}\text { (3) Using length as one of marking criteria enables me to write long } \\
\text { compositions. }\end{array}$ & 3 & 4.29 \\
\hline $\begin{array}{l}\text { (4) I think teachers should mark according to length, structure, content } \\
\text { and language. }\end{array}$ & 3.47 & 4.54 \\
\hline $\begin{array}{l}\text { (5) I benefit a lot from the teacher's in-class commenting on exemplary } \\
\text { compositions. }\end{array}$ & 4.17 & 4.5 \\
\hline (6) I keep revising my composition after the first draft was completed. & 2.93 & 3.8 \\
\hline (7) Teachers' positive feedback enhances my interest in English writing. & 3.87 & 4.42 \\
\hline $\begin{array}{l}\text { (8) I don't like the teacher's commenting on poorly written compositions } \\
\text { in class. }\end{array}$ & 3.1 & 4.71 \\
\hline $\begin{array}{l}\text { (9) I'd rather the teacher provided positive feedback if I can choose } \\
\text { between positive feedback and negative feedback. }\end{array}$ & 2.67 & 3.55 \\
\hline (10) I prefer the teacher's positive feedback. & 4.21 & 4.37 \\
\hline $\begin{array}{l}\text { (11) I feel I benefit from revising my composition after the teacher } \\
\text { comments on the exemplary compositions in class. }\end{array}$ & 3.63 & 4.15 \\
\hline $\begin{array}{l}\text { (12) The teacher's correcting all my mistakes in red dampens my } \\
\text { enthusiasm for English writing. }\end{array}$ & 2.83 & 3.85 \\
\hline
\end{tabular}




\begin{tabular}{|c|c|c|}
\hline (13) I enjoy revising my composition after I got it back from the teacher. & 3.47 & 4.36 \\
\hline \multicolumn{3}{|l|}{ 5. Whether you accept writing out of class? } \\
\hline $\begin{array}{l}\text { (1) I think that writing out of class can help improve my English writing } \\
\text { more greatly than writing in class. }\end{array}$ & 4.47 & 4.64 \\
\hline $\begin{array}{l}\text { (2) I prefer to write out of class if I can choose between writing in class } \\
\text { and writing out of class. }\end{array}$ & 4.15 & 4.5 \\
\hline $\begin{array}{l}\text { (3) I think a student must write out of class frequently if he/she wants to } \\
\text { improve his/her English writing. }\end{array}$ & 3.78 & 4.48 \\
\hline (4) I think it a better idea to write out of class than to write in class. & 3.47 & 4.63 \\
\hline (5) I like writing out of class. & 3.43 & 4.71 \\
\hline (6) I can write better compositions out of class than in class. & 4.43 & 4.54 \\
\hline \multicolumn{3}{|c|}{ 6. Whether exposure to authentic materials helps improve English writing? } \\
\hline $\begin{array}{l}\text { (1) Reading authentic materials in the original helps students express their } \\
\text { thoughts in an authentic way. }\end{array}$ & 3.62 & 4.65 \\
\hline $\begin{array}{l}\text { (2) Reading authentic materials in the original helps students improve } \\
\text { their English writing. }\end{array}$ & 3.85 & 4.75 \\
\hline (3) Extensive reading is helpful to my English writing. & 3.65 & 4.82 \\
\hline
\end{tabular}




\section{Appendix J}

\section{Data of the cloze test in Sub-study 1}

\section{Data of the cloze test of the EG}

\begin{tabular}{|c|c|c|c|}
\hline Participant & $\begin{array}{c}\text { 1st Test } \\
\text { (Sept. 2015) } \\
\end{array}$ & $\begin{array}{c}\text { 2nd Test } \\
(\text { Jan. 2016) }\end{array}$ & Note \\
\hline EG-Student 1 & 10 & 18 & \\
\hline EG-Student 2 & 13 & 21 & \\
\hline EG-Student 3 & 13 & 19 & \\
\hline EG-Student 4 & 12 & 19 & \\
\hline EG-Student 5 & 9 & 15 & \\
\hline EG-Student 6 & 16 & 18 & \\
\hline EG-Student 7 & 10 & 14 & \\
\hline EG-Student 8 & 12 & 18 & \\
\hline EG-Student 9 & 14 & 22 & \\
\hline EG-Student 10 & 10 & 14 & \\
\hline EG-Student 11 & 10 & 15 & \\
\hline EG-Student 12 & 11 & 18 & \\
\hline EG-Student 13 & 14 & 13 & \\
\hline EG-Student 14 & 11 & 18 & \\
\hline EG-Student 15 & 11 & 14 & \\
\hline EG-Student 16 & 11 & 15 & \\
\hline EG-Student 17 & 9 & 18 & \\
\hline EG-Student 18 & 12 & 19 & \\
\hline EG-Student 19 & 11 & 16 & \\
\hline EG-Student 20 & 13 & 16 & \\
\hline EG-Student 21 & 8 & 21 & \\
\hline EG-Student 22 & 9 & 19 & \\
\hline EG-Student 23 & 9 & 18 & \\
\hline EG-Student 24 & 12 & 16 & \\
\hline EG-Student 25 & 11 & 19 & \\
\hline EG-Student 26 & 8 & 17 & \\
\hline EG-Student 27 & 10 & 18 & \\
\hline EG-Student 28 & 7 & 16 & \\
\hline EG-Student 29 & 9 & 16 & \\
\hline EG-Student 30 & 8 & 15 & \\
\hline
\end{tabular}

Note: The full mark is 25 . 
Data of the cloze test of the CG

\begin{tabular}{|l|c|c|l|}
\hline \multicolumn{1}{|c|}{ Participant } & $\begin{array}{c}\text { 1st Test } \\
\text { (Sept. 2015) }\end{array}$ & $\begin{array}{c}\text { 2nd Test } \\
\text { (Jan. 2016) }\end{array}$ & Note \\
\hline CG-Student 1 & 13 & 20 & \\
\hline CG-Student 2 & 11 & 21 & \\
\hline CG-Student 3 & 15 & 20 & \\
\hline CG-Student 4 & 12 & 18 & \\
\hline CG-Student 5 & 13 & 16 & \\
\hline CG-Student 6 & 12 & 18 & \\
\hline CG-Student 7 & 12 & 15 & \\
\hline CG-Student 8 & 10 & 18 & \\
\hline CG-Student 9 & 14 & 16 & \\
\hline CG-Student 10 & 12 & 17 & \\
\hline CG-Student 11 & 10 & 16 & \\
\hline CG-Student 12 & 13 & 17 & \\
\hline CG-Student 13 & 10 & 15 & \\
\hline CG-Student 14 & 11 & 12 & \\
\hline CG-Student 15 & 15 & 16 & \\
\hline CG-Student 16 & 12 & 16 & \\
\hline CG-Student 17 & 9 & 18 & \\
\hline CG-Student 18 & 10 & 13 & \\
\hline CG-Student 19 & 15 & 16 & \\
\hline CG-Student 20 & 9 & 16 & \\
\hline CG-Student 21 & 10 & 16 & \\
\hline CG-Student 22 & 16 & 16 & \\
\hline CG-Student 23 & 14 & 16 & \\
\hline CG-Student 24 & 12 & 16 & \\
\hline CG-Student 25 & 12 & 16 & \\
\hline CG-Student 26 & 7 & 16 & \\
\hline CG-Student 27 & 8 & 16 & \\
\hline CG-Student 28 & 10 & 16 & \\
\hline CG-Student 29 & 9 & 16 & \\
\hline CG-Student 30 & 10 & 16 & \\
\hline
\end{tabular}

Note: The full mark is 25 . 


\section{Appendix K}

Data of the writing tests in Sub-study 1

Data of the writing tests of the EG

\begin{tabular}{|c|c|c|c|}
\hline Participant & $\begin{array}{c}\text { 1st Test } \\
\text { (Sept. 2015) }\end{array}$ & $\begin{array}{c}\text { 2nd Test } \\
\text { (Feb. 2016) }\end{array}$ & Note \\
\hline EG-Student 1 & 48 & 55 & \\
\hline EG-Student 2 & 44 & 47 & \\
\hline EG-Student 3 & 47 & 52 & \\
\hline EG-Student 4 & 43 & 51 & \\
\hline EG-Student 5 & 43 & 47 & \\
\hline EG-Student 6 & 46 & 48 & \\
\hline EG-Student 7 & 47 & 48 & \\
\hline EG-Student 8 & 49 & 54 & \\
\hline EG-Student 9 & 52 & 56 & \\
\hline EG-Student 10 & 50 & 54 & \\
\hline EG-Student 11 & 46 & 51 & \\
\hline EG-Student 12 & 48 & 52 & \\
\hline EG-Student 13 & 47 & 50 & \\
\hline EG-Student 14 & 47 & 50 & \\
\hline EG-Student 15 & 42 & 46 & \\
\hline EG-Student 16 & 48 & 50 & \\
\hline EG-Student 17 & 47 & 50 & \\
\hline EG-Student 18 & 48 & 52 & \\
\hline EG-Student 19 & 46 & 54 & \\
\hline EG-Student 20 & 47 & 47 & \\
\hline EG-Student 21 & 39 & 40 & \\
\hline EG-Student 22 & 42 & 45 & \\
\hline EG-Student 23 & 42 & 48 & \\
\hline EG-Student 24 & 43 & 46 & \\
\hline EG-Student 25 & 47 & 53 & \\
\hline
\end{tabular}




\begin{tabular}{|l|l|l|l|}
\hline EG-Student 26 & 48 & 50 & \\
\hline EG-Student 27 & 47 & 52 & \\
\hline EG-Student 28 & 45 & 49 & \\
\hline EG-Student 29 & 41 & 44 & \\
\hline EG-Student 30 & 39 & 43 & \\
\hline
\end{tabular}

Note: The full mark is 60 .

Data of the writing tests of the CG

\begin{tabular}{|c|c|c|c|}
\hline Participant & $\begin{array}{c}\text { 1st Test } \\
\text { (Sept. 2015) }\end{array}$ & $\begin{array}{c}\text { 2nd Test } \\
\text { (Feb. 2016) }\end{array}$ & Note \\
\hline CG-Student 1 & 46 & 45 & \\
\hline CG-Student 2 & 48 & 46 & \\
\hline CG-Student 3 & 47 & 46 & \\
\hline CG-Student 4 & 48 & 50 & \\
\hline CG-Student 5 & 50 & 52 & \\
\hline CG-Student 6 & 49 & 50 & \\
\hline CG-Student 7 & 47 & 50 & \\
\hline CG-Student 8 & 46 & 46 & \\
\hline CG-Student 9 & 48 & 46 & \\
\hline CG-Student 10 & 47 & 47 & \\
\hline CG-Student 11 & 48 & 48 & \\
\hline CG-Student 12 & 52 & 52 & \\
\hline CG-Student 13 & 46 & 40 & \\
\hline CG-Student 14 & 42 & 40 & \\
\hline CG-Student 15 & 51 & 53 & \\
\hline CG-Student 16 & 48 & 48 & \\
\hline CG-Student 17 & 47 & 48 & \\
\hline CG-Student 18 & 48 & 44 & \\
\hline CG-Student 19 & 48 & 50 & \\
\hline CG-Student 20 & 43 & 48 & \\
\hline CG-Student 21 & 42 & 44 & \\
\hline CG-Student 22 & 46 & 50 & \\
\hline
\end{tabular}




\begin{tabular}{|l|c|c|l|}
\hline CG-Student 23 & 50 & 53 & \\
\hline CG-Student 24 & 40 & 41 & \\
\hline CG-Student 25 & 47 & 50 & \\
\hline CG-Student 26 & 48 & 49 & \\
\hline CG-Student 27 & 43 & 35 & \\
\hline CG-Student 28 & 48 & 45 & \\
\hline CG-Student 29 & 48 & 48 & \\
\hline CG-Student 30 & 43 & 46 & \\
\hline
\end{tabular}

Note: The full mark is 60 . 


\section{Appendix L}

Key data concerning the five themes from the interviews of the 30 students in Sub-study 1

\begin{tabular}{|c|c|c|c|c|}
\hline Writing approach & $\begin{array}{l}\text { Attitudes towards } \\
\text { writing }\end{array}$ & $\begin{array}{l}\text { Relationship between } \\
\text { reading \& writing }\end{array}$ & Corrective feedback & Context \\
\hline $\begin{array}{l}\text { - Is an effective } \\
\text { teaching method; } \\
\text { Drives us to read } \\
\text { books, articles and } \\
\text { magazines in the } \\
\text { original; } \\
\text { Is a catalyst for } \\
\text { extensive reading and } \\
\text { "good medicine" for } \\
\text { broadening our } \\
\text { horizons; } \\
\text { Helps enlarge our } \\
\text { vocabulary and } \\
\text { expressions; } \\
\text { Learns to use a variety } \\
\text { of structures; } \\
\text { Helps improve our } \\
\text { writing proficiency. }\end{array}$ & $\begin{array}{l}\text { Writing is becoming } \\
\text { more fun and enjoyable; } \\
\text { Removes our fear or } \\
\text { EFL writing; } \\
\text { Enhances our confidence } \\
\text { in writing; } \\
\text { Develops a sense of } \\
\text { achievement in EFL } \\
\text { writing; } \\
\text { Brings my writing } \\
\text { initiatives into full play; } \\
\text { Wants to write instead of } \\
\text { needing to write; } \\
\text { Writing is a pleasure to } \\
\text { express our life } \\
\text { experiences, feelings and } \\
\text { opinions. }\end{array}$ & $\begin{array}{l}\text { Writing should not be } \\
\text { separated from } \\
\text { reading; } \\
\text { - } \quad \text { Reading is the } \\
\text { foundation of writing; } \\
\text { The more you read, } \\
\text { the more ideas you } \\
\text { have; } \\
\text { Reading authentic } \\
\text { materials enables us to } \\
\text { express ourselves } \\
\text { more fluently, clearly } \\
\text { and accurately. }\end{array}$ & 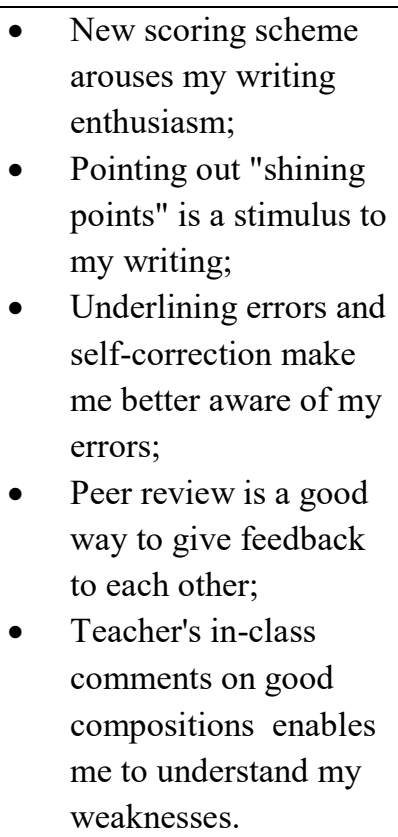 & 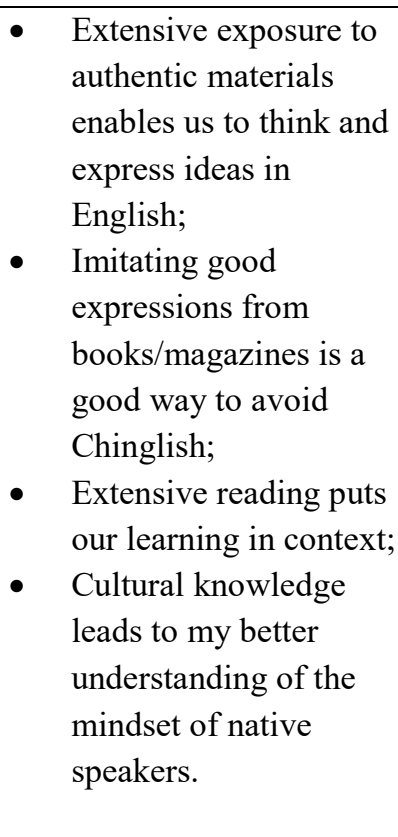 \\
\hline
\end{tabular}




\section{Appendix M}

\section{Data from the interviews of the five students in Sub-study 2}

Key data from the interviews of the five students in the joint program in five aspects

\begin{tabular}{|c|c|c|c|c|c|}
\hline & Writing approaches & $\begin{array}{c}\text { Attitudes towards } \\
\text { writing }\end{array}$ & $\begin{array}{c}\text { Relationship } \\
\text { between reading \& } \\
\text { writing }\end{array}$ & $\begin{array}{c}\text { Corrective } \\
\text { feedback }\end{array}$ & Context \\
\hline Student A & $\begin{array}{l}\text { Encourages students to } \\
\text { write through reading } \\
\text { and learn writing } \\
\text { techniques from the } \\
\text { authors; } \\
\text { Basic writing } \\
\text { techniques are not } \\
\text { difficult; developing } \\
\text { ideas is more } \\
\text { important and more } \\
\text { difficult. }\end{array}$ & $\begin{array}{l}\text { English writing is } \\
\text { not as hard as we } \\
\text { imaged as long as } \\
\text { you get used to it; } \\
\text { Writing is } \\
\text { becoming more } \\
\text { enjoyable. }\end{array}$ & 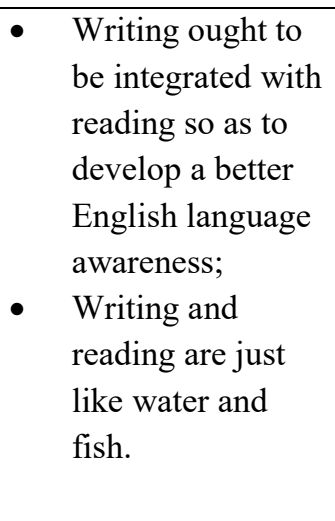 & $\begin{array}{l}\text { Pay more } \\
\text { attention to ideas } \\
\text { than to syntactic } \\
\text { errors; } \\
\text { - } \\
\text { Peer review is } \\
\text { encouraged; } \\
\text { - } \quad \text { Rubric also serves } \\
\text { as a guide for my } \\
\text { writing. }\end{array}$ & $\begin{array}{l}\text { - Have made great } \\
\text { progress in writing } \\
\text { because there's an } \\
\text { environment where } \\
\text { I'm exposed to } \\
\text { English every day; } \\
\text { - I attributed }\end{array}$ \\
\hline & $\begin{array}{l}\text { Peer review is a great } \\
\text { approach used in the } \\
\text { writing classes in the } \\
\text { US. Through reading } \\
\text { my peers' writing and } \\
\text { giving feedback to it, I } \\
\text { learn about different } \\
\text { styles of writing, the } \\
\text { ways of thinking of }\end{array}$ & $\begin{array}{l}\text { Enjoy free write; } \\
\text { the more I write, } \\
\text { the more } \\
\text { confidence I have } \\
\text { in writing; } \\
\text { Writing is } \\
\text { becoming part of } \\
\text { my life and is the }\end{array}$ & $\begin{array}{l}\text { - } \\
\text { Reading and } \\
\text { writing are highly } \\
\text { related. Writing } \\
\text { starts from } \\
\text { imitation. I think } \\
\text { and learn when I }\end{array}$ & $\begin{array}{l}\text { Professors work } \\
\text { with students on } \\
\text { ideas and suggest } \\
\text { using short and } \\
\text { simple sentences; } \\
\text { Professors help } \\
\text { students with how } \\
\text { to structure } \\
\text { sentences and }\end{array}$ & $\begin{array}{l}\text { I do feel my English } \\
\text { writing skills } \\
\text { improved a lot. The } \\
\text { most important } \\
\text { factor is the } \\
\text { environment where } \\
\text { everyone speaks } \\
\text { English and I read } \\
\text { extensively. }\end{array}$ \\
\hline
\end{tabular}




\begin{tabular}{|c|c|c|c|c|c|c|c|c|}
\hline Student B & $\begin{array}{l}\text { native English } \\
\text { speakers and how } \\
\text { these ways are } \\
\text { different from mine; } \\
\text { Language learning } \\
\text { process is more than to } \\
\text { study grammar, and it } \\
\text { is to important to learn } \\
\text { the culture. }\end{array}$ & & $\begin{array}{l}\text { reflection of my } \\
\text { life and study. }\end{array}$ & & $\begin{array}{l}\text { read, and then I } \\
\text { write down what I } \\
\text { think; } \\
\text { Reading broadens } \\
\text { my mind and } \\
\text { gives me more } \\
\text { space to write } \\
\text { about. }\end{array}$ & & $\begin{array}{l}\text { how to make } \\
\text { paragraphs } \\
\text { coherent. }\end{array}$ & \\
\hline Student C & $\begin{array}{l}\text { Journaling is a good } \\
\text { way to improve your } \\
\text { writing. The more you } \\
\text { journal, the better you } \\
\text { can write. } \\
\text { Writing originates } \\
\text { from life. Record what } \\
\text { happens to your life. } \\
\text { Your writing } \\
\text { inspiration comes } \\
\text { from life. }\end{array}$ & & $\begin{array}{l}\text { It has become my } \\
\text { habit to journal in } \\
\text { English; } \\
\text { Developing a sense } \\
\text { of achievement in } \\
\text { writing; } \\
\text { Am able to express } \\
\text { my thoughts more } \\
\text { fluently and } \\
\text { clearly. }\end{array}$ & & $\begin{array}{l}\text { Reading should } \\
\text { not be separated } \\
\text { from writing. } \\
\text { Writing cannot be } \\
\text { improved without } \\
\text { reading } \\
\text { extensively. The } \\
\text { relationship } \\
\text { between reading } \\
\text { and writing is like } \\
\text { input and output. }\end{array}$ & & $\begin{array}{l}\text { Pay more } \\
\text { attention to the } \\
\text { organization of an } \\
\text { essay and the } \\
\text { development of } \\
\text { ideas. }\end{array}$ & $\begin{array}{l}\text { My writing ability } \\
\text { has improved } \\
\text { considerably. I think } \\
\text { the major reason is } \\
\text { the change of the } \\
\text { environment where } \\
\text { I'm exposed to } \\
\text { English every day. }\end{array}$ \\
\hline Student D & $\begin{array}{l}\text { Practice writing every } \\
\text { day. Free write is a } \\
\text { good way; } \\
\text { Read extensively and } \\
\text { you'll get good ideas } \\
\text { and imitate good } \\
\text { expressions. }\end{array}$ & & $\begin{array}{l}\text { Writing is } \\
\text { becoming } \\
\text { increasingly easy } \\
\text { for me with } \\
\text { constant practice } \\
\text { and extensive } \\
\text { reading; } \\
\text { It's amazing that } \\
\text { I'm able to use a } \\
\text { variety of }\end{array}$ & & $\begin{array}{l}\text { Writing is based } \\
\text { on reading. } \\
\text { Reading can } \\
\text { widen my mind } \\
\text { and enables me to } \\
\text { write in a more } \\
\text { authentic manner. }\end{array}$ & & $\begin{array}{l}\text { Stress is laid on } \\
\text { structure, ideas } \\
\text { and details; } \\
\text { Work with a tutor } \\
\text { from the writing } \\
\text { help center; } \\
\text { Peer review is } \\
\text { also helpful. }\end{array}$ & $\begin{array}{l}\text { All our course books } \\
\text { are in English. The } \\
\text { more we read, the } \\
\text { more we understand } \\
\text { and master English } \\
\text { expressions and } \\
\text { culture, and are able } \\
\text { to write more } \\
\text { fluently and clearly. }\end{array}$ \\
\hline
\end{tabular}




\begin{tabular}{|c|c|c|c|c|c|}
\hline Student E & $\begin{array}{l}\text { Reading extensively } \\
\text { helps improve my } \\
\text { writing; } \\
\text { - } \quad \text { Free write and } \\
\text { journaling are two } \\
\text { good methods; } \\
\text { Teaching some writing } \\
\text { techniques is also } \\
\text { necessary. }\end{array}$ & $\begin{array}{l}\text { structures. } \\
\text { Writing is a } \\
\text { process that calls } \\
\text { for extensive } \\
\text { reading and } \\
\text { constant practice; } \\
\text { It's more important } \\
\text { to develop in-depth } \\
\text { ideas than to learn } \\
\text { only writing } \\
\text { techniques. }\end{array}$ & $\begin{array}{l}\text { Reading skills, } \\
\text { which are } \\
\text { different from } \\
\text { writing skills, can } \\
\text { be taught } \\
\text { separately; } \\
\text { Reading is input } \\
\text { while writing is } \\
\text { output. Extensive } \\
\text { reading is the } \\
\text { basis of writing. }\end{array}$ & $\begin{array}{l}\text { Positive } \\
\text { comments are } \\
\text { given; } \\
\text { - Suggestions are } \\
\text { given on } \\
\text { organization and } \\
\text { ideas; } \\
\text { - Peer review is } \\
\text { encouraged; } \\
\text { Seek help from } \\
\text { the writing help } \\
\text { center. }\end{array}$ & $\begin{array}{l}\text { - I find my writing is } \\
\text { improving quickly } \\
\text { because we have } \\
\text { much more } \\
\text { authentic input and } \\
\text { practice writing } \\
\text { more often; } \\
\text { There is a good } \\
\text { environment here } \\
\text { where we are } \\
\text { exposed to English. } \\
\text { The more you hear } \\
\text { and read, the more } \\
\text { you understand. }\end{array}$ \\
\hline
\end{tabular}


Key data from the interviews of the five students in the joint program regarding the differences between writing in Chinese and writing in English

\begin{tabular}{|c|c|c|}
\hline & Writing in Chinese & Writing in English \\
\hline Semantics & 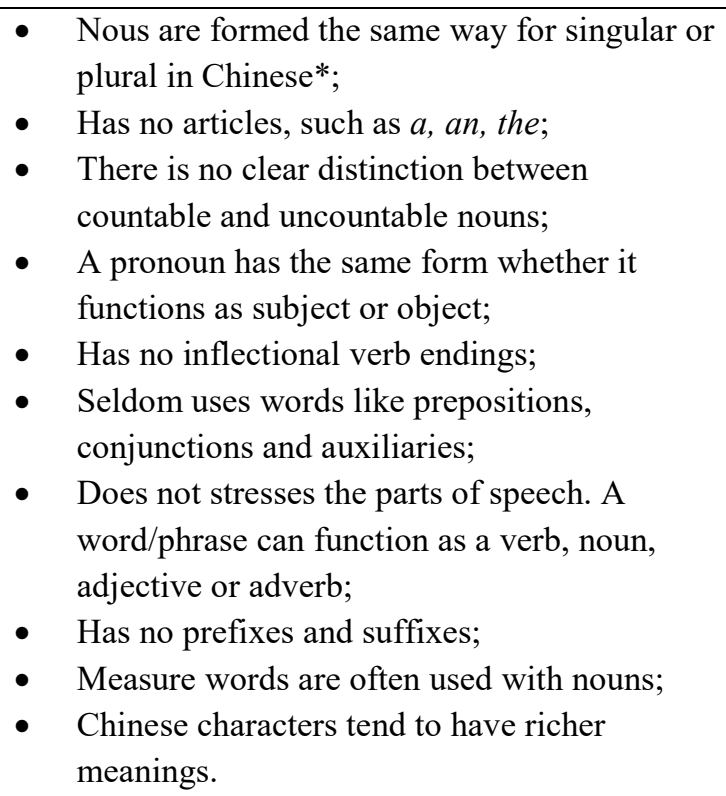 & $\begin{array}{l}\text { - } \quad \text { There is the singular-plural distinction; } \\
\text { - } \quad \text { There is the subject/object case distinction; } \\
\text { - Has inflectional verb endings; } \\
\text { - Has articles, such as a, an, the; } \\
\text { - } \quad \text { There is the distinction between countable and } \\
\text { - } \text { uncountable nouns; } \\
\text { - } \quad \text { Often uses words like prepositions, conjunctions } \\
\text { - } \quad \text { Has prefixes and suffixes; } \\
\text { - } \quad \text { Emphasizes the parts of speech of a word. }\end{array}$ \\
\hline Syntax & 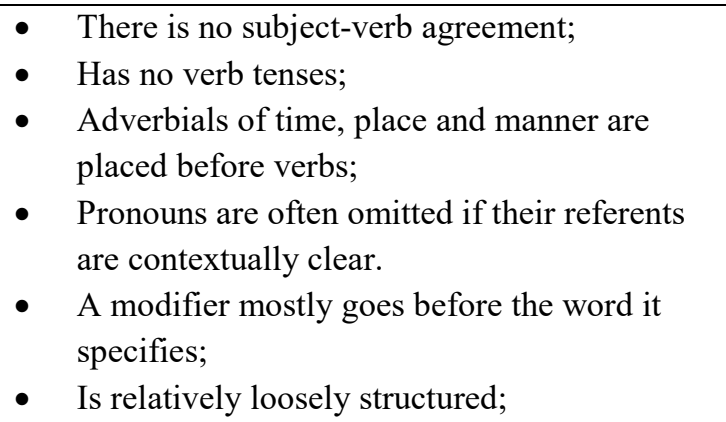 & $\begin{array}{l}\text { - } \quad \text { There is subject-verb agreement; } \\
\text { - } \quad \text { Has verb tenses; } \\
\text { Adverbials of time, place and manner are often } \\
\text { placed at the end of a sentence; } \\
\text { Pronouns cannot be omitted even if their referents } \\
\text { are contextually clear. } \\
\text { - The core structure of a sentence should stand } \\
\text { closely together, with other parts going before or } \\
\text { after the core sentence; }\end{array}$ \\
\hline
\end{tabular}


- Emphasizes meaning: a sentence is usually short with few modifiers or the meaning will be confusing;

- The active voice is much more widely used.
- Is more strictly structured;

- Emphasizes structure: a complicated sentence can express several meanings clearly;

- The passive voice is often used, especially in scientific articles.
- Words contains different connotations;

- Using definite and concrete things to express abstract ideas, such as idioms and proverbs;

Culture

- Visualizing \& generalizing thinking;

- Using abstract words to express ideas;

- Analytic \& logical thinking;

- Straightforward thinking.

- Tortuous thinking. 


\section{Appendix N}

Key data from the interviews of Sub-study 1 \& Stub-study 2 regarding the ways of developing writing skills and the use of English writing skills

\begin{tabular}{|c|c|c|c|c|}
\hline & CG & EG & $\begin{array}{l}\text { First two years } \\
\text { in China }\end{array}$ & $\begin{array}{l}\text { Last two years } \\
\text { in the US }\end{array}$ \\
\hline $\begin{array}{l}\text { Ways of developing } \\
\text { writing skills }\end{array}$ & $\begin{array}{l}\text { Memorize vocabulary } \\
\text { mainly from word } \\
\text { lists; } \\
\text { Learn grammar } \\
\text { explicitly from a } \\
\text { grammar textbook; } \\
\text { Accuracy and } \\
\text { appropriate forms are } \\
\text { emphasized; } \\
\text { Teaching is test- } \\
\text { oriented; } \\
\text { Learn to write step by } \\
\text { step guided by writing } \\
\text { textbook; } \\
\text { In-class writing } \\
\text { practice is proceeded; } \\
\text { Teacher corrects each } \\
\text { and every grammatical } \\
\text { mistake; }\end{array}$ & $\begin{array}{l}\text { - } \quad \text { Reading and writing } \\
\text { are combined; } \\
\text { No writing textbook is } \\
\text { used; } \\
\text { - Vocabulary and } \\
\text { grammar are learned } \\
\text { in reading process; } \\
\text { - Extensive reading is } \\
\text { encouraged; } \\
\text { - Positive feedback and } \\
\text { peer review are used; } \\
\text { - Comment on good } \\
\text { compositions in class; } \\
\text { - Free write and } \\
\text { journaling are required } \\
\text { in and out of class; } \\
\text { - Adopt new scoring } \\
\text { schemes; } \\
\text { Write at length; }\end{array}$ & $\begin{array}{l}\text { Memorized } \\
\text { vocabulary mainly } \\
\text { from word lists; } \\
\text { - Learned grammar } \\
\text { from the grammar } \\
\text { textbook and the } \\
\text { intensive reading } \\
\text { textbooks; } \\
\text { Accuracy and } \\
\text { appropriate forms } \\
\text { were emphasized; } \\
\text { Teaching was test- } \\
\text { oriented; } \\
\text { Learned to write step } \\
\text { by step guided by } \\
\text { writing textbook; } \\
\text { Only in-class writing } \\
\text { practice was } \\
\text { proceeded; }\end{array}$ & 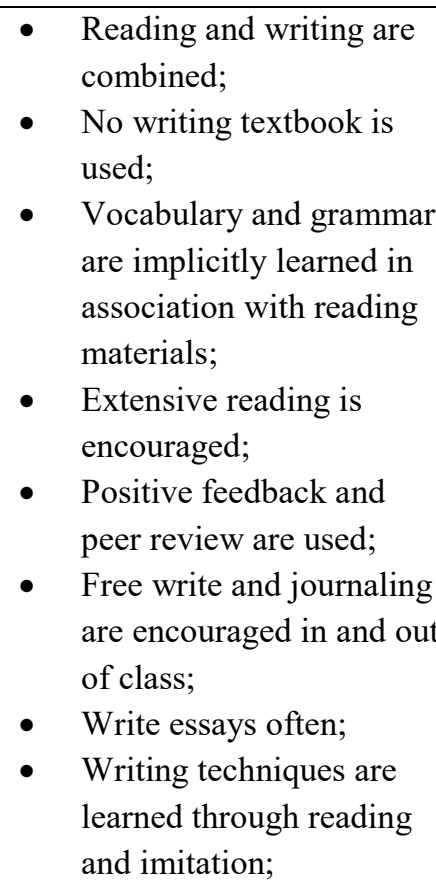 \\
\hline
\end{tabular}




\begin{tabular}{|c|c|c|c|c|}
\hline & $\begin{array}{l}\text { Write short } \\
\text { compositions only; } \\
\text { Take a lot of } \\
\text { simulation tests; } \\
\text { - Writing techniques are } \\
\text { learned and developed } \\
\text { through textbook. }\end{array}$ & $\begin{array}{l}\text { Writing techniques are } \\
\text { learned through } \\
\text { reading and imitation. }\end{array}$ & $\begin{array}{l}\text { Teacher corrected } \\
\text { each and every } \\
\text { grammatical mistake; } \\
\text { - } \\
\text { Practiced writing short } \\
\text { compositions; } \\
\text { Took a lot of } \\
\text { simulation tests; } \\
\text { Writing techniques } \\
\text { were learned and } \\
\text { practiced in class } \\
\text { through the teacher } \\
\text { and the textbook. }\end{array}$ & $\begin{array}{ll} & \text { Seeking help from } \\
& \text { Writing Help Center. }\end{array}$ \\
\hline $\begin{array}{l}\text { Use of English writing } \\
\text { skills }\end{array}$ & $\begin{array}{l}\text { Writing skills are } \\
\text { mainly used for taking } \\
\text { tests, esp. CETB-4 or } \\
\text { CETB-6. }\end{array}$ & $\begin{array}{l}\text { Writing is an } \\
\text { important tool for } \\
\text { communication; } \\
\text { Writing enhances } \\
\text { English proficiency; } \\
\text { Writing is developed } \\
\text { as one of the four } \\
\text { skills for future } \\
\text { academic pursuit. }\end{array}$ & $\begin{array}{l}\text { Writing skills were } \\
\text { mainly used for taking } \\
\text { tests, such as TOEFL } \\
\text { or IELTS. }\end{array}$ & $\begin{array}{l}\text { - Writing is an important } \\
\text { tool for communication; } \\
\text { - Writing is developed as } \\
\text { one of the four skills for } \\
\text { academic purpose or } \\
\text { pursuit. }\end{array}$ \\
\hline
\end{tabular}

